\title{
The Virtual Sphere and the Women's Movement in Post-Reform Iran
}

Sedigheh Karimi

Submitted in total fulfilment of the requirements of the degree of Doctor of Philosophy

Asia institute

The University of Melbourne

March 2018 


\section{Abstract}

The rapid development of Internet and communication technologies raises the question of what role these media and communication interfaces play in social and political movements and development in individual countries. Although activities in cyberspace, including blogging, participation in social networks and other facilities provided by the Internet for its users are a new phenomenon, they have profound effects on social and political relations in the communities involved. In the information era, Internet is an important part of social movements in democratic societies and local communities. When the government blocks other ways to mobilization, Internet may bring like-minded people together and help them to find support for action. Internet has provided a new space for social movements and the effect of the virtual activities of the users on the actions and, often on the lack of social movements is of high importance.

Meanwhile, the Iranian women's movement, like other social movements in contemporary Iran, realizes the impact and position of cyberspace and has made use of it. Many activists, for whom other ways for expressing their demands have been blocked, have entered this space and taken advantage of it for expressing their opinions and communicating information to other people. In fact, the dominant socio-political forces and the atmosphere of repression, and fear have led many Iranian women to use the virtual space to campaign for women's empowerment and equal rights. They have realized that the Internet may inform the outside world of the movement's goals and activities and facilitate maintaining contact with other members of the movement. In fact, the open space that provides a platform for sharing information and has given the chance to the Iranian women's rights activists to perform their activities in a space with a decentralized structure where there is less pressure than there is in the real world. Campaigns formed following the cyberspace market boom indicate that cyberspace has indeed ushered in a new era in the history of the Iranian women's movement.

The present study provides an analysis of the role of the Internet in the activities of the women's movement and explores the extent to which cyberspace has been assisting the women's movement in achieving its objectives. The thesis investigates whether there has been successful interaction between cyberspace and the Iranian women's social movement resulting from a 
dynamic adaptation between functions of social and political groups in the real world and the virtual world. It also examines how factors such as social participation, increasing awareness, changing beliefs, traditional views of women and social mobility have been affected by the application of the Internet, and whether cyberspace has been able to make women's voices heard in Iran's patriarchal society. 


\section{Declaration}

This is to certify that:

- The thesis comprises only my original work towards the PhD except where indicated in the Preface,

- Due acknowledgement has been made in the text to all other material used,

- The thesis is fewer than 100000 words in length, exclusive of tables, maps, bibliographies and appendices 


\section{Acknowledgment}

This study gave me the opportunity to meet fifty women activists inside Iran who willingly told me their life stories, sharing with me their personal experiences and beliefs, their passion and resilience, their hopes and joys, as well as their concerns and frustrations. I owe these women my deepest gratitude. This study would not have been possible without their contributions. I also feel humbled by the conversations I have had with these dedicated, persistent and strong women as the sacrifices they made to provide a better future for all Iranian women were limitless. They hope that their resilience and commitment to the Iranian society may overcome ignorance and hostility and eventually lead to the recognition and appreciation of all Iranian people.

I would also like to show my gratitude to a number of people who offered their support in different ways during these PhD years. In particular, I wish to thank my supervisors Dr. Muhammad Kamal for sharing his pearls of wisdom with me during the course of this research and Dr. Christina Mayer for her support and constructive comments. Last but not the least, I would like to thank my family, my lovely kids Sara and Sina for supporting me spiritually throughout writing this thesis and my life in general. 


\section{Table of Contents}

Title page

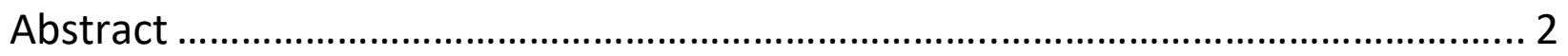

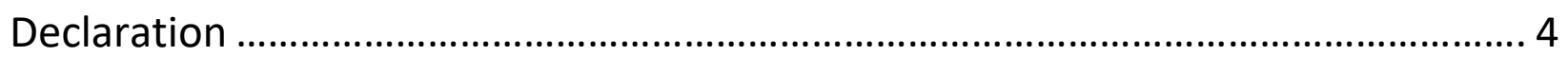

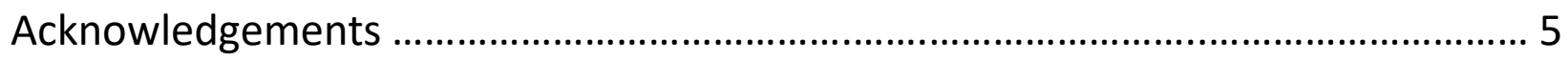

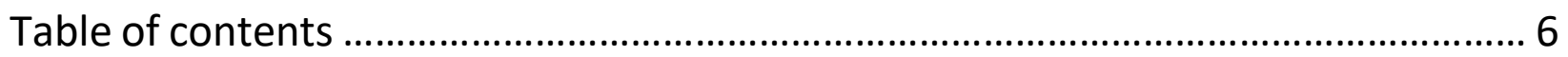

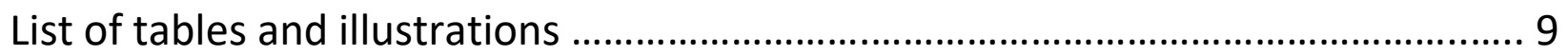

Chapter One: Introduction

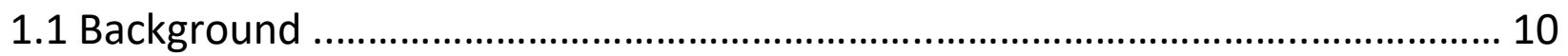

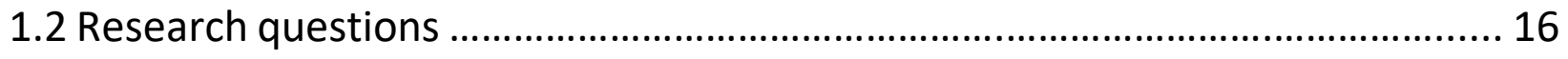

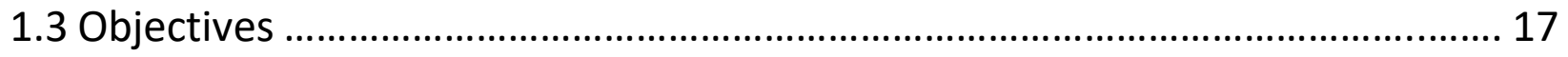

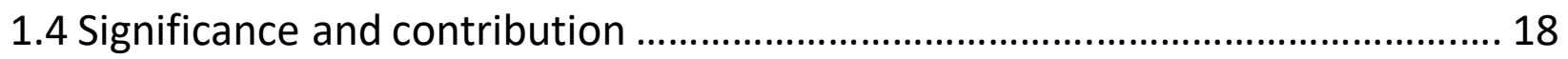

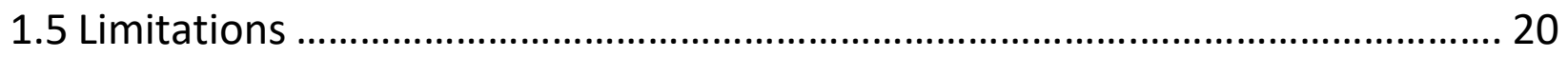

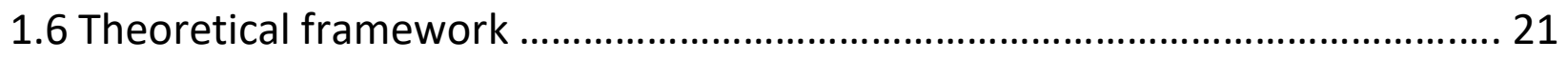

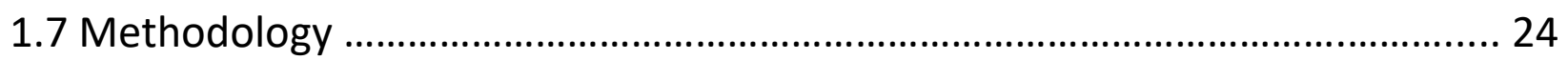

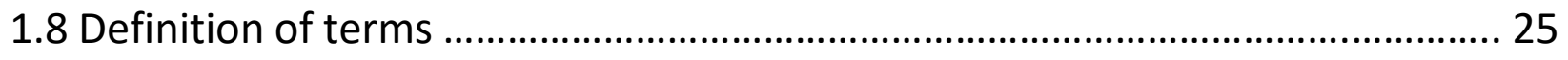

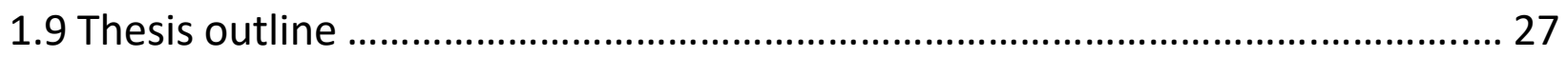

\section{Chapter Two: Literature Review}

2.1 The Internet and Political movements ............................................................. 30

2.2 The Islamic Republic of Iran and the Internet ..................................................... 37

2.3 The Iranian women's movement and the Internet ............................................ 43

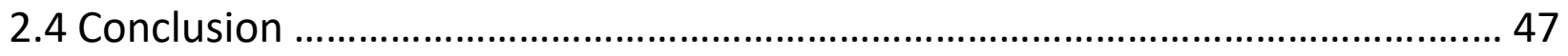

Chapter Three: Rouhani's Equity Government: A new period of reform in Iran?

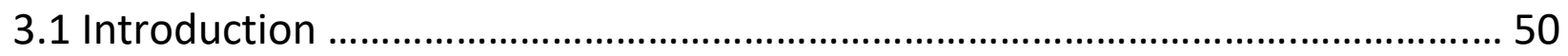

3.2 Definition of reform and reformism in the Iranian context ............................ 50 


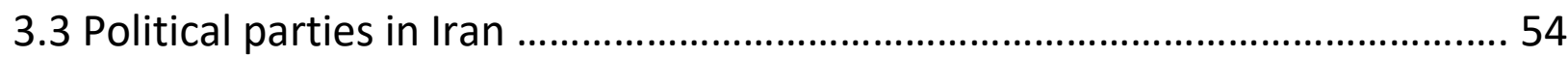

3.4 Socio-Political environment in the Reformist Period ........................................ 58

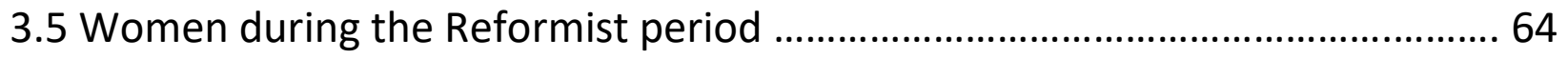

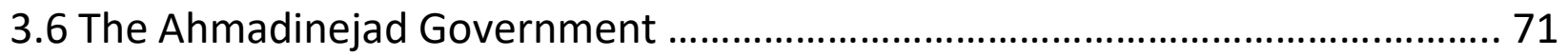

3.7 Socio-Political environment in the Post-Reform Period .................................... 71

3.8 Women under the Conservative Government ................................................. 74

3.9 Socio-Political environment under the Equity Government .............................. 79

3.10 Women under the Rouhani Government ................................................... 81

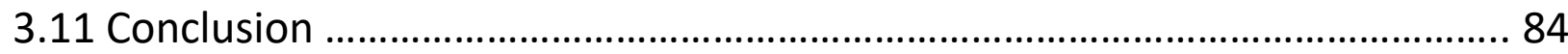

Chapter Four: The state of female activities In Iran

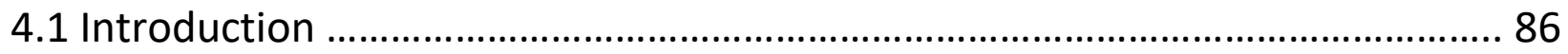

4.2 Charles Tilly's Theory of Resources …............................................................. 87

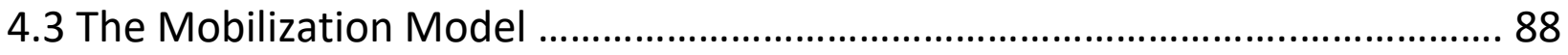

4.3.1 The First Section of the Mobilization Model ............................................... 88

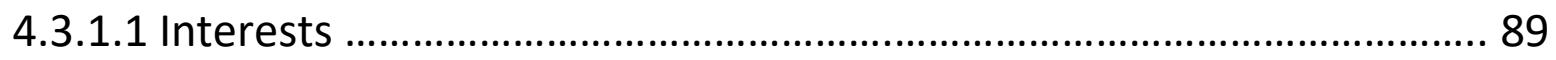

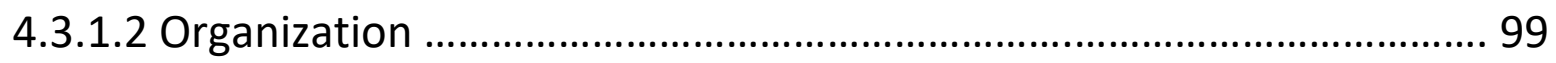

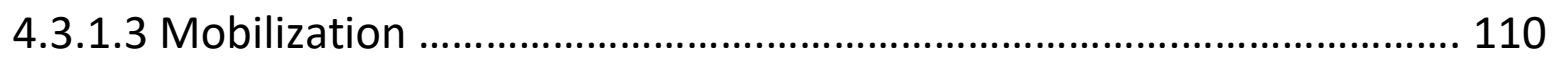

4.3.2 The Second Section of the Mobilization Model ......................................... 116

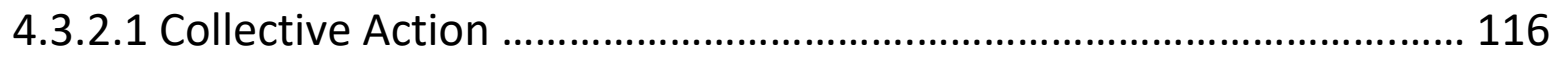

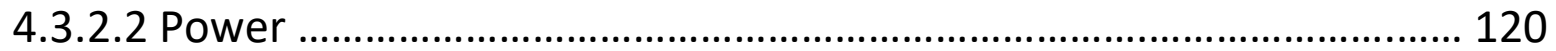

4.3.2.3 Repression and Facilitation ............................................................. 129

4.3.2.4 Opportunity and Threat ................................................................... 132

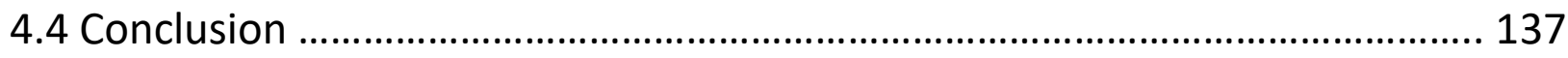

\section{Chapter 5: Discussion}

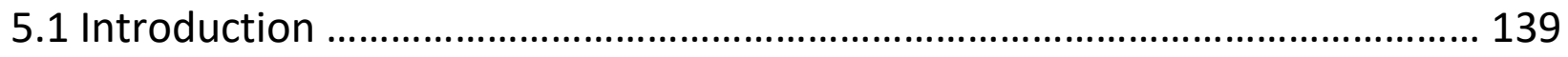




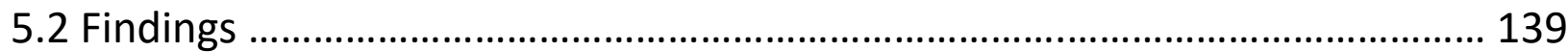

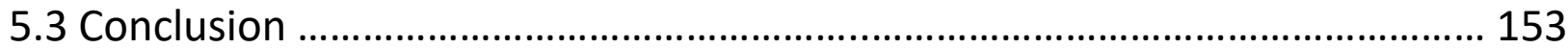

Chapter Six: Conclusion

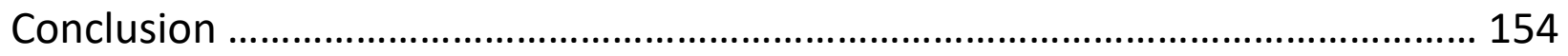

Bibliography

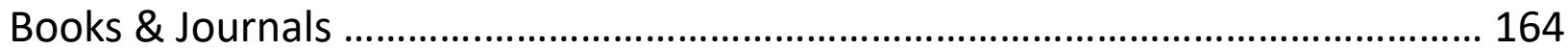

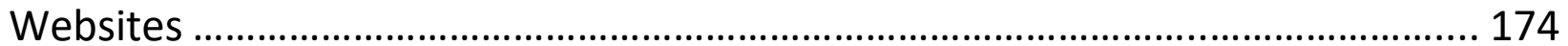




\section{List of Tables and Illustrations}

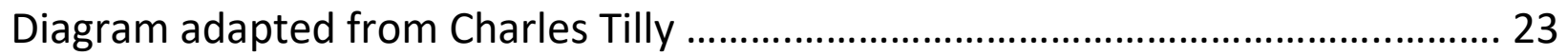

Table 1: Educational level of the interviewees ......................................................140

Table 2: Findings related to the opinions of the interviewees about women's status

in Iran

Table 3: Relationship between education and the opinion of interviewees ....... 141

Table 4: Reasons proposed to explain women's status in Iranian society ........... 142

Table 5: Relationship between education and the reasons proposed to explain women's status in Iranian society 143

Table 6: The impact of economic, legal, physiological and cultural factors on the situation of women from the interviewees perspective

Table 7: Findings related to the evaluation of the relationship between the Iranian women's movement and feminism from the interviewees' perspective 145 Table 8: Comparative assessment of men and women from the interviewees perspective

Table 9: Findings related to the relationship between the Internet and Iranian women's movement from the interviewees' perspective 149 Table 10: Findings related to the solution of women's problems in Iran from the interviewees' perspective 


\section{Chapter One: Introduction}

\subsection{Background}

In the twenty-first century, the virtual sphere has played a crucial role in social activities. The growth and expansion of the Internet has facilitated the spread of information to the extent that weblogs and social networking sites have evolved into everyday communication media. They have played a pivotal role in social interactions by reinforcing communication patterns and interactions among users in virtual environments.

Due to this growing trend, the Internet has encompassed the socio-cultural and political activities of users, as well as providing a platform for the sharing of ideas, viewpoints and concerns with a wide range of interlocutors. The unique attractions of these networks have brought about an unprecedented acceptance by the masses to utilize them to achieve their socio-cultural and political objectives.

There are differing viewpoints about the influence of the Internet on socio-political movements ${ }^{1}$. Some, like Robert Putnam (2000, p. 175), have a sceptical view towards the role of the Internet in enhancing social capital. His point of view is that the Internet may be more useful for maintaining existing ties than for creating new ones. Neither can the Internet lead to organizational and political participation if users have no interest in such matters. Cyber sceptics such as Putnam downplay the significance of new technology and argue that using the Internet gives people a false sense of participation and keeps them from actual physical protesting. Some scholars, such as Malcolm Gladwell and Clay Shirky (2011, pp. 28-41) go so far as to assert that new media is a tool of repression. In a majority of cases, in fact, once authoritarian regimes understand the threat posed by the Internet, they launch concentrated efforts to expand their political control.

On the other hand, there is a plethora of opposite views regarding the positive and influential role of the virtual space in the formation, continuation and success of social movements. Scholars

\footnotetext{
${ }^{1}$ In this research there is no distinction between social and political movement in Iranian women's movement; therefore socio-political movement is a term that describe a movement by the group of activists operates together to obtain a goal.
} 
such as W. Lance Bennett (2006), Bruce Bimber et al (2005 and 2012), Jennifer Earl and Katrina Kimport (2011) believe that, although weblogs and social networks are not independent factors in political outlets, in addition to being inexpensive they have succeeded in gathering and spreading data via a bottom-up approach. Moreover, weblogs and social networks have exposed people to new patterns of interactivity, thereby familiarising them with the likes and trends of one another. Accordingly, this has enabled the Internet to become an indispensable part of social movements in many countries.

One of the most profound impacts of the virtual sphere is the way in which it has enabled social interaction in closed societies where the government has blocked other pathways for mobilisation, such as public gatherings, peaceful protests, and freedom of expression. It might be said that the Internet has redefined 'mobilization' and 'summoning of the masses'.

The Internet is revolutionizing the way people protest and express dissent, especially in closed societies. It can be employed as a medium for organizing and disseminating information. The Internet provides new mechanisms for collecting information about any movement and accelerating the diffusion of relevant news to protesters (Golkar, 2011, p. 57). Therefore, any political and social activity in this environment, which is a virtual and unreal one, will be regarded as a political or social movement since it has originated from the virtual space and runs into the real world. Consequently a change, no matter how transient or insignificant, will emerge. These activities could be realized in different websites or weblogs as well as other social networks such as Facebook and Twitter.

Iran was one of the early adopters of the Internet in the Middle East, with Sharif and Guilan Universities offering the first connections to the global network in the early 1990's (Johari, 2002, p. 49). The Iranian population became familiar with the Internet phenomenon in 1993 and was the second country in the Middle East to be connected to the Internet, after Israel (Rahimi, 2007, p. 49). The demand for Internet subsequently rapidly increased, making it very popular in a few years. At the beginning, no one could foresee how swiftly it would spread in Iranian society. The number of Iranian Internet users increased from 600,000 in 1996 to 42,000,000 people in 2012 according to the Internet World Statistics (IWS) 2 . In 2010 more than half of the population in Iran

\footnotetext{
${ }^{2}$ http://www.Internetworldstats.com/me/ir.htm
} 
(53.3\%) had access to the Internet, and Iran was ranked as one of the countries with the highest percentage of Internet users in the Middle East (Lerner, 2010, p. 562).

One of the main reasons behind the upsurge of public interest in the Internet is the sudden increase in the youth population after the 1979 revolution. According to United Nations (UN) reports, over one third of Iran's entire population is between the ages of 15 and 29 (Basmenji, 2005). As the post-revolution baby boom has come of age, it has led to a significant rise in adult education. Subsequently, the literacy rate has risen to above $79 \%$ (Asemi, 2006). Consequently, the number of Internet users all around Iran increases day by day. To a certain extent, the Internet has already helped young people liberate themselves from constant societal pressure and the social control of the regime (Golkar, 2011, p. 53).

In recent years and particularly with the rise of political opposition, the rapidly growing and changing Internet has provided creative ways for political dissidents to challenge state authority. However, the Iranian government has tried to control the Internet and restrict access to it by filtering websites and limiting its connection speeds. As Geneive Abdo (2010) explains, the regime's system for blocking access to the Internet has become more sophisticated since Internet use has grown. The regime is aware of the Internet's power and tries not only to control it but use it as a tool for its own ideological purposes and political propaganda.

Iran's Internet censorship goes beyond simply blocking access to particular websites and services. Admittedly, Iran has only one public Internet service provider (ISP). The government therefore has been able to dramatically slow down bandwidth speeds in an effort to delay messages meant for the organization of large-scale protest (Rahimi, 2008, p. 49). According to an Iranian newspaper, the number of filtered websites doubled from 5 million in the year 2008 to 10 million in 2009 (Sarmayeh newspaper, 25/07/2009). To access such platforms as Facebook and Twitter, Iranians have employed Virtual Private Networks (VPNs), or use applications designed to hide IP addresses typically known as Deep Web Browsing (Kamran, 2009).

In response to the development of information communication technology, the Iranian regime has heavily invested in filtering Internet social networks, imprisoning bloggers and forming a Cyber army which is responsible for fighting against Cyber civil society. These efforts, however, 
have not been successful in preventing the growing number of users from accessing information (Alfoneh, 2013).

Among the range of social movements in contemporary Iran, the women's movement has improved with the usage of the Internet. The dominant socio-political system and the atmosphere of repression, secrecy, and fear have led many Iranian women to use the virtual space as a platform in the fight for women's empowerment and equal rights. This has compromised the government's monopoly on media, expanded social networks, enhanced capacity, and empowered both activists and citizens at large.

The tangible presence of women in socio-political activities dates back to former President Mohammad Khatami's second term in 2001-2005. A large number of activists and people interested in women's studies exceedingly appeared on media in the prime of the reform era in Iran. Therefore, an open environment for the movement allowed socio-political activities to continue. A number of magazines for women such as Zanan, Jameah, Khaneh, Fekr-e-Rooz and others were published for the first time. A separate page or a special column was usually allocated for women in many reformist newspapers. Furthermore, the number of female reporters increased significantly. In addition, women's participation in editorial boards and councils increased substantially, too. Khatami's presidency saw the burgeoning of nongovernment organizations that laid the foundation for a more vibrant civil society. Many NGOs were founded around women's issues (Siddiqi, 2006).

The social and political activists' vast efforts in this period triggered a severe reaction from the conservatives in the government who were backed by the religious Supreme Leader Ayatollah Ali Khamenei. For the religious conservatives who manipulate the country's system, the change in the socio-political climate was nothing to celebrate or even tolerate. As part of the crackdown, the Guardian Council ${ }^{3}$ banned all reformist candidates from running for presidency in 2005. Mahmoud Ahmadinejad came to office, ushering in a more conservative period in Iranian politics and society. Censorship and Internet ban were among the first major dilemmas on the list of the government's protocol in handling situations. Amidst the condemned issues in media, "women",

\footnotetext{
${ }^{3}$ The Council consists of twelve members. Six jurists to be elected by the Parliament and 6 members appointed by Supreme Leader of Iran. It is a council empowered to vet legislation and oversee elections. It approves and disqualifies candidates seeking to run in local, parliamentary, presidential, and Assembly of Experts elections.
} 
and especially the demands of their movement in Iran, became controversial. This situation overlapped with the presidency of Mahmoud Ahmadinejad in 2005. Eventually, the news and reports were not allowed to use the term "feminism" or mention the names of certain famous female activists (Sadeghi, 2010, p. 217).

Suffering from seclusion and having no control over the situation during this time, including having limited opportunity to pursue their goals, women's movements came together with the objective of finding a suitable substitute for what they had lost. Iranian women subsequently used the Internet as a tool to help them in pursuing their demands. This led to the usage of virtual spaces towards socio-political activism for women who had previously been deprived of this form of activism. The Iranian women's movement became a pioneering social movement in Iran that embraced the Internet as an emancipating tool.

In the early days of the Internet, at the beginning of this trend, women's blogging played a significant role. Female bloggers, predominantly the young, were among the pioneers of blogging in Iran. Blogging made it possible for them to write about their ideas and needs without the fear of censorship or chastisement. Moreover, they could create virtual identities for themselves without the fear of being recognized and consequently punished. They could now freely reveal their "hidden" selves. Due to the ability to engage in free online participation, there was a drastic improvement in Internet use by women in Iran. Another outcome of women's blogging was attracting younger people to the women's movement. Since the crackdown on newspapers and chronicles in the Ahmadinejad presidency between 2005 and 2013, more female journalists and reporters concerned about women's conditions turned to blogging, which in turn led to the reinforcement of the women's movement (Sreberny \& Khiabany, 2010). The use of blogging by women accelerated the spread of the movement's news regarding gatherings and related agendas. As an example, due to having access to the Internet, bloggers could easily announce that a meeting was taking place. Since they were present at those meetings themselves, they could report the right and exact information to others not present. Prior to the advent of the Internet, individuals not present would often receive the wrong information after every meeting that was held (Rahimi, 2011). Gradually, with the expansion of the Internet, and subsequently the emergence of online social networks such as Twitter and Facebook, the role of the Internet 
has raised people's awareness of the movement's aims and objectives which was conducive to social mobilization (Sadeghi, 2010).

Sites and pages related to women, were not designed only to spread news, but also served as a mobilizing force and means of organization, too. The exchange of views, the proliferation of opinions, and the consciousness-raising process that took place on the Internet encouraged debate on gender equality and women's rights which was invaluable to the women's movement. Internet had opened up space for activists to air their views. A full online participation enabled Iran's women's movement to connect to international women's movements, as well as spreading news to the mainstream news media.

One of the successful strategies for using the Internet in the social struggle against the regime has been the One Million Signatures Campaign for Changing the Discriminatory Laws against Iranian Women launched in August 2006. In a short time, this campaign allowed Iranian women to shed light on some of the limitations of Iranian society, while demonstrating their qualitatively different experience to the world (Barlow, 2012, p. 59). By having access to the Internet, women activists of the campaign inside Iran were able to raise awareness of their struggles transnationally. The Internet also provided a way for people living outside of Iran, who could not be reached in face-to-face interactions, to sign petitions demonstrating solidarity with the plight of Iranian women (Sameh, 2010). The Internet also offered a way for the campaign to garner contributions from donors (Lerner, 2010).

The Anti-stoning campaign in May 2006 aimed to eventually persuade the Iranian authorities to abolish executions by stoning and bring their legal practices into line with their obligations under international law. Due to the crackdown on civil society after 2005, discussed above, the campaign had limited opportunities to hold meetings and engage in activities in public. But after a successful virtual campaign to save Mokarrameh Ebrahimi from being stoned in 2007, campaign activists recognized the power of the Internet (Terman and Fijabi, 2010).

The Green Movement, whose members were active and participated in demonstrations during the disputed presidential elections in 2009, is another example of women using online and virtual space to pursue their goals. Saeid Golkar (2011) argues that the Internet has helped political 
activists expand the Green Movement by increasing their capacity to mobilise the masses and delegitimise the regime.

However, the women's movement has been suppressed by the authorities, despite all the achievements that it has gained through its online participation. Websites concentrating on women and their issues are filtered and have become unreachable again and again. Moreover, some activists in the women's movement have been summoned to court, detained, convicted and imprisoned. The more people visited and welcomed women's websites, the more these websites' news became reliable. However, as a consequence of this increase in activity on these sites the suppression by the Iranian regime became more severe.

Some believe that, due to the ever-increasing censorship and suppression exerted by the authorities in the last few years, women have gradually lost their voice in formal settings resulting in a situation where female activists do not have participation in their respective socio-political environments (Rahimi, 2011, p. 165). This trajectory raises some important questions: to what extent have the Internet and virtual spaces been able to aid the Iranian women's movement in achieving its goals? And what are the challenges and rewards of Internet use for the women's movement?

Accordingly, this research is seeking to investigate the role of the Internet in the Iranian women's movement through the application of Charles Tilly's theory of "the mobilization of resources" as an epistemological framework (Tilly, 1977). Moreover, through a focus on existing viewpoints about the role of virtual space in social movements, this study will examine the opportunities and limitations which are faced by the Iranian women's movement in this regard.

\subsection{Research questions}

The research questions for this study are:

What role has the Internet been playing in the formation and expansion of social movements in Iran?

Has the use of the Internet contributed to the women's movement in promoting its demands and aiding it to reach its goals, and if so, how? 
What challenges and limitations has the Internet brought about for the women's movement In Iran?

\subsection{Objectives}

This research can be classified as an embedded single case design with two units of analysis. These include interactive Internet media and social activism. By 'interactive Internet media' this thesis describes blogging and websites related to women's issues, and social media like Facebook and Twitter. This research examines data coming from these sources, and explores whether online activity translates into collective action creating a social movement. In conducting this research, women's actions are observed through Iran's situation in recent years, to show whether the virtual space has had an impact on women's mobilization and movement.

As stated above, the phenomenon under consideration in this research is the effectiveness of the Internet in promoting the women's movement as the dependent variable in the research. However, effectiveness is a rather ambiguous term and difficult to measure. Therefore, some standards should be set that to show if the Iranian women have achieved their goals and whether their efforts could be considered as an active movement. In this regard, by studying the way in which the participants of the Iranian women's movement use the Internet to achieve their goals, this research puts forward the following hypotheses:

1. Any changes that have occurred to Iranian law related to women in the last decade, including those that have improved the status of women in Iranian society, will be considered. By this statement this thesis is not ignoring the fact that there are other factors that have influence on changing the laws but suggests that the Internet gives women greater empowerment.

2. Members of the Iranian women's movement are able to use the Internet as a communications tool for spreading news about the conditions of Iranian women, breaking taboos, mobilising and organising women in protests against anti-women legislation such as education rights, hijab and divorce laws.

3. The Internet has allowed the Iranian women's movement the opportunity to connect with other international women's movements and coalitions by raising awareness about the plight of Iranian women within international circles. 
4. The patriarchal discourse derived from Iranian political culture has been affected by the existing discrimination against women in Iranian political culture, which has been aggravated after the Islamic Revolution, has affected women's activities.

Accordingly, the independent variable of this research is the growth of Internet media. Components such as weblogs, social networks and websites created solely for women, for example activities on social media platforms like Twitter and Facebook which advocate for women and which constitute the virtual sphere, will be examined.

\subsection{Significance and Contribution}

On the one hand Iran is an extreme case in the case study of segmented and conflict-ridden societies. It is peculiar in two ways. Firstly, because it achieved its new political system after the Islamic revolution in 1979. The outcomes of the revolution led the country into a self-imposed isolation, being at odds with its neighbours and with the wider international community. Secondly, Iran is peculiar for the nature of its diversity. Two distinct and non-overlapping cleavages divide Iranian society: one between the religious and the secular, and the other between different ethnicities across the country. Millions of individuals from various ethnic, religious, and linguistic minority backgrounds reside in Iran. These groups include Azeris, Kurds, Baluchis, Arabs, Christians, Jews, Zoroastrians, Baha'is, Sunni Muslims, and others. Living in this cultural diversity and the complexities of Iranian society does not allow women to be actively involved in society due to their lack of freedom. Yet they cannot remain inactive as they are being deprived of their rights. Patriarchal culture, together with Islamic tradition, stresses that women belong to the home. The family unit in Iranian society has more often than not acknowledged women's right to education but has reservations about the utilisation of that education. While there is a strong correspondence between educational status on the one hand and interests in social participation on the other hand (including female students and voters outnumbering males for many years), a gap still exists between men and women.

The Internet and virtual space have to some extent been able to assist Iranian women in achieving their goals by capitalizing on their functionality of raising awareness and ability to mobilize. 
However, certain characteristics of the virtual sphere, society and culture in Iran, such as the lack of appropriate interaction between virtual space and the real world, due to the expectations of the women's movement have not been fulfilled. In addition to this, the Iranian government has traditionally relied on its control of the mainstream media to silence or limit opposition voices while restricting access to alternative, mainly foreign, media sources. Traditional media had a unidirectional and hierarchical structure in which the state could monopolise the production of content. The Internet and new social media, by contrast, are fundamentally challenging this by turning users into both consumers and producers of content. In addition, the importance of using the Internet in modern life, especially its influential role in socio-political movements as well as its effective functionality in the formation, continuation and success of socio-political movements (such as the ones which emerged in the Arab Spring) has seen the actualization of some of the aims of the Iranian women's movement's anti-discriminatory fight for equality.

It is important to point out, though, that, while at the international level the women's rights movement has made progress, in Iran women are still struggling for gender equality and, by extension, their civil liberties. Undoubtedly, no society can develop when half of the members of its population are regarded as second-class citizens, and their needs and demands to develop and excel are ignored. In other words, sustainable and rapid development occurs in a country where women and men, regardless of their genders, contribute to its growth. Consequently, the involvement of women in the political process is necessary to strengthen democracy, although their place is inadequately established in active political life. Therefore, as previously mentioned, since the Iranian women's movement has turned to a new strategy to use virtual space and the Internet to achieve its goals, this study seeks to examine this strategy with a realistic approach of understanding the strengths, weaknesses, abilities and limitations of the Internet.

Despite the importance of this subject, there are only a few publications about the role of the Internet in the formation and expansion of the Iranian women's movement in Iran. In the past, many scholars have dedicated their time to studying Iranian women and their social movements. After the examination of past studies in this area, it has been discovered that so far research and discussion have been centred on how citizens embraced such a new tool to create political movements. Using evidence-based research, a few scholars examined the impact of social media 
on political communication. Although past research has done an excellent job in exploring the vast topic of 'Iranian women', most literature on the subject have struggled to grasp what this new phenomenon actually means and struggled to analyse how this new form of communication has been affecting the social and political life of the country. Therefore, the aim of this study is to complete past research on the women's movement in Iran because the overpowering potential of the Internet has created a gap between research literature on Iran and women's studies. This thesis proposes that the Internet is not merely a new form of communication but it provides unique opportunities for activists and social movements that open up precisely such a public sphere. This work is an attempt to fill some gaps in women's studies on Iran by examining the impact of new technology in a developing society.

\subsection{Limitations}

As this thesis uses a quantitative research design, the lack of probability sampling is an important, obvious limitation to this research. However, not employing a probability sampling technique is not viewed as a limitation because a qualitative research design is used together with quantitative method. In qualitative research designs, a non-probability sampling technique is typically selected over a probability sampling technique. Using a combination of qualitative and quantitative data can improve an evaluation by ensuring that the limitations of one type of data are balanced by the strengths of another.

The biggest barrier to the present research has been the filtering and censorship exercised by the Iranian government. It was, however, possible to conduct an operational research, designing a questionnaire and interviewing local people in Iran, and to subsequently analyse the findings.

The scope of the research is geographically limited as it only covers women in Iran. The research for this thesis covers the period from 2005 to 2017, that is, from the beginning of the Mahmoud Ahmadinejad administration to the end of Hassan Rouhani's first term as president, and does not go beyond that. This special time frame of the post-reform era in Iran will be a decisive and significant period in determining the destiny of Iran's political history as the failure of reform 
movements has provided an insightful experience for those who long for democracy and reform in Iran.

The researcher's familiarity with the subject has helped formulate appropriate research questions for this study. In-depth knowledge about this subject comes from the researcher herself being an Iranian woman, who is able to perceive and feel the situation from the inside, and not an outsider with no prior local knowledge who would need to familiarize themselves with the circumstances first and might fail to recognize concealed realities. Likewise, since this research is more qualitative than quantitative, during the interviews the quality of the findings is directly dependent upon the skills, experience and sensitivity of the interviewer. Therefore, being part of the Iranian community has definitely helped. Being a female researcher familiar with women's movements and their objectives in Iran, it was possible for the author to engage in investigating the role of the Internet in the Iranian women's movement as well as seeking the reasons of its success or otherwise through an analysis of the possibilities and limitations of virtual space in Iranian women's society.

In addition, it greatly contributed to the feasibility the research that the researcher's mother tongue is Persian as it made possible to access information both in Persian and English, to communicate with Iranian women activists directly, and to gather data more easily. There was a possibility of data limitation due to a lack of reliable data, but the researcher has been able to resolve this problem by accessing foreign media and academic sources. Finally, through a true and realistic understanding of virtual space opportunities and challenges, the researcher has been able to use this novel and inclusive instrument to assist with the emancipation of, and achieving equal rights for women in Iran.

\subsection{Theoretical framework}

This case study seeks to examine the relationship between the Internet with all its related virtual networks and Iranian women's socio-political movement. This has been done through the analysis of the possibilities that the Internet has provided for social movements. In so doing, this study has relied upon Charles Tilly's Theory of Resources (Tilly, 1977) as the epistemological and 
methodological paradigm in the analysis of social movements. The role and also the effect of the virtual environment have been examined using Mobilization Model procedures, that is, "power, mobilization, interests, organization, repression-facilitation, opportunities-threat" (Tilly, 1977, pp. 2-4) along with the elements of the comprehensive package of social movement manifestation, "worthiness, unity, commitment and numbers" (Tilly, 1977, pp. 3-4). It has been shown that successful interaction between the virtual environment and social movements, which appear and continue in the real world, can realize what social movements, including the women's movement, are seeking. In fact, the contention of this paper is that the Internet can achieve this via enforcing the above-mentioned elements in Tilly's theory of the mobilization of resources. In his works, From Mobilization to Revolution (1977) and Social Movements (2004), Charles Tilly attempts to present a hypothesis to describe and explain social movements and collective actions. Like Karl Marx and Max Weber before him, he sees social conflicts as the root of all social reactions including revolutions and social movements. He uses the mobilization model to explain collective action and pays special attention to the concept of benefit and organization in this pattern. In order to define these two concepts, Tilly mentions group and network relations. Group relations consist of the relationships that people create based on common features with others. Network relations, on the other hand, involve people who establish relationships based upon special interpersonal ties.

The next concept in his scheme is mobilization during which people transform from passivity to activity in their ordinary life. In his view, mobilization has three forms: 1. Defensive mobilization which forms against an external threat; 2. Aggressive mobilization, which emerges upon an opportunity that the mobilization of resources has grasped; and finally 3. Provisional mobilization, which stores resources upon foreseeing challenges and rewards (Tilly, 2004).

Tilly then contends that the three concepts of opportunity-threat, repression-facilitation and power are the external factors of social actions.

A diagram is used to make the mobilization model clearer. "The diagram shows that the main determinants of a group's mobilization are its organization, its interest in possible interactions with other contenders, the current opportunity-threat of those interactions and the group's 
subjection to repression" (Tilly, 1978, pp. 3-7). According to this diagram the main reason the group does protest against repression is the represented interest for any member or participant.

\section{Mobilization Model}

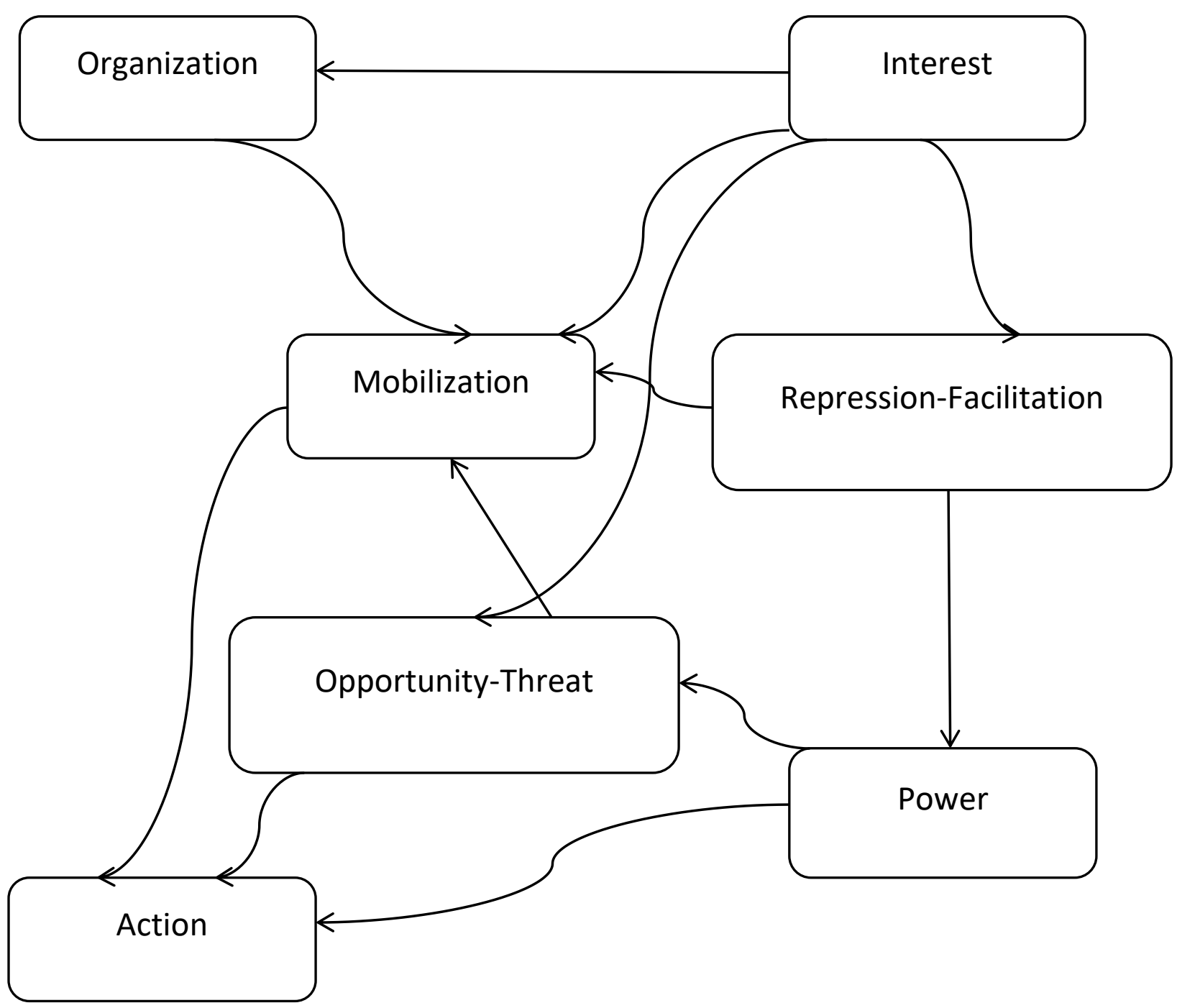

Diagram 1 adapted from Tilly $(1977$, p. 3)

Further, Tilly comments that social movements emerge when three elements are present:

1. A campaign: a sustained, organized public effort making collective claims on target authorities

2. Social movement repertoire: a form of political action

3. Participants' concerted public display of worthiness, unity, numbers and commitment (WUNC). 
The presence of these three elements would then constitute a social movement.

This research has used Tilly's theory to analyse the factors and elements which contribute to the women's movement in Iran. The underpinning assumption in this research is the role of the Internet on mobilization procedures as well as of worthiness, unity, numbers and commitment features.

This analysis has also considered the theories of sociologists, such as Robert Putnam, who have a sceptical view about the impact of the Internet on the accumulation of social property. Such an approach makes it possible to maintain an objective perspective in looking at the experiences of this movement, the actions taken and their consequences in order to know the results and proposed drawbacks. Consequently, this leads to a better understanding of ways to minimize damage and find resolutions for problems. Although the Internet has not been Tilly's concern as a moving force in social and political movements, an instrumental perspective has been adopted as a new foundation for the formation or enforcement of socio-political movements. In other words, the assumption is that the Internet can be manipulated so as to demonstrate worthiness, unity, numbers and commitment to a cause.

\subsection{Methodology}

Methods employed in this research include systematically searching relevant literature and conducting in-depth interviews with focus groups and experts in the field. This research is a single in-depth case study which considers only women in Iran and provides an analysis that covers the period from 2005 to 2017 (13 years). This research will study the position of women in various spheres over these years, discussing how the Internet has been facilitating their actions. The main interaction in this thesis is between the case and the theory. This research is mostly qualitative in nature and has an observational design.

The starting point of this research was to read relevant and sufficient material in order to understand the existing arguments, take notes and create a filing system. These files have contained not only the plots of results and pages of calculations, but all sorts of notes, references, sources and addresses. This attempt has critically assessed the literature to gain a full and in- 
depth understanding of the subject and to identify the gap in the literature that was to be addressed by the research. This effort has provided information with which to compare and contrast the findings.

After the completion of the literature review, it was necessary to conduct fieldwork in Iran, and for this purpose a questionnaire was designed and prepared. Also the research ethics clearance sought from the university and it took the researcher more than six month to get the approval of the research project by Human Ethics Advisory Group (HEAG). As the nature of this research was exploratory, this thesis involved the preparation of a questionnaire and in-depth interviews with a relatively small number of focus groups of women's activists. Finding women activists was easy since the researcher had been living, studying and working in the society targeted by the research for more than twenty years. The focus groups had more than fifty women activists who were interviewed via telephone, email, Skype, or face-to-face (where each meeting took at least forty minutes). The researcher established good rapport with some of the activists and contacted them for interviews. Questions were structured and semi structured to give the interviewer a comprehensive overview. The questionnaire contained a series of questions about the interaction between the Internet and the women to obtain statistically useful information about a given topic. To collect the data the researcher has used two different methods. These included personally administrating the questionnaires and electronically surveying interviewees via email or Skype. Through personal surveys, physical observations have been more comprehensive than electronically produced ones, since adding more questions as applicable to certain persons being interviewed by having a closer look at their situation. All information has been kept strictly confidential, and the interviewees' anonymity has been protected. All interviews have been voice-recorded, transcribed and kept in a safe and secure place. Data classification and identification was essential because the data needed tagging so they could be found quickly and handled efficiently. After the completion of the data collection, the issues raised by the findings have been discussed and resolved.

\subsection{Definition of terms}


It is essential to define some key terms, which have been used throughout this research:

Basij: The militia is an Iranian volunteer force of Islamic government loyalists which is deployed in the streets at times of crisis to dispel dissent.

Chador: A piece of cloth worn by women covering the body from head to toe in order to follow the Islamic dress code.

Harim-e-Khaneh: Persian term meaning a protected area especially for women where no one is allowed to enter without the permission of the male head of the family. It is mostly used to show that men have the responsibility to control and protect female members of their families.

Internet: A space of interaction; a platform including weblogs, social networks, as well as websites for opposition and dissident activities, and other facilities.

Iranian women's movement: The movement of contemporary Iranian women is not limited to a certain place, and people involved in it are not easily traceable. This new form of political activism has provided the possibility for the definition of more needs of, and goals for Iranian women. However, the lack of an organisational structure has brought about passivity and despair for a large proportion of the movement's activists.

Jihad: Arabic term, meaning "effort", or "striving in the way of God". Some Muslim groups employ it to describe the religious duty of fighting against the enemies of Islam.

Khaneh: Persian term meaning "house" but it is used as a gender space to which women belong and where they should spend most of their life.

Majlis: The Iranian Majlis refers specifically to one of the Iranian parliamentary institutions. It currently has 290 representatives, increasing from the previous 272 seats held.

Post-reform Iran: A new phase in the political history of Iran which brought to power moderate and reformist politicians. This phase came after eight years of rule by conservative politicians (2005-2013), taking advantage of the failed experience of the reform movement's momentum which hoped to transform the autocratic political system into a more democratic one.

Sharia: Islamic law based on the teachings of the Koran and the Prophetic Tradition (hadith).

Sheikh: Arabic term literally meaning "elder" and carries the meaning of "leader" or "governor". It is commonly used to designate Islamic scholars who got this title after graduating from an Islamic school or a spiritual leader of a mystic group. 
Ulama': Arabic term, meaning the guardians and interpreters of religious knowledge, of Islamic doctrine and law.

Ummah: Arabic term, meaning the whole community of Muslims bound together by ties of religion.

Welayat-e-faghih: Welayat is a God-given authority invested in the Prophet Muhammad and the 12 Imams in Shia thought. By 940 it was declared that the 12th Imam would remain hidden until the Day of Judgment ${ }^{4}$. Political and social motives throughout Shia history led to the emergence of a new concept also called Welayat-e-faghih. Welayat-e-faghih is an Islamic term means guardianship by Muslim Jurists. This idea presupposed that Muslim Jurists are the rightful political leaders for society. The idea was probably first introduced by Ayatollah Mulla Mohammad Mahdi al-Naraqi (d. 1209), and later was employed by Ayatollah Khomeini at the time of the Iranian revolution in 1979. This theory was put into action as part of Iran's Islamic political system. This goes against the realization of the Shia claim of leadership.

Zanan: Persian term meaning "women".

Zananegi: Persian term to describe women who behave in a traditional way where Islamic norms and rules are adhered to. Muslim women are meant to be dutiful and often submissive wives, daughters and mothers.

\subsection{Thesis outline}

The first chapter of this study describes the research design adopted to achieve the aims and objectives. The chapter outlines the background of the topic, provides a brief review of current knowledge about it, and indicates gaps in knowledge. The second section presents the research questions for this study, while the third section discusses the research objectives and hypotheses. The fourth section of this chapter outlines the significance and contribution of this research to existing scholarship, and presents a new perspective to add to previous contributions on this topic. The fifth section provides the ethical considerations of the research and its limitations. The

\footnotetext{
${ }^{4}$ https://www.al-islam.org/excerpts-from-the-holy-quran-an-eternal-guidance-to-mankind/hereafter-dayjudgement-paradise-hell
} 
sixth section presents the theoretical framework, with the seventh section discussing the methodology used in the study and the stages by which the methodology will be implemented. The first chapter ends with a presentation of the definition of terms and the thesis outline.

Chapter Two provides a literature review demonstrating a thorough knowledge of the field of study and providing arguments to support the specific scope of this study. This chapter discusses key arguments and prominent works in the field, previously adopted approaches to research, providing critical evaluation of existing literature. It is shown that, in spite of the importance of this subject, there is a paucity of publications about the role of the Internet in the formation and expansion of the women's movement in Iran. Therefore, this research has explored the role of the Internet in the development and activities of the Iranian women's movement thereby filling a gap in existing scholarship.

Chapter Three concentrates on post-reform Iran. After the 1997 election and the victory of Muhammad Khatami, who tried to change and shape the image of Iran both at home and abroad, it appeared that reform was the way of the future as it was supported by the overwhelming majority of Iranians, especially young Iranians. However, eight years later hardliners got back into power. At that time while the state denied the public's aspirations for civil rights and democracy, Iranian dissident groups have persisted in fighting back, using alternative forms of communication such as the Internet.

Chapter Four contains a full discussion, interpretation and evaluation of the results with reference to the relevant literature. This chapter also includes theory building. As stated above, this research employs Tilly's Theory of Social Mobilization to analyse the features and components that contribute to the women's movement in Iran. This work seeks to analyse the extent to which the Internet offers space for an expansion of social movement theory in Iran. A likely prediction for the future of the Internet and Iranian activism is that an online element will help generate some of the elements of Tilly's social movement repertoire, specifically when utilized to inspire sympathetic individuals to palpable political action.

Chapter Five details the outcomes of the study and presents the findings without interpretation, inference, or evaluation. This chapter addresses the results from the data analysis only and does not discuss other research literature or the implications of the findings of this thesis. Direct 
quotation and paraphrasing of data from focus groups, interviews, or background are used to support the generalizations made. This analysis also includes information from field notes and other interpretative data. Tables and figures have been used to illustrate and summarize all numeric information.

Chapter Six presents the conclusions, limitations, and recommendations for further research of this thesis. The final chapter summarizes the problem that this thesis set out to solve, describing what it has achieved, and explores prospects for future research.

The thesis concludes with a Bibliography listing all sources used. 


\section{Chapter Two: Literature review}

\subsection{The Internet and political movements}

The use of the Internet is becoming a feature of political and civic engagement for many people. The utilization of the Internet by social movements should be understood within a larger theoretical framework which addresses the implication of the Internet for political engagement. Yet the burgeoning literature on this subject is rife with disagreement over a fundamental question: whether the widespread use of the Internet will lead to diverse political structure in terms of quality in the near future. There is an extensive body of literature that addresses this question, but the debate over the consequences of Internet use for social movements remains polarized. Some scholars celebrate the enlightening and liberating potential of the Internet, while others critique it.

Some of the popular claims about the Internet, communication, and political change are inflated, even hyperbolic, but not all can be easily dismissed (Bimber, 2007, p. 134). Cyber optimists like Amitai Etzioni (1999) see in the Internet the possibility of an advancement of the state of public affairs through "tele-democracy" since the Internet has been shown to surge political knowledge (Xenos \& Moy, 2007, p. 711). Technologist Mitchell Kapor claims the Internet will "enable a Jeffersonian revolution"(Pavlik, 1996, p. 146). In other words, cyberspace is a place for people with a wide range of interests including radical groups interested in fomenting social and political discontent. Lawrence Grossman (1995) discusses that a third great era of democracy is arriving via the use of technology. Since the distance between talk and organized action has grown smaller like-minded people are now able to better locate and converse with each other via Internet media. Nicholas Negroponte (1995) even goes so far as to expect "the nation-state to evaporate" under the influence of new technologies. They believe that it is now inconceivable that social and political reform or revolution can occur without the Internet and social networking playing a significant role (Abbott, 2012, p. 342).

From the cyber optimism point of view, the Internet is potentially a first global public sphere, a medium through which politics could be made truly participatory at both regional and 
international levels. The Internet is the first medium through which individuals and independent collectives may hope to communicate in their own voices with an international audience of millions (Downing, 2001, p. 119). The Internet also facilitates new forms of network and action (Chadwick, 2007). Therefore, at the individual level, Internet use can lead to higher levels of civic and political engagement. Hence, cyber optimism suggests a relationship between the Internet and the proliferation of movement mobilization and protest action in contemporary societies (Lee \& Man Chan, 2012, p. 149).

Scholars sharing the above views have demonstrated that the Internet has increased political participation in social movements through a variety of mechanisms, such as reduction of participation costs, decentralisation and distribution of media production tools, promotion of collective identity, and creation of community (Feezell, Conroy \& Guerrero 2009; Garrett 2006; Tolbert \& McNeal 2003; Weber, Loumakis \& Bergman, 2003). The Internet has strengthened social movements by increasing the motives for collective action (Brunsting \& Postmes 2002; Krueger, 2006). The Internet is enabling groups previously incapable of political action to find their voices.

It has also been emphasised that social movements may be unconventional political events, but they have been perceived as legitimate and as "standard operating procedure across the political spectrum" (Putnam, 2000, p. 176). Like other kinds of political participation, the success of social movements heavily depends on effective communication between the private and public spheres, because mobilization of resources of individuals that are embedded in private lives, either material or non-material, is necessary to accomplish a collective goal, which benefits a community, the public, or society as a whole (Bimber et al., 2005, pp. 367-372).

As Shirky (2011, pp. 28-41) points out, one of the most revolutionary features of the Internet is that it creates a "shared awareness" of the realities of public and private life. The state may have ever growing and sophisticated tools of surveillance, but now ordinary citizens have the ability to use similar tools against the state (Fuchs, 2012, p. 781). In this regard Zuckerman argues that overt and heavy-handed attempts to control access, such as with the Green Dam software, may actually have the effect of radicalising ordinary users (Gills, B. K., \& Gray, K, 2013, p. 140). This is because blocking content effectively "teaches people how to become dissidents and how to find 
and use anonymous proxies", which in itself becomes a "first step in learning how to blog anonymously" (Abbott, 2012, p. 339). Recent data from Pew research centre on social media in the USA found that Internet users are more likely to be politically active than non-users, with Facebook users in particular "more likely to be politically involved than other Americans" (Howard, 2011, pp. 84-107). Such results do not seem to be isolated.

Howard echoes Zuckerman's view, arguing that, while social networking and the diffusion of the Internet does not substitute for traditional political activism, "in times of crisis banal tools for wasting time become the supporting infrastructure of social movements" (Howard, 2010, p. 6). Howard gives the example of the surge in traffic of political blogs in Iran during the failed Green Revolution (Howard, 2010, p. 9).

It is clear that the Internet enables new grassroots movements to spring up quickly and operate for a time, but many doubt whether such Internet-based efforts can persist. Bimber (2001, p. 133) and Garrett (2006, p. 208) suggest that perhaps this may become the model for new social movements: transient, decentralized groups will spring up and remain active through a single political effort, content to fade away afterward with the knowledge that should the need arise, a similar group can quickly be built up again.

Shirky (2011, p. 32) also argues that new communication technologies now create a "conservative dilemma" for autocrats. This dilemma comes from the fact that traditional methods of countering dissident voices, propaganda and censorship, are now less effective. Since citizens can 'fact check' government narratives in a way that was impossible before, the value of propaganda is reduced, while censorship of the Internet can have adverse economic and commercial ramifications (Karagiannopoulos, 2012). While it is possible to opt to 'shut down' the Internet domestically, as the Islamic Republic of Iran did in December 2009 and the Egyptian government briefly did in February 2011, this strategy risks alienating regime supporters and harming the economy (Golkar, 2011, p. 61). It is extremely difficult for state authorities to differentiate between political use and apolitical use because of the nature of new communication technologies (Castell, 2012).

This dilemma also provides a retort to those who argue that the overwhelming majority of users of the Internet are apathetic, more likely to chat with friends, download music and play games. 
As Shirky (2011, p. 39) continues, the problem for autocrats is that "tools specifically designed for dissident use are politically easy for the state to shut down, whereas tools in broad use become much harder to censor without risking politicizing the larger group of otherwise apolitical actors".

The last, and one of the most critical, issue with new communication technologies is that they allow the individual to both be a producer and a consumer of technology, since the cost of producing digital content has now been significantly reduced with the growth of smartphone use (Livingstone, 2004, p. 7). This represents a significant change in the nature of communication away from hierarchical systems that are easier to control centrally to networked systems that are not. The outcome of this is that "citizens and civic groups promote their points of view online, but also use information infrastructure as a tool for resisting state control and battling with opposing points of view"(Howard, 2011, pp. 16-24). Such resistance can take the form of citizen journalists, ironic videos or of more routine symbolic forms of protests that spread virally (Abbott, 2012, p. 347).

Some scholars warn of the dangers and consequences of the reliance on the Internet by social movements. Although some Internet enthusiasts have hyped up its democratic essence, caution is required as its potential is constantly in danger of being prevented from developing. Critics advance a number of counter-arguments, of which the most commonly heard is that the Internet generates democracy bubbles. 'Democracy bubble' means that as more citizens participate, the greater are their expectations for affecting political change, and these high expectations, when they fail to materialize, will actually make citizens feel deflated, reduce the sense that their actions matter, and ultimately make them far less likely to engage in the future (Coleman \& Shane, 2012, pp. 123-178). The end result would be leaving society and communities would be worse off than they were initially. Public opinion tends to identify certain "mirages" about the existence of pervasive pro-democracy movements as being real. However, their existence only takes place within the range of perceptions of those who place irrational trust in the liberating capabilities of the Internet (Torres Soriano, 2013, p. 341). Some of the movements located in cyberspace have lacked a genuine social base. Thus, for example, most of the browsers on the 
Internet who were active in the protest movements against electoral fraud in Iran were located far from it (Lerner, 2010, p. 562).

Some authors point to the weakness of the social ties that are created entirely through cyberspace. According to Malcolm Gladwell (2010), "The social network platforms are built on weak link. These weak links are conducive to high-risk activism". The reduced staff cost and limited effort involved in joining these new virtual collectives have the direct consequence of not being very sound, once it is necessary to take the leap from the "virtual" to the "physical". When government repression and physical violence takes place, these groups become quickly disrupted, or their actions barely effective (Torres Soriano, 2013, p. 347).

Cyber pessimists assert that the Internet can be even more readily harnessed by their oppressors (Deibert \& Rohozinski, 2010, p. 43). Accordingly, new technologies might be manipulated to expand the reach of the state rather than to minimise it (Kress, 2003, p. 164). This new form of technology has provided non-democratic regimes with the ability to impose control and supervision over societies. This, in turn, leads to other types of suppression as the Internet allows governments to reach into the most private aspects of individuals' lives (Downing, Ford, Gil \& Stein, 2001, p. 272). Security organisations can simultaneously carry out effective and detailed control over the lives of hundreds of thousands of people. Spying on browsing enables states to find out not only what type of information they produce and consume, but also whom they associate with (Deibert \& Rohozinski, 2010, p. 52).

One of the most notable of these is the Green Movement in Iran. After the protests around electoral fraud in the 2009 presidential elections, the authorities put up a website where over a hundred photos of the demonstrators taken by the police were published, with the intention of getting Internet users to help them to identify the dissidents (Dabashi, 2010, p. 135).

Researchers such as Ronald Deibert and Rafal Rohozinski (2010) consider three "generations" of techniques for browsing control in the hands of governments. The first is focused on filtering Internet content and the monitoring of public spaces. The second generation includes a legal environment that legitimizes the control of information, including informal requests to companies providing services to withdraw content, the technical closing of websites, or cyberattacks. Finally, there is also legal action through Internet surveillance, direct physical pressure 
to intimidate people and groups, and the compartmentalising of cyberspace, to create national "zones". One example of this latter practice has been Iran's attempt to set up an "intranet", cut off from the global net and "clean" of content that is not permitted under Islamic law (Karagiannopoulos, 2012, p. 161).

In the worst case scenario, authoritarian regimes are increasingly shutting down their communications grids to deny opponents the ability to coordinate in real time and broadcast documentations of an event (Shirky, 2008, p. 171). Furthermore, governments can also set the price for the Internet, as a way to subject users to a hierarchy of access, transferring the Internet from an indispensable source of information into a luxury for the majority of the population (Atkinson, 2010, pp. 3-8)

While the Internet will certainly change the informational environment of individuals, it will likely not alter their overall interest in public affairs or their ability to assimilate and act on political information (Bimber, 2007, p. 136). While the Internet makes it much easier for active people to seek out information and networks of like-minded others, what gains traction online is the least common denominator (Boyd, 2008, p. 243). Therefore, only a minority use Internet for a political purpose.

Opponents of the Internet have also claimed that information on the Internet is often unreliable, transient or biased (Morozov, 2010). It may indeed be hard to believe that all the information is written by well-known trustworthy sources or scholars. There is no quality assurance when it comes to information found on the Internet as anyone can post anything. Morozov (2010, p. 115) raises objections against the use of the Internet citing the fact that nowadays authoritarian regimes are co-opting online discussion by spreading their propaganda and misinformation. $\mathrm{A}$ much more aggressive form of misinformation is one used by the Iranian regime in order to boycott the announcement of the opposition to call for protests and demonstrations. Using social networks, the Iranian intelligence service distributed information about the location of snipers, threatening protestor that they would act when demonstrators marched past (Gedmin, 2010). Thus, the Internet can be used by governments invoke fear in citizens and to erode the value of the opposing discourse. 
Even though cyber optimists and cyber pessimists seem to maintain irreconcilable positions, both perspectives in fact possess multiple points in common. Both cyber pessimists and cyber optimists infer a certain simplification in the causes that feed the processes of political change. Both perspectives suggest a strong correlation between the spreading of the Internet and social media and the political evolution of the societies (Torres Soriano, 2013, p. 333).

In sum, the key argument of the cyber optimistic perspective is that as the number of Internet users in a given country increases, the degree of political freedom in that country also increases. The cyber pessimist hypothesis, on the other hand, argues that as the number of Internet users in a country grows, a loss of political freedom is incurred.

In this view the Internet is neither necessary nor sufficient for the success of social movements. On the far end of this spectrum cyber-pessimists contend that new social media in fact makes it more difficult and more costly to control society and open up new spaces for political activity (Etling et al, 2009, p. 54).

Cyber optimists may be correct in observing how the Internet has facilitated the capacity of citizens to control political power and even enabled activists to get footage out of their country to the global media audience, express their opinions or increase the horizon of political participation. The pessimists, on the other hand, have understood how to connect those potentialities with the parallel development of a sophisticated system for controlling the Internet and monitoring its users. However, they might overestimate in attributing the cause of its effects to the particular instrument. What they consider to be structural characteristics of the Internet, does not stop it from being the mere consequence of human actions. Users are the only ones in charge of the nature of the political change.

This work agrees with the relatively small body of works arguing that the Internet has a neutral value (Torres Soriano, 2013, pp. 334-342), and there is nothing intrinsically pro-democratic in it that it is used for limiting freedoms. So, it is not the instrument itself that determines the result of struggle for obtaining freedom, but rather the context of the political and social organisation. Above all, the factor that determines who will be the winner at any time is level of organisational skill possessed by the people involved. 
As Larry Diamond (2010, p. 70) observes, the arguments used by both positions stem from a world-view about the Internet and its effects, based upon metaphors that fail to adequately summarize the nature of this technology or the behaviour of those who use it. In fact, the effects of the Internet on political change depend on the context and the ability of the actors who use it.

While this thesis mostly accepts Howard's (2010) estimation that while the Internet itself is not a pivotal factor for democratization, it nevertheless does limit the options for authoritarian regimes, not least because the technology is democratizing in the sense that it connects, empowers and informs a greater number of people than what has been possible ever before. As Howard Rheingold (1993, p. 276) remarks, "if properly understood and defended by enough citizens the technology does have democratizing potential in the way that alphabets and printing presses had democratizing potential".

This thesis proposes that the Internet is not merely a new form of existing communication but instead confers unique opportunities for activists and social movements that open up precisely such a public sphere. Additionally, while the use of such tools remains a minority pursuit largely by segments of the middle class this does not diminish their democratizing impact, since existing hierarchies of information and communication control are still being democratized. Thus, it is now inconceivable that social and political reform or revolution can occur without the Internet and virtual sphere playing a significant role.

This work makes a contribution to filling this gap by providing some insights into the participation of Iranian Internet users and their purpose to use such a tool.

\subsection{The Islamic Republic of Iran and the Internet}

The Islamic Republic of Iran has been experiencing one of the most dynamic periods of its recent history. Change is occurring in all spheres of life. This is mostly due to the emergence of new technology which is exercising a powerful and persuasive influence on youth and women. The popularity of the Internet among young men and women in a conservative society such as Iran has sent an alarming signal to hardliners concerned about the immoral use of it. In short, the 
conventional belief in the power of state control seems to be demolished. Clearly, the controlling state has devoted considerable attention to the Internet, which it regards as a threat to national security or, worse, as imperialist invasion.

According to the Supreme Leader of the Islamic Republic of Iran, Ayatollah Ali Khamenei, the potential danger of the new technology should be recognized. He has asked officials to "be careful, sensitive and alert with regard to the extremely dangerous cultural breaches and to perform the defensive duties required of them" (farsnews.com, 17 December 2010). He continued that officials confronting the various cultural breaches should not be concerned that they are infringing upon people's freedoms, because "freedom, as a great divine blessing, is completely different from carelessness, indifference and recklessness" (farsnews.com, 12 October 2011). His concern is that the Internet has developed into a fast-paced interactive process which reflects new ways of constructing social capital that may have implications of emerging new cultural projects and building communities, especially in the sphere of politics (Rahimi, 2011). Hence, the Internet as a public sphere is about diversity of contacts and exchange of ideas, which consequently challenges older forms of control.

The widespread use of the Internet has attracted the attention of all, including those who were seeking to find a way to resist government policies, as well as governments and grassroots movements. The impact of the Internet on Iranian politics resembles the introduction of earlier information technologies (such as the telegraph in the late nineteenth century and the cassette tapes in the 1970s), which also created new individual and social spaces for dissent. The telegraph was used by the pro-constitutionalists to send political messages and information abroad, and cassette tapes were used to record and disseminate major speeches by revolutionary figures like Ali Shariati or Ayatollah Khomeini throughout the revolutionary period of 1970s (Rahimi \& Gheytanchi, 2008, p. 51). With the arrival of the Internet, dissidents can spread ideology and information with the click of a mouse, and it is very easy for current dissidents to employ the same strategy that the current Islamic government used to come into power. The fear of another revolution in Iran has caused the Iranian government to employ many techniques to control and censor the Internet. 
Iran's Internet censorship goes beyond simply blocking access to particular websites and services. Iran has only one public Internet service provider (ISP), so the government has consequently been able to dramatically slow down bandwidth speeds in an effort to delay messages meant for organizing large scale protest (Rahimi, 2008, pp. 41-42). According to an Iranian newspaper, the number of filtered websites doubled from 5 million in the year 2008 to 10 million in 2009 (Sarmayeh newspaper 14/11/2009). To access such platforms as Facebook and Twitter, Iranians have had to employ Virtual Private Networks (VPNs) or use applications designed to hide IP addresses typically known as Deep Web Browsing (Kamran, 2009). In response to the development of the communication technology, the regime has heavily invested in filtering Internet social network, imprisoning bloggers, and forming a Cyber-army which is responsible for fighting against cyber civil society. These efforts, however, have not been successful in preventing the growing number of users and their access to information (Alfoneh, 2013, p. 123).

While Iran's leaders have been trying to avoid Internet-induced unrest since 2001, they are slowly but surely accepting the reality that the Internet today has come to pose a serious threat to their power. They clearly understand that the virtual world will create a new society whose control and management will be extremely difficult. Therefore, the impact of media such as the Internet has provoked the reaction of many including the government and influential domestic groups such as religious clerics as it threatens their source of power.

The political use of the Internet by reformist elements of the ulama is one of the examples which indicate the potential for the Internet to appeal to very different groups. The new technology empowered dissidents to propagate their democratic interpretations of Islam without supervision of the state. The target audience is not only the religious establishment but also younger domestic and global audiences. For instance, the post on Grand Ayatollah Morteza Montazeri's personal website has shocked the state. His published memoir (Rahimi \& Gheytanchi, 2008) provided many detailed descriptions with regards to some of the most critical moments in the early revolutionary state which had been a devastating critique of the Islamic Republic.

Online political activities similar to the example cited above, emphasize the importance of the Internet to the government as well as to its detractors. It is worth noting, however, that the 
Iranian government's response to these new forms of dissent has been severe. On 7 November 2001, the Supreme Council for Cultural Revolution (a conservative-dominated body) declared that ISPs must remove anti-government and "anti-Islamic" sites from their servers, and all Internet service providers should be placed under state control (Rahimi, 2008, p. 39). A year later, the Supreme Council ordered a new commission to create a list of illegal sites. At the same time, the Chief of the Judiciary, Ayatollah Mahmoud Hashemi Shahroudi, called for the "establishment of a special committee for legal investigation of Internet-related crimes and offenses," and proposed the creation of a new legal office to deal especially with Internet offenses (Semati, 2008, p. 7). In February 2004 a new supplement to the law laid out specific sentences for publishing information damaging to Iran's national security or revealing sensitive data about the government. It also created a list of 20 types of web-based sedition (Hendelman-Baavur, 2007, pp. 85-86). Finally, the Council set up its own Internet surveillance agency, the Supreme Council of Virtual Space. These actions show the ruling system's appreciation of the serious challenges the Internet may pose.

However, despite the continuous assault on the new technology the critical websites have continued to grow, gaining more popularity among intellectuals and ordinary people. They have subsequently become a culture, a new way of living, and an undefeatable reality. Online participation, as was the case with the 2003 student protest or the post-election uprising in 2009, has proven the significant role the Internet can play in Iran. It can open up new forms of dissident politics and enhance motivation for political movement. Consequently, this new technology provided a new communicative sphere, a virtual domain that operated beyond the supervision of state authorities.

Clearly, the Internet threatens the society created under authoritarian role since authoritarian regimes control people through the implementation of state ideologies which also proactively promote a system of surveillance. Political influence has governed resistance to the new technology from the conservatives in Iranian society. On the other hand, opposition to the government saw the Internet as the next frontier for successful activism in Iran (Lerner, 2010, p. 559). Therefore, debates for and against the use of the Internet spread across the country and 
there has been a specific tendency towards exaggerated claims on the impact of the new technology.

For instance, the conservative cleric Ayatollah Ali al-Sistani approached the question about how people should make use of social media like the Internet by arguing that "the father or husband may be wary if their wives and children keep communicating with others on social media, since they are responsible for them, and can prohibit wives and children from acting in such a way, as these behaviours are against the Islamic religion" (Retrieved from (Sistani.org) on 21/5/2016). Ayatollah Naser Makarem Shirazi asserts that "as the Internet can be used or abused containing both useful and harmful information, people are only permitted to use it if they do so correctly and in accordance to the Islamic sharia law" (Retrieved from (makarem.ir) on 2/6/2016). Moreover, in agreement with the concerns of the regime, Ayatollah Lotfollah Safi Golpayegani stressed that "generally, if virtual spaces are used properly, in ways that does not cause moral corruption of mind, and are used instead to disseminate and spread religious ideologies, they are welcome all together and have no negative ramifications. However, visiting websites which corrupt souls, weaken the flesh, and inspire devilish thoughts is forbidden" (Retrieved from (safi.ir) on 26/5/2016).

The clerics share the same starting point. They all view the Internet as a powerful tool which can manipulate society. Therefore, propaganda through cyberspace plays a major role. However, the risks and threats of using this technology without careful planning can result in inconsistency and lack of cohesion, and waste of resources. Hence, the wielding of power in the Internet must be in the hands of those who have control over the content and shape of the messages disseminated via the Internet. Consequently, the Iranian state was quick in its response embracing the Internet rather than seeing it as a threat and discovering that it needs to be used to their advantage, as an extremely negative response to the Internet will only partially resolve their problem. However, the popularity of the Internet continues to soar despite the clampdown by the regime, especially among the younger generation.

As a result, a major shift has become evident in the regime's activities. Widespread resources are openly allocated to explicitly formulate and implement a systematic approach to the new media 
landscape under the banner of responding to what the state calls a 'soft war' ${ }^{5}$ (Akhavan, 2013, pp. 95-117). This strategy is intended to subvert what the state claims are media-based assaults on Iranian values and culture, by educating the public about the perceived enemy's media tactics and producing competing media content. According to the regime's narrative, having access to the Internet is associated with the risk of exposing Iranians to non-religious ideas and their assimilation into secular politics. The state has promoted the idea that the Internet is the main tool for the West in its cultural invasion (Shirazi, 2010, p. 927). In November 2009, for instance, only a few months after the presidential election, Supreme Leader Ayatollah Khamenei said in a speech to his supporters: "Today, the country's top priority is to fight against the 'soft war'" (Retrieved from (farsnews.com) on 25/5/2016).

This progress revealed a new chapter in the Islamic Republic's history of online governance. During this phase, the state started making itself as ready as possible to fight against the opposition. It has employed a group for trolling, spreading misinformation and hacking dissident websites. The postelection period (2009) marked a new confrontational stage in the use of proactive measures to stifle dissident activities online (Rahaghi, 2012, p. 156). The emergence of an online civil society which functioned autonomously from the state has proven the importance to insist on dominating access to the Internet.

In doing so, state supporters were encouraged to participate in the 'soft war'. In other words, a mission defined by the conservatives to fight against a 'soft war'. It aims to fulfil this mission by informing its readers about new books, publications, articles, software as well as the latest news, reports, and relevant developments in research on the issue of soft war (Retrieved from (psyop.ir) on 15/7/2016). They are keen for state supporters to keep abreast of the latest media technologies so they would know how to confront activists in creative ways (Rahaghi, 2012, p. 173). The state's vast resources are being devoted for producing and disseminating information to this end.

\footnotetext{
${ }^{5}$ The 'soft war' in Iran is a perception of actions and a discourse of counter-moves. Being subject to a potential threat, the Iranian government expanded state influence over cyberspace outlets to spread pro-government propaganda. Therefore, paramilitary commanders have called for the allocation of more resources, recruitment of another ten million Basiji bloggers, and the creation of a cyber-army of loyalist content producers to fight the 'soft war' (Farivar, 2011; Flock, 2011; Fowler, 2009).
} 
The history of the Iranian state's involvement with the Internet reveals a curious combination of strategies from the censorship policy, blocking websites and arresting dissidents to using the medium to spread state propaganda. The state has complete control over the Internet inside Iran: if it chooses to, it can collapse the entire system. After experiencing dissidents' use of the Internet to the political purpose, the state has become an active online participant. The result has been a range of activities, including projects that have sought to influence content produced on the Internet.

Overall, during the eight years of the reformist President Mohammad Khatami being in office, state control of the Internet was relaxed because the reformists had legislative power. However, these relaxed policies came under significant pressure following student uprisings in 1999. However, until the presidency of Mahmoud Ahmadinejad in 2005, cyberspace provided a relatively secure space for activists (Rhodes, 2007, p. 117). Ahmadinejad's presidency provided hardliner politicians with a chance to cause a major decline in dissent by controlling the Internet. Despite the state crackdown and blocking of activist websites, there were ongoing activities such as street demonstrations in 2009 and the One Million Signature Campaign, discussed in detail further below in this section. The current situation, however, is much more complex than before. This is due to the fact that hardliners have lost most of their power with the election of President Hassan Rouhani in [2013]. One year after the election, President Rouhani stated that "Iran should embrace the Internet rather than see it as a threat" (Retrieved from (reuters.com) on 2/6/2016), in remarks that challenge hardliners who have stepped up measures to censor the Web. Today Internet censorship has eased somewhat under Rouhani's new government but he lacks the power to open it up completely (Retrieved from (Alef.ir) on 30/8/2014).

\subsection{The Iranian women's movement and the Internet}

There is growing recognition that the Iranian women's movement has shown visible signs of resistance. Over the course of history, women were gradually gaining awareness through their participation in many political discussions and movements at different times. They have learned how to develop a resilience, so that they would be able to continue moving forwards. Therefore, 
in response to the challenges posed by the end of the reform period and the rise of the new conservative government, the first sparks of change in the tactics and strategies of the women's movement came within the context of Mahmoud Ahmadinejad's radical government in 2005. As a result of political repression many reformist newspapers, magazines and organizations were closed. As a result, joint meetings between various women's organizations were held to discuss priorities, demands and reforms. Accordingly, the new approaches and policies that preserves and strengthens the Iranian women's movement has gained momentum.

It is a fact that the women's movement was structurally too dependent on various political parties dominated by male politicians. Women had no voice in this male-dominated climate which set the priorities of struggle to the male politicians' vision and formulae (Jahanshahrad, 2012, p. 237). Hence, Iranian women saw the time as ripe for the creation of an independent women's movement and divorcing the women's struggle for equality from their dependence on the political fortunes of men of power. Based on Iranian history, the leadership of the women's movement fundamentally was grounded in nongovernmental organizations (NGOs) and can be described as organization-oriented. This means that most necessities such as offices, projects, financial resources, and sometimes even human resources, could be readily identified by the government. However, Mahmoud Ahmadinejad's radical government in 2005 imposed severe restrictions and the activities of women's NGOs were subjected to strict surveillance. A strategic plan was adopted to replace the organization-centred approach with a campaign-centred one (Abbasgholizadeh, 2014, p. 834). Well known activist Noushin Ahmadi Khorasani comments on this as follows:

"We had several options: the first was to support a political front that was considered to be more democratic. This seemed to me logical, since, clearly, the further political space expands, the better conditions for women's activities will be. A second option was to use the opportunity and the political opening that always comes during election [campaigns] to air our independent voice. A third option was to ignore this opening, not to do anything, and to leave everything to the future" (Osanloo, 2008). 
The women's movement chose the second option and prepared to take the risk of turning their back on the state. Thus, the rally became the official birth of what was proclaimed as "a fresh chapter in the women's movement" (Tohidi, 2016, p. 79).

Women have not been strangers to the virtual sphere since numerous websites have been created that have had activities in relation to women's issues published online. For instance, IranDokht.com and Persianfemale.com are both known as noteworthy sites dedicated to Iranian women. These websites have been providing information dealing with women's concerns. Furthermore, the prolific posts of diverse bloggers writing in Persian by mostly women or with regards to women ${ }^{6}$. Subsequently, they expanded the virtual terrain enough to consider that Internet-based participation has become the voice of the movement. Consequently, a series of incidents and restrictions at that time attracted them more and more to the virtual atmosphere and the Internet has emerged as a substitute for real-life activities carried out in person.

Several campaign-centred groups have been formed. They are best recognizable for their associated websites, such as Change for Equality (http://we-change.org/site/english/), Feminist School (the intellectual wing of the women's movement), or Fair Family Law. None of these organisations was registered with the government nor were they accessible through a particular physical location. The campaign structure was Internet-based and allowed participants to join or leave without the obligation to recruit or be employed.

The One Million Signatures Campaign, for example, was organized and best identified by its associated website (Change for Equality: http://we-change.org/site/english/) and, accordingly, it could not be accessed through a particular physical location. In relation to this, Parvin Ardalan, the Iranian women's rights activist who launched this campaign pointed out that "Every print magazine for women we had was closed, so we created a new world for ourselves in cyberspace" (Soguel, 2010).

The starting point of the campaign was a rally on 12 June 2006 in Haft e Tir square in Tehran but it was officially launched only on 27 August 2006. It was announced by word of mouth, and for the first time through Internet sites as well. The One Million Signatures Campaign aims at

\footnotetext{
${ }^{6}$ The blogosphere, as noted by Stanyer (2006), is an interconnected universe of blogs, and women have been among the leading bloggers within the Iranian blogosphere.
} 
pressuring the state to recognize the equality of men and women in all laws of the land. This movement has been against gender discrimination in the Iranian legal system. The Internet provides the women participating in the campaign with a way to reach out to international supporters who are encouraged to sign petitions demonstrating solidarity with the plight of Iranian women, as well as to Iranian citizens who cannot be reached in face-to-face interactions or who live outside of Iran (Sameh, 2010, p. 453). The Internet has offered a way for the campaign to garner contributions from donors (Lerner, 2010, p. 564).

Another campaign fought via the Internet is the Anti-Stoning Campaign in launched May 2006 with the aim to save lives and with the aspiration to eventually persuade the Iranian authorities to abolish executions by stoning and to bring their legal practices into line with their obligations under international law. Due to the crackdown on civil society after 2005, the Campaign had limited opportunities to hold meetings and activities in public. However, after a successful virtual campaign to save Sakineh Mohammadi Ashtiani from being stoned in 2007, campaign activists recognized the power of the Internet (Terman and Fijabi, 2010).

The sentence of death by stoning handed down in the case of Sakineh Mohammadi Ashtiani in Iran is one of the examples to this point. A court sentenced her to be stoned to death in 2006 but the sentence was suspended in 2010 in the face of international pressure (Retrieved from (https://www.theguardian.com/world/sakineh-mohammadi-ashtiani) on 13/7/2016). Her sentence was then reduced to 10 years of imprisonment because of activist online participation on the Internet. The Islamic Republic of Iran has tried with everything in its power, to cut off the relations between Sakineh and her family on the one side, and her lawyer and the public opinion on the other. However, the virtual space created a link between them (Retrieved from (https://www.amnesty.org/en/documents/MDE13/001/2012/en/) on 24/6/2016). Finally, the Islamic Republic of Iran, under intense pressure through international public opinion against the stoning sentence of Sakineh, were forced to released her, change the law and to stop this cruel practice. This, in turn, provoked an outcry among the conservatives since stoning was a part of Islamic religious law that should not have been denied within the conceptual framework of a functioning Muslim society based on Sharia. 
A more recent example of using the Internet to organise peaceful protests was the Green Movement. Nevertheless, in this protest, which followed the controversial election in June 2009, the presence of thousands of women among the protesters was an unexpected and endearing sight. The noticeable appearance of women coincided with the death of Neda Agha Soltan ${ }^{7}$. Therefore, she emerged as the face of the anti-government movement and a symbol of resistance and opposition (Mortensen, 2011, pp. 5-9). The protesters used the Internet to disseminate a video recording of Neda Agha Soltan's death. This new method of interaction has the enabled women's movement to revolutionise the way they protest and has made movement stronger.

During the 2009 election campaign and post-election period, the women's movement not only made itself and its own demands visible, but also greatly influenced the Green Movement's direction, content, philosophy and mandate. The Internet made it possible for women to create transnational and trans local spaces that at times seemed to approach an ideal public sphere. Therefore, women's activist seized the moment to catch local and international attention, increasing alertness toward their struggle for change.

In the past thirty years, the Islamic Republic of Iran has consistently crushed any voice of dissent, especially the voices of women. Therefore, the dominant socio-political and atmosphere of repression, secrecy, and fear have led many Iranian women to use the virtual space campaign for women's empowerment and equal rights (Karagiannopoulos, 2012, p. 158). One of the most profound impacts of the virtual sphere is the way in which it has enabled social interaction in closed societies where the government has blocked other pathways for mobilisation, such as public gatherings, peaceful protests, and freedom of expression.

\subsection{Conclusions}

The review of the theories of the impact of the Internet on social movements leads to the conclusion that the use of this life-changing technology is inevitable. This could be confirmed by

\footnotetext{
${ }^{7}$ Whilst participating in the protests following the June 2009 elections, Neda Agha Soltan was shot dead by Iranian officials.
} 
the Arab Spring and Green Movement in Iran. Today, the ever-increasing use of the Internet is seen as an essential medium in the modern world. For instance, according to a report in 2012 (Retrieved from (huffingtonpost.com) on 29/11/2012), one thousand pieces of news and thirtyfive thousand photos and videos were uploaded on Facebook every sixty seconds during which ten thousand and five hundred comments and twenty-three thousand messages were also communicated (Retrieved from (huffingtonpost.com) on 29/11/2012). Facebook has approximately one billion and three hundred thousand users, a figure slightly higher than the population of China (Retrieved from (abc.net.au) on 4/2/2014). The number of photos and comments were one hundred thirty five times more than the number of articles published (Retrieved from (huffingtonpost.com) on 29/11/2012). These figures reveal the fact that in the last twenty years, despite spending billions of dollars, Iran's government has not only been unable to curb the use of these social networks but also has contributed conversely to the prosperity of the market of anti-filter software. According to a recent report from Majles research (Retrieved from (rc.majlis.ir) on 4/5/2014), rules and regulations concerning the Internet have lost their force. According to the same report, until the mid 1380's A.H. (2005-2010 C.E.), the users of the Internet were looking for entertainment, while now they are using the Internet to inform themselves of the latest news and for its analytical and intellectual merits, which has become a cause of concern for the Iranian government.

Through an examination of the history of the Iranian women's movement, it can be observed that women have started their participation in this matter via recognizing the significance of the Internet and have used it to achieve more success in attaining their goals. In spite of the government's attempts to suppress and control the Internet, Iranian female activists have not given up hope in achieving their aims. They have also demonstrated their familiarity with the new trend of the Internet and their ability to familiarize themselves with ways to use technology to attain their objectives.

Numerous studies have examined the impact of the Internet on social movements. Regarding Iran, these studies have mostly looked at the Green Movement (Jonbesh Sabz). However, it is difficult to find a study with the focus on the relationship between Internet and women's movement per se. Studies such as Golkar, (2011), Rahimi (2003), Hashemi and Postel (2011), 
Mottahedeh (2010), Duranti (2013), Gheytanchi \& Moghadam (2014), Marks (2013), Payrow Shabani (2013), Fathi (2012), Ansari (2012), Shabani (2013), Ghorashi \& Boersmawhich (2009) have dedicated their time to reviewing the linking between social movements and the use of the Internet to supplement the process of socio-political activities of the dissidents. Although past research has done an excellent job in exploring the vast topic of social movement and the Internet, none have addressed the connection between Iranian women's movement and the Internet. What's more, most research focused on social movement as a whole, only a minority considering the Iranian women's movement. However, despite the efforts of these studies to cover the field properly, the real activists in these movements have been forsaken in their research. A truly significant point which is overlooked regarding these studies is what motive brings women activists towards the Internet and what goals they are after. According to Tilly's theory, a movement will not succeed until its activists know to what extent and how to use a tool. The goal of this research is to examine Iranian women's movement more deeply, and analyse women activities through the use of the Internet to facilitate their actions and based on previous studies, the researcher is confident that research hypothesis will not be proven false. 


\section{Chapter Three: Rouhani's Equity Government: A new period of reform in Iran?}

\subsection{Introduction}

This chapter will explore whether Iran entered a new period of progressive reform with the election of the Rouhani Government. In this regard, a few auxiliary questions arise: What is the meaning of reformation? What is the goal and interpretation of leaders of reformation theory? what approaches do reformists take towards socio-political issues? what is the effect of new socio-political status towards women? Finally, what approaches has the women's movement taken towards changes to continue their existence and adjust their activities?

Therefore, this chapter will analyze the views of policy-makers during three periods: The Reform period (1997 - 2005), the Post-Reform period (2005 - 2013), and the Equity Government (2013 - the time of writing). It will examine their similarities and differences to respond to the above questions. However, the intention is to provide a thorough analysis of socio-political status of women such as educational attainment, cultural politics and legal disparities during these three periods of time. It seeks to discover changes connected to women under the three recent governments in Iran to give a better understanding of contemporary social realities of women and women's movement in Iran.

\subsection{Definition of reform and reformism in the Iranian context}

Reform is defined as 'efforts to promote structural changes, and subversion to improve or attempt to repair a faulty structure full of difficulties like centrally managed system that caused policy paradox, economic bust, unemployment, austerity and lack of freedom' (oxforddictionaries.com). Reforms have occurred in most countries around the world with different motives which have had different purposes and different results. For example, the Arab Spring which started on 17 December 2010 was an attempt to overthrow autocratic regimes where a small minority elite had occupied most positions of power. According to those who 
exercised reforms in the Arab Spring countries, this movement was an extended effort to establish democracy when people demanded a fundamental structural change to the established order (Fuchs, 2012). In Egypt and Tunisia, people demanded reforms through widespread protests and street demonstrations. The reforms they aspired for were not a misplaced hope; they were legitimate rights which were demanded.

The 1979 Islamic Revolution of Iran, in which the Pahlavi monarchy was replaced by an Islamic state can be called a reform (Brownlee, 2015). After the revolution in Iran, people no longer called for another revolution because they understood that changing a regime would not contribute to the improvement of their social, political and economic situation (Entessar, 2012). Quite conversely, the revolution has brought irreparable damage and destruction to Iranian society that will take years to return to normal. In this context, reforms in the social and political structure of Iran have taken on a different meaning. They have been put forward gradually and can be slowly accepted by the existing regime. Not only does this kind of reform not harm ordinary people, it also improves their social, economic and cultural conditions step by step, so that there would remain nothing of autocracy except in name. This is a situation where a majority of people can administer their own affairs, and democracy can be executed in the true sense of the word (Hajarian, 2014).

Thus, reforms are rooted from different areas of social stands. The field of Islamic jurisprudence provides a few examples in a sense that Islam has the capacity to accept change and revision. So it is possible to re-examine existing jurisprudential principles, and issue new rules and orders when situations change (Ahmed, 1992, p. 223). In the era of the Prophet Muhammad, the practice of women not working outside their households can be explained by the social and economic conditions of the time. However, it has been suggested that in that period men and women enjoyed equal rights. The extensive changes that have occurred in the lives of women in recent times confirm the need to examine and revise their status in society.

In this context, for example, Ayatollah Jafar Sanei said, "Moving in compliance with jurisprudential rules and proper social principles by accepting a live, dynamic ijtihad along with time is necessary to move forward because the present-day and developments require an ijtihad which accepts the impact of the elements of time and place in ijtihad. The impact of these two 
elements in ijtihad requires social recognition and acceptance of the social impact of religious decrees (fatwa). This is our answer to many new problems, considering it will open new horizons of jurisprudence to us. But neglecting it will lead to falling behind the cycle of moving in the society" (Ayatollah Jafar Sanei, Inheritance of wife from her husband, p. 12) However, "Reformist" is defined in the Dehkhoda Dictionary ${ }^{8}$ as: "A seeker of reformation of the affairs of a country; reformist; seeker of basic modifications in state affairs to improve the situations. Reformists are those politicians or parties that want reformations without revolution. Reformists are in contrast to those who believe reformations must take place by revolution." (Retrieved from (http://www.vajehyab.com/dehkhoda) on 21/5/2016). Reformists seek the gradual change of society in its economic, social, political, and cultural aspects.

In the Iranian context, reformist thought is not exclusive to former President Mohammad Khatami's government, but it is representative of a sector of society. Khatami is a symbol of reform and has been able to institutionalize his ideals into a more precise ideology with logical goals and outcomes (Hajarian, 2002, p. 14). In the narrow space where political organizations (such as political parties) have not been active, Khatami's election to the presidency in 1997 raised persistent hopes of the reformation of Iranian society (Akhavan Kazemi, 2009, p. 21). His agenda of the reform movement centered around the concepts of moderation, tolerance, accountability, and rule of law. His idea was a new political movement, one that is focused on gradual reform within the confines of the existing framework of the Islamic Republic. (Safayi Farahani, 2010, p. 167).

In reformism, the main principle is movement along constitutional law and tracking claims without breaching the law. Reformists believe that the law should be changed through applying existing legal principles. Reformism is a school of thought seeking gradual and infrastructural changes in political, economic, and cultural structures. Historically, reformism is construed as objective reactions towards revolutionary Socialist ideas that believed there was no way for reformation unless there was a revolution from the masses.

In Iran, reformism covers a broad spectrum and there is no unique goal for their movement. However, reformists do not seek revolution, but they seek to change government gradually

\footnotetext{
${ }^{8}$ The largest comprehensive dictionary of the Persian language.
} 
towards democracy and the recognition of human rights (Retrieved from (ketabnak.com/book/41055) on 3/4/2016)

In fact, Iranian reformists are similar to 1960s left wing rebels ${ }^{9}$ and were called such after 23 May 1997 (the 2nd of Khordad Movement ${ }^{10}$ ). They entered parliament following their victory in the 6th election in 2000 with the election of Mohammad Khatami as president. He won with more than 20 million votes (Kamrava, 2001, p. 168). The reformist movement obtained a majority chairs in the 6th Parliament and their first on the Tehran City Council. This trend, which was known as the "May 23rd Movement", meant that they could hold government in two four-year periods and Parliament in one four-year period.

The 9th election and the victory of Mahmoud Ahmadinejad in 2005 completely sidelined the reformist movement. Reformists failed in the 2 nd Tehran City Council election and were pushed aside in the 7th election in 2004 of the Islamic Consultation Council. This meant that they were completely sidelined in the political scene of Iran. Nevertheless, the victory of Hassan Rouhani in the 11th election in May 2013 created a new path for returning reformists to the political scene of Iran. Saeed Hajarian, a reformist theorist in Iran, believes: "Reformism has degrees. Someone believes there is no definition for reformations. By my definition, reformation is compatible with the concept of democratization. Reformists seek a democratization project; some wish to proceed fast, others prefer slower progress". Shahrvand Emruz Weekly, 3/2/2007, pp. 62-63). The general approach of a reformist government is political and cultural development. This approach is based on the belief that political development and cultural enhancement are necessary for achieving development. Thus, the government of Khatami came into the arena using the motto of political development and reformation of the existing political structure.

\footnotetext{
${ }^{9}$ The Islamic 'left wing rebels' are those who were disqualified from running for office as they were purged and generally "disempowered" by Islamic conservatives following the death of Ayatollah Ruhollah Khomeini in 1989, such as Mohammad Mosavi Khoeini, Mehdi Karubi, Mir Hosein Mosavi And Ali Akbar Mohtashami. ${ }^{10}$ The 2 nd of Khordad Movement usually refers to the coalition of 18 groups and political parties of the reforms front to bring the reformers back to the power which resulted in Mohammad Khatami's presidency. At that time, the Parliament was still dominated by conservatives, and posed considerable problems to Khatami and his Cabinet until the victory of the reformists in the February 2000 Majlis elections.
} 


\subsection{Political Parties in Iran}

Article 26 of the Iranian Constitution outlines and accepts the presence of political parties within the Iranian political system (Tabriznia, 1992, p. 197). However, Iranian political parties have never found their dominant position in Iranian politics as other political parties have in developed countries (Akhavan Kazemi, 2009, p. 32). In fact, classification in the political literature of Iranian society differs from that in the world political literature. Political party activities are not organized as it is expected from the definition of a political party. In the Iranian case, there are not clear political borders between different political factions in Iran. Political groups and parties in Iran are not willing to be associated the traditional notions of 'left' or 'right' that usually defines political affiliation on the political spectrum. However, there have always been different trends in such an exclusive space; trends that have been embedded as part of the internal discourses and stem from the developments of Iranian society (Zibakalam, 1999, p. 195). The most predominant of these political trends that political affiliation adheres to are the left and right discourses, where each one is divided into two further branches: 'traditional' and 'modern'.

Generally, those parties that affiliated themselves with the 'right' support Islamic jurisprudent authority, religious management, religious economy, and traditional culture. Those that have affiliation with the 'left' seek political reforms, economic development, privatization, cultural development, and scientific management (Tajzadeh, 1999, p. 14-15). It should be mentioned that the traditional and modern branches in these discourses have not arisen due to long-standing political principles, due to the representatives of these branches having moderate or radical views, and tried to create new branches. One example is how the political branches in the left wing converged during the presidential elections in 1997 and consequently, they won under the motto of "reformation". In fact, the developments on 23 May 1997 created a new categorization in defining political affiliation. The emerging groups would be defined as either "reformers" or "conservatives", instead of the previous 'left' and 'right' or traditional and modern dichotomies. However, many of Khatami's supporters have found his apparent weakness and disinclination for confrontation disappointing from a man on whom they had counted to bring real change and were asking "Why has he not adopted a long-term strategy for presidency?" His response may 
be illustrative as he declared: "We do not win to have a program, but to obtain millions of votes to trigger the media to send our message" (Mehrnameh, 3, November 2012, p. 21). In fact, Khatami didn't stand in the election to win, but believed that internal social developments will produce a wave from which reform would arise.

Subsequently, the election of Mohammad Khatami as president represented a new political period in Iranian politics called the "reformation period". Khatami was an idealistic and openminded politician who claimed for a 'Dialogue of Civilizations' in the international arena. He had proposed to improve relations with the United States, suspend uranium enrichment indefinitely, and reduce social restrictions even though these policies were opposed by hardliners. However, internally, despite his best attempts the space for perusing freedom was limited as Khatami encountered many problems during his two presidency periods. His attempts at governance and implementing reforms were severely criticized by traditional society and led to a type of internal struggle (Ghavam, 2005, p. 116).

The internal conflict between the advocates of reform and Mohammad Khatami and the destructive actions of extremists within the regime nearly pushed the reform movement away from the Iranian socio-political environment. The proponents of reform (which included university students and women who had voted for Khatami) criticized him for his inability (in spite of having 20 million supporters) to stand against other powerful institutions in the state including Supreme Leader Khamenei, the Guardian Council, the Expedience Discernment Council and the Basij. The internal crises caused by these extremists and the obstacles they created against Khatami's reformist moves made him aware of the fact that an uncalculated decision or resignation could create an even more serious crisis in the country which would block the future path of the reform movement.

The reformists' political wing deviated from its main objectives, since it had no codified and predefined plans to follow once it had acquired power. Even though during the four years of Khatami's government, most chairs in the parliament were occupied by reformers, there were still many obstacles to prevent society from implementing reforms. The supporters of Khatami had suffered enormously from continuing domestic crises such as the murder of academics and writers, and the July 1999 Student Riots. They turned their backs on him and the reform 
movement, turning to his major critics, questioning the very trend of the reform movement (Hajarian, 2012).

It is in this point of Iran's history that another individual, Mahmoud Ahmadinejad, came onto the political scene challenging the existing order. He introduced himself as the representative of the forgotten part of society, that is, underprivileged and claimed that it was time to replace the existing reformist government. Mahmoud Ahmadinejad 's ideology identified itself as being nearer to the conservative platform and essentially espoused their ideals, albeit a little more radically. Even though the election of Ahmadinejad heralded the onset of a new chapter in Iranian history, it still encountered broad opposition from the rest of society. However, the election was construed by some experts as a natural and spontaneous movement. Some scholars (Habibi, 2014) believe that Ahmadinejad took advantage of a wave of change. Ahmadinejad's platform stated that "the current situation must go" but did not say what should replace it. People accepted him because they understood his platform and intent, which was against the situation that prevailed in Iranian politics for the last 30 years (Kakejani, 2012, p. 98). Ahmadinejad's victory was the start of a painful chapter in Iranian political history called the "post-reform period".

The two main rivals, Mahmoud Ahmadinejad and Hashemi Rafsanjani, came face to face at the presidential election of Iran in 2005. As one of the founders of Islamic Revolution, Hashemi Rafsanjani had been at the center of power, so was not welcomed by the masses. Consequently, Ahmadinejad won with the motto of "change" (Jalayipur, 2013). After the election, a new wave of repression had been created which saw a return to the original principles of the Islamic Revolution. This sidelined reformists and saw the rise of the Conservatives within the establishment. With the support of conservatives, Ahmadinejad instituted strict measures to control free speech and suppress opposition with methods ranging from harassment to arrest and imprisonment. Ahmadinejad also criticized the manner in which Iranian officials had conducted international nuclear negotiations and ordered to remove seals placed on Iran's uranium enrichment equipment and reprocessed related activities (Warnaar, 2013, p 47).

During the first four-year period of the Ahmadinejad administration (2005-2009), the inflation rate surged and unemployment skyrocketed due to the implementation of highly inflationary 
public programs and subsidies. This was exacerbated by the series of sanctions on Iran by the UN Security Council. Ahmadinejad 's government had the highest oil income and the highest budget deficit since the Iranian Revolution. All these issues - the flagging economy as well as political crackdowns - came to a head during the June 2009 presidential elections. Iran's crippling inflation rate, high unemployment, and the question of how its oil revenue was being spent were at the top of Iranian voters' minds. Two candidates surfaced to challenge Ahmadinejad: Mirhossein Musavi and Mehdi Karubi. These two candidates tried to recall supporters of the reformist movement (Retrieved from (http://fararu.com/fa/news/22739/) on 19/6/2016). This attracted the youth vote more than others and created overwhelming excitement in the country.

Ahmadinejad continued his traditional-religious trend in policy and politics. Villagers and residents of small towns, who saw oil money on their table, turned toward him again during the 2009 election. However, in spite of him having the vote of people from small towns, after the announcement of the election results which stated a win for Ahmadinejad again, a large social movement comprising of millions of people sprang up and accused the administration of frauding the vote. The Green Movement under the leadership of Mirhossein Musavi and Mehdi Karubi, was subsequently suppressed. The Supreme Leader, Ayatollah Khamenei, also supported this suppression. Finally, the leaders of this movement were imprisoned. Nevertheless, internal conditions in Iran both politically and economically became increasingly worse as unpopular policies in economic terms and internationally, isolated Iran more and more (Retrieved from (http://www.khabaronline.ir/detail/367456/Politics/parties) on 7/5/2016).

Fear dominated society with internal pressures from the government on one hand, and the existential probability threat of war due to a continuing inability to negotiate with international actors regarding the development of Iran's nuclear program on the other. This led many citizens to conclude that Ahmadinejad had guided Iran to the brink of a precipice. Even the conservative faction of the Iranian establishment tried to exempt itself from Ahmadinejad's political platform and sought to introduce new moderate candidates for the next election.

At this period of time, Iranian civil society was seeking a savior to save the country from the current economic and political turmoil it was facing. Despite strict security, political limitations and lack of media opportunities, reformists tried to use their past experiences to garner support 
in the next election. But the larger problem with this was that the grass roots of Iranian society were not eager to participate in voting. However, when Rafsanjani entered on the side of the reformists, there was a wind of change. The subsequent rejection of him by the Guardian Council (2013) created a wave of factualism. Retrieved from (http://www.yjc.ir/fa/news/4371853/) on 13/6/2016).

There was so much worrying and fear in Iranian society after Rafsanjani's rejection that the nation decided to vote for Hassan Rouhani. Rouhani became a symbol of the authority of Rafsanjani and the liberalism of Khatami, and it seemed that he was a practical politician. He wanted to modify existing policies and it seemed that he could combine the thinking of Khatami with the will of Ahmadinejad. Many people believed that Rouhani was a modern conservative who could create a new 'May $23^{\text {rd' }}$. The main question was whether Iran had gone past the post-reform era and had entered a new phase or not. To respond to this question, it is necessary to provide a clear interpretation of the period. The Reform Period lasted from May 1997 to July 2005, and included two four-year periods of presidency of Mohammad Khatami. Post-reform period stretched from July 2005 to July 2013, including two four-year periods of presidency of Mahmoud Ahmadinejad; and the third period from July 2013 and continuing at the time of writing in 2017. Valid political, social, and cultural indices may be used to evaluate each period objectively.

\subsection{Socio-Political Environment in the Reformist Period}

One of the most basic forms of communication between women's groups in Iran was to hold women's circles (Biran, 2002, p. 27). These circles were held among women in their homes on memorable anniversaries such as the anniversary of the Constitutional Revolution and celebrating the anniversary of Qurrat Al-Ain (Tahereh) ${ }^{11}$. Activities, such as reading books and watching and interpreting movies, were organized so that women could gather and discuss their

\footnotetext{
${ }^{11}$ Qurrat al-Ain (ca. 1814-1852) was the daughter of a prominent mullah of Qazvin. She clashed with her father over religious issues. She became a strong opponent of the clergy and separated from her husband, to whom she was forced to yield custody of their children. By 1844 she was a major force within the Babi movement (which eventually became the Baha'i religion). She made a public appearance unveiled to claim rights on behalf of women. She paid for her courage with her life (she was executed) but she left a legacy that influenced thinking about women's position in society as well as religion and culture among Iranian women for years to come.
} 
common concerns and share their opinions with like-minded women. The circles were held in the presence of women who were already part of diverse pro-revolutionary political parties (nationalist, leftist, and nationalist-religious). These were women that had been widely excluded from participating in political and social life at the beginning of the victory of the revolution, who now, despite their great efforts, felt nothing but frustration and despair (Mirhoseini, 1999, p. 112).

Their approach was mainly political and revolutionary, and due to the bitter experience of violence and suppression at the beginning of the revolution, the fear of public participation was institutionalized in these women. As a result, their main activity was limited to holding women's circles in their homes. Speakers at the meetings have tried to distribute articles published by feminist women abroad and explain different approaches to women's issues. These circles largely helped raise the historic, political, social, and legal awareness of women. Gradually, in most women's circles, celebrating International Women's Day (8 March) became highly popular and accepted as one of the common points of these gatherings (Mirhoseini, 1999, p. 278).

After the Islamic Revolution, women lost many rights in almost all spheres of life. Thus, their social positions and legal status was dramatically declined by the Islamic government. Clearly, Islamist politics had produced an extremely disadvantaged position for women (Moghadam,2004, p. 2). There was no possibility of any other movement either related to women or in regard to social and political issues. It was only in their small circles at home that women could try their best to maintain their presence within society hoping that open political atmosphere would allow them to be active outside their home (Mahbaz, 2005, p. 67). Magazines, newspapers, and quarterly journals that attempted to address the concerns of women and the social, cultural, political, and economic problems for the progress of the generation of women were quickly banned and suppressed (Mahbaz, 2005, p. 164).

Therefore, having a popular base in society plays an important role in achieving the demands of a movement. As mentioned above, the domestic circles and gatherings were considered as a simple, yet powerful base for the women's movement. On the other hand, the revolutionary violence of the Islamic government during the clerical consolidation of power in 1979 and under later administrations resulted in the emigration of many politically active women of different 
political and ideological groups abroad. There was however, an uninterrupted relationship between Iranian women who stayed in the country and those who left, with an undeniable influence on one another (Moazami, 2011, p. 131). Of course, the influence of the latter group was much stronger on women inside the country, especially by the end of 2000. This was because they had become familiar with feminist issues in western countries, where the feminist movement had gained significant ground, and could receive and analyze these new ideas and transfer them into Iran. As mentioned earlier, articles that had been published abroad were distributed in the women's circles. The articles were usually written by Parvin Paydar, Nayereh Tohidi, Afsaneh Najmabadi, Shahla Haeri, Farzaneh Milani, Nahid Yeganeh, Ema Delkhanian, Shahrzad Mojab, Hoora Yavari, Shahran Tabari, Mahnaz Afkhami, Haleh Afshar, Janet Afari, among others (Biran, 2002, p. 202).

On the other hand, the Iranian Women's Research Conference that was held annually by Golnaz Amin in European countries and America, inspired egalitarian activities within Iran (Ahmadi Khorasani, 2012, p. 17).

Women's circles were gradually converted to regular meetings and found a good and effective role in social life and activities of women. Restrictions in the social structure and on women's access to power and wealth made them invest in education to accumulate cultural capital to change the existing family structure. The idea behind this was that this will lead to the formation of a collaborative family structure in the future. The women's movement was not seeking employment and professional identity through higher education but instead looking for social status. In effect, they wanted the participation of women in the realms of politics and economics to become more developed. Therefore, women considered education as an effective step in recognizing their rights in civil society. They enrolled at schools and universities to pursue their studies and, according to statistics, there was a very high percentage of educated women in a variety of academic disciplines, in so much as they outnumbered men (Ansari, 2002, p. 147).

In fact, women who had bitter experiences of the revolution came to the conclusion that they should engage in low-cost individual resistance in terms of physical and emotional well-being rather than costly collective engagement. However, this does not mean inaction. In fact, resistance changed from a collective to individual form because there was a great deal of 
frustration with the political process, and the repressive structure of the state (Rajabzadeh, 2002, p. 39).

The second decade of revolution (from 1989 to 1999) witnessed the emergence of women as writers and intellectuals who were employed by the press or engaged in book publication (Farshadmehr, 2003). There was a strong emphasis on feminist ideology (which was still considered 'western'). Those attached to the concept of feminism were associated with antigovernment ideas and what usually followed was suspension and the closure of possible employment opportunities. During this stage, the women's movement no longer looked towards empowering women to change the status quo but instead sought for status and dignity (Kouhi Esfehani, 2014, p. 39). First, the women's movement was seeking an unrestricted social arena; therefore, informing men and women in particular of their equal rights in the power structure was of high priority. Consultations and negotiations with government officials led to the establishment of the Women's Affairs Office and subsequently the Women's Affairs Department General at the ministerial level and at the provincial level (Kouhi Esfehani, 2014, p. 45).

In regard to the changing social conditions, the women's movement has constantly changed its strategy over time. The women's movement essentially concluded that women should be strong. Society would have to listen to them and acknowledge their customs, moral and social conditions (Sadeghi, 2004, p. 50). As long as they were perceived as being powerless, lobbying the government would not be beneficial because the government would not change its policy, despite all the consultations and negotiations. Meanwhile, the authorities must acknowledge the presence and participation of a large number of powerful and intellectual women in Iranian society. Therefore, women's activists have tried to convince the ruling elites that not only egalitarian and powerful female images have authentic and indigenous roots in Iranian ancient pre-Islamic history the quest for equal rights is not incompatible with progressive understandings of Islamic tradition (Retrieved from (http://sur.conectas.org/en/womens-rights-feministmovements-iran/) on 9/7/2016).

It is not through changing the structure of government that a government becomes more femaleoriented or respects the rights of women (Mahdi, 2004, p. 443). Women's movement activists include a wide range of people who consciously advance women's rights and move in the 
direction to change the conditions of women in society. As mentioned earlier, they do not aim at structural change within a revolutionary context, but are instead looking to reform the system. This is because the Iranian Revolution has shown them that merely changing the political structure of Iran would not be conducive to women's rights. Therefore, like the youth movement or the environmental movement, the women's movement is not political. Their relationship with the government is not necessarily on the basis of elimination or participation.

The main idea behind the women's movement is demanding women's rights regardless of the necessity of a change in the political structure (Ahmadi Khorasani, 2012, p. 89). So it is not dependent on the current political structure. It may only grow to have conflict with the political structure because of the advancement of its goals. In fact, activists of the Iranian women's movement have tried every possible way to spread their words and pursue their goals. For example, the protests of 22 June 2006 led to the formation of the One Million Signatures Campaign (Barlow, 2012, p. 43), where women activists used the street as a forum to protest. As stated by Mahboubeh Abbasgholizadeh, "Part of the women's movement attracted the attention of politicians, the media and public opinion by logging on to the streets, in order to discuss women's issues as social dialogue" (Retrieved from (https://en.qantara.de/content/interviewwith-iranian-womens-rights-activist-mahboubeh-abbasgholizadeh-no-woman-can-be) on 18/7/2016).

Another instance of the effectiveness of the actions of the Iranian women's movement is the gaining of child custody for Iranian women. This was highlighted after the death of Aryan Golshani (in 1997) who had been abused by her father. Her funeral turned into a street rally in support of women's right to child custody. Until this incident, addressing and writing on child abuse was taboo in Iranian society. However, the Iranian media began reporting such offences after this case, and it became a societal issue that needed to be addressed. A court session was held for the above-mentioned child represented by Shirin Ebadi ${ }^{12}$. As a consequence of this trial and its findings, a bill was ratified in 2003 which would modify the existing custody law.

\footnotetext{
12 Shirin Ebadi is an Iranian lawyer who was awarded the 2003 Nobel Peace Prize for her efforts to promote human rights, in particular, the rights of women, children, and political prisoners in Iran. She is the first Muslim woman to receive the Nobel Peace Prize, and only the fifth Muslim to receive a Nobel Prize in any field (https://nobelwomensinitiative.org/laureate/shirin-ebadi/)
} 
In spite of a few significant progressive activities, in late 2006, a number of NGOs were closed, including the Rahi Baraye Tavanmand Zistan Institute (A Path to a Capable Living), Koneshgarane Davtalab Institute (Volunteer Actors), and the Civil Society Organizations Training Center, and no charges were brought to justify the closure (Zanan Magazine, 1/5/2007, No. 128). These organizations were established with the aim of providing free services to women, including the training of local women through holding different classes. The classes were seeking to inform women and make them more determined in demanding their rights. For example, Internet cafes were established in small towns for women for learning how to use the Internet. The government's impression was that the funding spent on these institutions was, in fact, used to advance the women's movement and that there was a secret plan to undermine the government so they had to be stopped (Ahmadi Khorasani, 2012, p. 74). Even though the activities of the Iranian women's movement are almost costless and people join for their personal interest and very simple meetings are held in homes still the government has no tolerance even for small actions (Abbasgholizadeh, 2014, p. 837).

At This stage of repression, women's movement tried to create a suitable social platform for change in society. Therefore, the attempts to clarify concepts such as freedom, democracy, the relationship between religion and democracy, civil society, reforms, public participation and so on, which could potentially emancipate the socio-cultural and political spheres in the country should constitute the movement's priorities (Kouhi Esfehani, 2014, p. 49). These changes were brought around by the penetration of secular and liberal ideology into Iranian culture which could effectively lead to a more lenient political atmosphere. This could also be supported by the conservative ideology against revolutionary values. However, these measures triggered a tough resistance against the opposite cultural institutions such as that of clergymen. Consequently, the press belonging to the government, which preserved the Islamic and revolutionary values of the traditional conservatives, denounced the government for its negligent attitude towards the top managers of culture. These pressures made Khatami view the extremists as the main trigger of crisis in Iran (Mirebrahimi, 2009, p. 28).

Another approach of NGOs in cultural and political development was to acknowledge the role of non-governmental organizations. Mohammad Khatami stated about his presidency period: "I 
believe that the pillars and support of a civil society should be complemented by science and thought. Every new government brings a series of special political formalities which sometimes are baseless and are like artificial flowers without any roots in their pots. In fact, political formalities must have roots in a societal context to produce broader political parties, and formations from the people of that country. Thus, during my presidency, we have tried to expand non-governmental formations to give identity to different parts of the country such as women, youth, and experts for activating the main cells of civil society to guarantee the formation of new powerful parties" (Retrieved from (www.tebyan.net/newindex.aspx?pid=12469) on 23/6/2016). The Reformist government of Khatami significantly sought to expand NGOs. These organizations were formed through voluntary participation of citizens without interference of the government. They were divided into two groups: non-beneficiary and public-beneficial ones (Sanasariyan, 2004, p. 192). Their activities were devoted to scientific, cultural, social, philanthropic, environmental and civil subjects such as sport, the arts, women affairs, health and medical treatment, and rehabilitation. The main feature of these organizations was that they were not political parties and were not affiliated to any political identification.

There were more than 20,000 public and non-governmental organizations in Iran during 2004, which was about 15 times more than those that existed in 1979. One example of such NGOs was the formation of women's NGOs whose number increased from 67 organizations in 1997 to 248 organizations in 2000 . This is a nearly $400 \%$ growth in three years. These organizations reached 480 at the end of the second period of Khatami's presidency, resulting in a growth of $616 \%$ in comparison with 1997 (irngo.org).

\subsection{Women During the Reformist Period}

Although Khatami's report and performance during his eight years of presidency was not very successful, his presidency precipitated the onset of new events and demands in Iranian society, especially for women and young people. These included new discourses in Iran, including women's rights where different groups of women found more opportunities for activity. 
In each society, there are challenges are of high priority and the society tries to remove or adjust them. As a consequence, movements which are closely dependent on those challenges emerge. In Iran, the emerging movements used the opportunity to improve the situation of women and address their demands and seek for their benefits. If these benefits are defined well, they will be in line with the improvement of Iranian society and change the closed space of civil society into an open one (Ahmadi Khorasani, 2012, p. 21). Consequently, many improvements were made after 1997. Urbanization was expanded, and literacy increased, while women and youth participation levels also increased. This year also saw deficiencies in the executive and managerial levels addressed more professionally by the government. In this period, more attention was paid to civil society, because it was a remedy for the middle class of Iranian society who had been suffering over the previous decades. During this period, however, relations between the people and the government did not improve and showed great signs of weakness.

The Reformist Movement sought to create conditions in which people could organize themselves and, consequently, entities which were independent of the government could be formed. Reformists applied fundamental changes to society and incrementally increased the efficiency of the Iranian political system to settle conflicts about individual and cumulative benefits through political development. In other words, the government's goals were to create policies that would lead to the removal of poverty and dependence on the government, making structural developments, and essentially lifting the poor above the poverty line. Inappropriate development is the cause of these policies (Jalayipur, 2013, p. 451).

International and domestic media sources announced that women and young people had empowered Khatami to his election win in 1997 (Ebadi, 2008, p. 28). Khatami's election changed the psychological atmosphere of Iranian society concerning women. Women made unprecedented gains in a country where conservative clerics had used their rigid interpretation of Islam for the past twenty-two years to impose stringent dress codes, rules of behavior, career limitations and domestic control over women. For the first time after the Islamic Revolution, Khatami assigned a woman to the Deputy Presidential post and to that of the head of the Environment Ministry; Masumeh Ebtekar was in charge of this ministry during the Reformist period. In fact, this decision was controversial in the conservative atmosphere of the time. 
Consequently, one of the first initiatives of the new government was to establish The Center for Women's Participation. The articles of association of this center are listed in Sax (2012, p. 16):

- An effort to increase participation of women in different areas through scientific studies and submission of strategies to Government Boards, Parliament, the Women's Cultural-Social Council, and other legal authorities in order to settle rules and regulations, and in formulating major policies

- To provide consultation to the president in the areas of women's affairs including providing precise studies about their current situations and lives

- Study of scientific strategies and reinforcement of managerial and training roles for women with families as well as those women who have significant roles in higher levels of society

- To provide necessary strategies to increase the general knowledge of women

- To challenge the stereotype of Iranian women as subservient and passive creatures

- Effort to recognize women's problems in society, family, labor, and applying changes to related laws (Sax, 2012, p. 16).

In fact, this organization was the first higher authority after the Iranian revolution that actively sought to increase the participation of women and follow up their requests in the framework of the Islamic system. Some of the actions of this center from 1997 to 2005 were:

- To approve the Women's Socio-Cultural Participation Development Plan;

- to enhances women in governmental management positions;

- to startup and reinforce the Women Studies Center at the University of Tehran and the University of Shiraz;

- to establishes a database for researchers of women studies;

- to promotes university libraries to provide women's books and journals;

- to hold an International Women, Sport, and Civilizations Discourse congress;

- to hold a conference on The Role of Women Participation in Utilities Consumption Management;

- to hold a conference on Iranian Women;

- to hold a conference on Women's Political Participation in Islamic Countries;

- to support the conference of Generational Affairs in Iran;

- $\quad$ to support the International Conference of Identities, Differences, and Human Rights; 
- to hold a conference on Family Health (Family and Sexual Health);

- to establishes a workshop for studying schools of thoughts in Iran and the contemporary Islamic world;

- to hold a conference on The Celebration of Zanan Motefaker Jahani (Thoughtful Women around the world);

- to hold a conference on the Tribute to Female Quran Scholar

- to attend the celebration of Mother's Day;

- to attend the celebration of Fajr decade every year ${ }^{13}$;

- to hold specialized exhibitions;

- to hold a Women and Research festival;

- to hold The International Conference of Iranian Women;

- to develops international development plans;

- to improves leisure activities for girls;

- to develops rural sports;

- other research and plans for women. (Osanloo, 2009, p. 186)

After the 9th Presidential Election (2009), The Center for Women's Participation was changed to The Center for Women and Families (Barlow 2014). However, it was not only the change of name but the government decreased the budget for women's affairs, and put its appropriations and allocation under the auspices of the Center.

Another event in this period was attending to women's problems in major socio-political plans. While in previous five-year plans there was never a plan for women and the 3rd Five-Year Plan ${ }^{14}$ (2000-2005) had only one article about women, Article 158. The 4th Five-Year Plan (2005-2010), had more than forty-three articles about women.

In the first election of city councils in 1998, 7.3\% of candidates were women. In this polling, women could obtain one-third of the chairs in the city councils. In nearly all provinces (except

\footnotetext{
${ }^{13} \mathrm{Fajr}$ decade is a ten-day celebration of Khomeini's return to Iran in 1979. The annual celebration is held between 1 and 11 February. Its beginning coincides with the date of Khomeini's arrival and its ending with the Iranian Revolution.

${ }^{14}$ Every five years Iran has a new five-year economic, cultural, and social plan that must be approved by Iran's Parliament. The five-year plan is designed to guide government policy.
} 
Ilam, Sanandaj and Yasuj) women were became members of the city councils. At the end of this round of polling, 114 women were the first or second candidates to be elected in city councils in 109 cities. In 176 cities, at least one woman, in 48 cities two women, in 8 cities 3 women, and in one city 4 women were elected as members of these councils. In one of the villages of Kahnuj Province, all members were women (Retrieved from (http://theiranproject.com/blog/2013/12/15/all-irans-women-mayors/) on 10/6/2016).

On 7 December 1998, President Khatami announced that female admission to universities were over 51\% (Retrieved from (http://www.refworld.org/pdfid/4157d0904.pdf) on 24/6/2016). Avoiding discrimination for or against either gender in higher education during the reformist period opened the way for the acceptance of more women in universities. Women and girls acquired a significant number of places at universities based on their abilities and knowledge. The proportion of girls in universities went from $47.9 \%$ in 1997 to $53.4 \%$ in 2004 , which indicated a $9 \%$ increase (Rashti, 2015, p. 476). The political and social participation of women showed significant growth in these years. Khatami's vision for the political and social participation of women was outlined in one of his messages to the Women, Equality and Peace Conference held on 23 June 2008. He stated: “Today's society needs an active presence of women at civil, political, and executive levels. Denying participation to this large and efficient force had destructive effects in different decision-making areas. Since reformation ideas and approaches are based on such realities, reformists should try to empower Iranian women to empower society, and try to open new horizons for the presence and practical participation of women in the political, cultural, and managerial areas, relying on fundamental Islamic and national principles (Retrieved from (http://mohammad-khatami.persianblog.ir/post/40/) on 5/4/2016).

Political and social centers such as electoral office, civil entities, and political parties are known mechanisms for increasing the role of women. Therefore, when women have a presence in civil society and hold senior government jobs their social and political status would improve. In this regard, the number of women elected in the 3th Parliament in (1988) was 4 out of 270 members, and reached 13 out of 290 members in the 6th Parliament in the second year of the Reformist Government (2004), which shows a significant growth (Retrieved from (http://hamshahrionline.ir/details/169329) on 16/8/2016). In 1997, only 67 NGOs were for 
women, but in 2017 their number reached 480, a 616\% increase in growth (Retrieved from (http://www.bashgah.net/fa/content/show/13345) on 27/7/2016). The Communication Network of Non-Governmental Organizations for Women was started in 1995 with 76 members, and by 2017 it had more than 900 members. This network is the first public organization with a consultative place the United Nations Economic and Social Council (ECOSOC), and it is still has not got a permanent place in the Organization of Islamic Cooperation (OIC) (Retrieved from (http://www.bashgah.net/fa/content/show/13345) on 30/6/2016).

The addition of Iran to the UN Convention for the Removal of Discrimination against Women of 1997 (Retrieved from (http://www.unic-ir.org/hr/convenantion-women.htm) on 11/7/2016) was one of the other goals of the Women's Participation Center and was placed on its agenda in 1998. Some articles of the Convention oppose Islamic verdicts, but there was a belief that a basic right for women could be guaranteed within an Islamic framework of governance provided those in government were inclined to interpret the faith in the spirit of equality. Despite opposition by the establishment, the Women's Participation Center, Parliament, and the Reformist Government tried to join the Convention. As part of a series of progressive legislative measures, the reformist-dominated Sixth Parliament actually ratified CEDAW. However, the Guardian Council, which is charged with vetting and approving all legalization to ensure compatibility with Iran's Constitution and Islamic precepts, rejected the bill. The Council cited supposed religious objections, but never actually specified what those objections were (Shekarloo, 2005).

In addition to convincing the Government, Parliament, and the Expediency Council, the Women's Participation Center tried to convince the public to try to develop the legal and religious ground work for CEDAW ratification. Holding lectures and meetings for students, provincial conferences, publishing papers, and conducting interviews in radio and for news agencies in 2002 and 2003, were some of the activities that the Centre undertook to promote this decision (Retrieved from (http://zananmag.org/spip.php?article120) on 13/6/2016).

One of the important issues for women during these eight years was attempting to change criminal and civil laws. According to the 2002 research results of the Women's Participation Center, one of the complaints of women in Iranian society was the continued modification of these rules and regulations relating to women (Osanloo, 2009, pp. 138-145). 
Although the laws passed during the eight years of Khatami's presidency (1997-2005) in an endeavor to solve the problems of women were not effective enough, the efforts made by the Khatami administration in this direction were, in themselves, significant and praiseworthy. As such one of the serious problems facing Iranian women relates to those who marry foreigners. According to Articles 964 and 976 of Iran's Civil Law, an Iranian woman who marries a foreigner may not transfer her citizenship to her husband and children, though an Iranian man who marries a foreigner may transfer his citizenship to his wife and children (Retrieved from (http://www.mei.edu/content/new-challenges-iranian-women) on 9/7/2016). Although the reformist parliament sought to change this the Conservatives reaffirmed it. However, the modification of laws related to the age of marriage which raised from 15 years (in Lunar calendar) to 15 years (in Solar calendar) for boys, and from 9 years (in Lunar calendar) to 13 years (in Solar calendar) for girls, child custody for boys and girls, which previously was two years was raised to seven years were the most important legal victories achieved by Khatami's government.

Another law was the "removal of the prohibition to send single female university students abroad" (Article 3 Note 1 of send student abroad Act). In this law, the condition that a female student must be married before being allowed to go overseas was removed. During the last days of Khatami's government, Zahra Shojaei, the Head of the Women's Participation Center said to reporters: "The result of the Legal and Juridical Comprehensive System Plan was converted to an article about the modification of the related laws (including Article 67 of Civil Act), and is now taking its final steps".

Cultural and artistic participation of women during the Khatami Government experienced a notable resurgence. The growing rate of female publishers during 1997-2000 was more than 56\%, and the number of women writers increased by more than $300 \%$ (Tohidi, 2010, p. 29). Another positive example is that women's sport experienced significant growth during the Reformist Government. During the years 1997-2003, the number of training courses for women increased by $53.19 \%$, the number of female coaches by $147.21 \%$, and that of female referees by $120.30 \%$. (Retrieved from (http://khabaronline.ir/detail/314415/society/family) on 26/7/2016). 


\subsection{The Ahmadinejad Government}

Mottos like "return to the forgotten values of the Islamic Revolution", "struggle with persecution", and "expansion of equity" demonstrated a challenge to the ideology of the Reformist Movement. Although there are many published speeches by scholars about the victory of Ahmadinejad, it must be remembered that he was president for two consecutive periods (2005-2009 and 2009-2013), meaning that his presidency had a major effect on the value system of Iranian society. What is seen in the performance and approaches of the 9th and 10th Governments, indicates a severe conflict between their approaches, and those of the Khatami administration and the Reformist Movement in many economic, political, and cultural aspects. Insight into the views and the performance of the Ahmadinejad administration can be gained through examining the events of this period briefly.

\subsection{Socio-Political environment in the Post-Reform Period}

Ahmadinejad's government took office in 2005 with the expressed intention of reviving Islamic values and principles. The President increased his support for traditional and paramilitary organizations, such as the Seminary, the Basij, and mosques, while also increasing the budget of these entities. The organizations receiving increased budgets included:

- $\quad$ The institute for the publication of Imam Khomeini's work

- $\quad$ The Basij Organization

- $\quad$ The Mosque Affairs Center

- The Endowments and Charity Affairs Organization

- The Hajj and Pilgrimage Organization

- The Islamic Culture and Communications Organization

- $\quad$ The Global Meeting of Proximity to Islamic Religion

- $\quad$ The Ahlebait ${ }^{15}$ Global Meeting

\footnotetext{
${ }^{15}$ The term refers to the family of the prophet Muhammad.
} 
- $\quad$ The Propaganda Office of the Seminary

- The Coordination Council of Islamic Propaganda

- $\quad$ Islamic Republic News Agency (IRNA)

- $\quad$ Foundation for the Preservation of Holy Defense Values and Work (Ghasemi, 2016, p. 318) Undoubtedly, the freedom of the press and the media under each government is an index for freedom of speech and cultural activities. Ahmadinejad's government created a situation for the media where they could not survive. There were numerous obvious and hidden pressures that lead to many old printing companies closing down. The pressures had many forms: the removal of subsidies, exclusive governmental advertising, claims against press editors and writers, issuing frequent warnings, blocking advertising from certain companies, and so on. It was quite paradoxical that during the second quadrennial of the Ahmadinejad administration that the President announced that he had no problems with the media, but in fact there were many claims to that effect. After the end of Ahmadinejad's government and during Rouhani's government, these claims ceased.

Even though many publishing companies were seized in this period, Ahmadinejad tried to compare the seized newspapers with those of the Reformist Government. A few newspapers had been seized during Khatami's presidency through juridical orders, and that was because the Conservatives were dominant in the judiciary. In fact, during the 9th Government (2005-2009), The Press Supervisory Council also acted as a censoring authority and seized media offices. Therefore, the special court for the press ordered the closure of 120 newspapers and magazines, and sent many journalists to prison (Retrieved from (http://mardomsalari.com/template1/News.aspx?NID=181725) on 24/7/2016).

A journal seized on 28 January 2008 through an order of the Press Supervisory Council was Zanan Magazine. Zanan Magazine was part of the years-long movement for women's suffrage in Iran and it became a space for Iranian women to discuss and reflect on women's issues. However, the Fars and the ISNA news agencies ${ }^{16}$ announced that Zanan Magazine (managed by Shahla Sherkat) was to be seized following a decision by the Press Supervisory Council. The rationale for this action was that the magazine raised subjects that "threatened the mental security of society,

\footnotetext{
${ }^{16}$ Two of the most conservative websites and media outlets in Iran.
} 
endangering the spiritual health of society and painting a gloomy picture of life in Iran" (Retrieved from (http://www.al-monitor.com/pulse/originals/2015/05/iran-womens-magazine-zananemrooz-suspended.html) on 4/8/2016).

The examination of subsidies to the media sector in Iran during the Ahmadinejad administration demonstrates that Ahmadinejad's government only supported Ahmadinejad's own party, in spite of his equity motto, and cut legitimate financial support for other opposition press agencies. The seven newspapers that received one-third of subsidies in 2012, were Jame-Jam, Javan, Resalat, Iran, Ettela'at, Keyhan, and Vatan Emruz, while the journals subsidised included Ebtekar, Abrar Varzeshi, Tabnak, Tamash, Jomhurin Eslami, Khabar Jonub, Khabar Varzeshi, Khorasan, Donyaey Eghtesad, Shargh, Mardomsalari, Asre Mardom (Retrieved from (http://www.parsine.com/fa/news/193093) on 4/8/2016).

To limit the freedom of speech and increase censorship of the contents of the virtual space, the Ahmadinejad Government approved the Sites and Weblogs Organization Plan under which all Iranian sites and weblogs had to submit their information to the Ministry of Islamic Guidance. This plan limited freedom of press and weblogging more than previously had been done. Therefore, they had faced ongoing threats direct and indirect from government (Retrieved from (http://www.alef.ir/vdca.enek49nma5k14.html) on 16/8/2016). Limited Internet speed was another action of Ahmadinejad's government. Mohammad Soleymani, the Minister of Communications and IT in the Ahmadinejad Government stated at the end of October 2006 that Iran's government had decided to limit Internet speed. He said: "Home users do not need more than 128 kb/s" (Retrieved from (http://www.bbc.co.uk/persian/science/story/2006/10/061020) on $19 / 8 / 2016)$.

This action was challenged by many experts. They believed that the number stated was not enough for the development of the IT industry. In contrast, some believed that this limitation was intended to prevent the downloading of images from satellite channels. Other limitations included controlling and recording telephone conversations and SMS. The Ham-Mihan newspaper announced on 7 June 2005 that the government would record telephone conversations and SMS up to six months through an order issued by the Ministry of Communications and Chairman of the Judiciary. Mohammad Soleimani, Minister of 
Communications said: "We can record telephone conversations, but it needs judicial authorisation" (Retrieved from (http://ham-mihan.org/Released/86-03-17/348.htm) on 3/8/2016).

\subsection{Women under the Conservative Government}

Conservative discourses emphasize traditional Islamic concepts and values and try to distance themselves from western values and feminist ideologies. Instead, they aim to promote the ideal of the family unit. Socio-political participation of women is viewed as a reinforcement of a woman's status in the family. Thus, Ahmadinejad's government changed the name of the Women Participation Center to the Women and Families Center (Barlow, 2014). In this regard, Ahmadinejad's government tried to establish the roles and participation of women in society during his introduction and execution of the Fifth Five-Year Plan. Women and family affairs were reflected in the Fifth Five-Year Plan, however, Article 230 outlined their established roles.

The government will promote family and women in social arenas by cooperation of related organization including the Women and Families Center and by approving plans to reinforce family, review related rules and regulations, prevent social damages, organize their economic affairs, organize jobs for family-oriented women directors, social security, leisure time, research, expand cover culture, promote health, develop democratic organizations, promote the potential of women managers, develop international interactions, deepen religious beliefs, and modify the administrative structure for women. (Bqe, 2015, p. 61)

The government ordered executive force to execute the Comprehensive Cover Plan and prepare work environments according to Islamic social values (Part B of Article 209 of the Fifth Plan), and to promote working from home, as opposed to full-time occupation, to preserve the family and ethical values in society (Retrieved from (http://www.ilna.ir/83495/50-) on 10/8/2016). Unlike Article 158 in the Third Plan, Article 111 in the Fourth Plan, and Article 230 in the Fifth Plan (which 
prioritized women's role and the family ${ }^{17}$, in the Fifth Plan there is an apparent marginalization of women's affairs. This is compared to the previous discourse in the Fourth Plan which gave the highest priority to women's affairs (Retrieved from (http://khordadnews.ir/print.php?id+24414) on 26/8/2016). There were many policies initiated around women's issues during the governance of the conservative Ahmadinejad Government, which demonstrates its attitude towards women's affairs, including the ones presented below:

\section{Oppose the One Million Signatures Campaign}

The One Million Signatures Campaign was initiated in 2006 by a number of women and men advocating equal rights for women and men. Its first intended activity was holding a conciliatory meeting on 12 June 2006 on the west side of Hafte-Tir Square, Tehran. This meeting was suppressed by security forces before its commencement, and more than seventy people were arrested (Barlow, 2012, p. 78). For the first time, women police officers were used to persecute people who participated in this campaign. The members of this campaign held training workshops about the socio-legal affairs of women and collected signatures of women advocating changes to women-related rules, and the equality of women and men. They hoped to gathered at least one million signatures from inside and outside Iran. During this time, however, police arrested many actors who participated in this campaign (Ahmadi Khorasani, 2010). However, the movement's practical achievements were its successful pressuring of Parliament to amend the inheritance law in 2008, giving women the right to inherit their husband's property. Also in 2008, women were granted the right to equal blood money in accidents covered by insurance companies, and Parliament prevented passage of Articles 23 and 25 of the "Family Protection" bill proposed by the Ahmadinejad government in 2007, which would have enabled men to take additional wives without their first wife's consent and would have mandated that women pay a tax on their fiance's mehrieh (Sameh, 2010, p. 451).

\section{Sexual segregation plan}

Sexual segregation practiced by the Ministry of Health and the Ministry of Education included separation of educational books for girls and boys, and separation of playgrounds. These policies

\footnotetext{
${ }^{17}$ On the one hand the plan was more of an "essay" or "collection of wishes", lacking specific objectives and ways to reach them; on the other hand practically women became more restricted by enforcing such laws as compulsory reduction of working hours and disapproval of the participation of women in some academic courses.
} 
were enforced through the support of the clergy. There were rumors about increasing the quota of men for university admissions. By executing this plan, a quota $40 \%$ higher than the women were considered for men in medical programs to prevent female candidates from entering these fields. Numerous objections and meetings in this regard caused the Chairman of the Education Evaluation Organization to announce that they were considering a 30\% quota for men in the 2008 University rounds (Retrieved from

(http" //asrenou.net/php/view print version.php?objnr+5881) on 23/8/2016).

3. Reduction of Office Hours Act for Women with Special Circumstances This act was introduced to support families and it mandated that working hours in the home are considered as a part of women's working hours.

4. Family Protection Act (1975)

Some parts of this act have been criticized by political and social actors, as they have construed it as weakening the family unit and acting contrary to the Iranian Constitution. According to Articles 23 and 25 of the Family Protection act, men are not required to seek permission from their first wife to marry a second wife. They only need to prove that they can financially afford to support more than one wife. This act was praised by conservatives as taking another wife is a Muslim man's right and polygamy is permitted in Islam (Retrieved from (www.dadiran.ir/portals/0/khanevade.doc) on 17/8/2016).

\section{Allowing Women to Enter Stadiums}

One of the progressive actions by Ahmadinejad was permitting women to enter stadiums, which had been opposed by traditional clergymen and seminaries. This initiative was abandoned due to opposition from Supreme Leader Ali Khamenei. Regarding the presence of women in stadiums, Gholamhossein Elham, the spokesman of the government said: "The Supreme Leader Khamenei ordered to respect the views of Islamic clergymen". He added: "Following this order, Ahmadinejad has emphasized acting according to the Supreme Leader's decisions" (Retrieved from (http://www.hawzah.net/fa/Magazine/View/6432/6448/73720/) on 30/8/2016).

\section{First Female Minister}

For the first time in the history of the Islamic Republic of Iran, Ahmadinejad appointed a woman as a minister. Dr. Marziyeh Vahid was appointed Minister of Health, which raised severe reactions 
from traditional clergymen. However, this time the government was allowed to uphold this appointment due to the interference of the Supreme Leader Khamenei (Retrieved from (http://biographyha.com/8002/biography-marzieh-vahid-dastjerdi-photos.html) on 29/8/2016). Despite the election of women on government boards during the Khatami administration, the appointment of the first woman as a minister created a positive record for Ahmadinejad. However, it seemed that this action was done to gain public attention after the controversial 2009 election.

7. Banned of a 32-volume Book on Violence against Women

The writers of the national plan titled Study of Domestic Violence Against Women have stated that both copies of this 32-volume book were banned during the Ahmadinejad presidency. Shahindokht Molaverdi, Deputy Minister for Women's Affairs in Rouhani's government, announced that there was no copy left of this book. This project was initiated by the National Committee for the Removal of Violence against Women. Ashraf Borujerdi, one of the executors of this project and consultant of women's affairs during the Reformist Government says: "This book was eliminated during Ahmadinejad's government by Zohreh Tayebzadeh Noori, a current member of parliament. Also, the copies of this book in the Ministry of State were banned" (Retrieved from (https://www.khabaronline.ir/detail/387638/society/family) on 5/8/2016).

As Borujerdi said: "This research concluded to the diminution of two practical projects: 'Creation of Safe Homes', and 'Act of Women Support'. But the 'Creation of Safe Homes' was not executed because of opposition by the Social and Cultural Council of Women" (Retrieved from (https://www.khabaronline.ir/detail/387638/society/family) on 27/8/2016) . The outcome of this research was a 32-volume book, of which 28 volumes contained reports from the provinces of Iran. This collection studies violence in homes through women's views as victims, and one volume is about domestic violence from the point of view of men as the agents of violence (Retrieved from (www.bbc.co.uk/persian/iran/2014/11/141130-nm-research-women-violence) on $24 / 8 / 2016)$.

8. Limiting Higher Education Opportunities for Women

The Women Studies programs was started in 2001 at Masters level at Al-Zahra University, Allameh Tabatabayi University, and Tarbiat Modarres University for the first time since the 1979 
Islamic Revolution. However, this program was stopped as the government believed that it was in contradiction with the Islamic faith and changed it to family studies and women rights in Islam. (Retrieved from (http://www.ilna.ir/165/279015) on 29/8/2016).

9. Decrease of Growth Rate of Civil Organizations in Women Affairs

In 1997, only 67 NGOs worked in women affairs. This increased to 480 by 2004 (Shirazi, 2012, p. 48) and produced a more suitable space for actors in women's affairs than previously seen. But this space was eliminated during the 10th Government and many NGOs were dissolved. This trend for expansion of NGOs in women's affairs (which was seen during the time of the Reformist Government), continued in the following years although the numbers fluctuated. In 2013, there were 1665 NGOs in Iran demonstrating a low growth (3\% growth) of women organizations during $\begin{array}{llll}\text { Ahmadinejad's government from } & \text { (Retrieved }\end{array}$ (http://www.bbc.com/persian/iran/2010/06/100612_elec anniv_ngos.shtml) on 2/8/2016).

10. Opposing the UN Convention on the Elimination of All Forms of Discrimination Against Women Ahmadinejad opposed Iran joining the UN Convention on the Elimination of All Forms of Discrimination Against Women on the basis of the views of traditional clergymen. This act was proposed by Khatami in Parliament in 1998, but it was not implemented. Efforts in this direction were not continued in the last days of the Reformist Government and the starting days of the Conservative Government.

Zohreh Tayebzadeh, Chairman of the Women and Families Center in Ahmadinejad's government stated that: "I do not reject the idea that legal gaps exist in securing women rights, but this will not be accepted by Iran signing the UN Convention on the Elimination of All Forms of Discrimination Against Women. While I am alive and I am the manager of this center, I will not let Iran join such conventions. I believe on the road to reform, our starting point should be the Islamic Sharia. We can find suitable interpretations and explanation of the equal rights of women from the Quran and Islamic traditions and we will not follow western patterns" (Retrieved from (http://asre-nou.net/php/view-print-version.php?objnr+5881) on 5/8/2016). 


\subsection{Socio-Political Environment Under the Equity Government}

The $11^{\text {th }}$ Government (2013-2017) has recorded some important instances of success in their annual performance which are not tangible to the community, but their effects will be recognizable in the long term. Despite ideological differences, the relationships between the Parliament, the Government, and the Judiciary are friendly and respectful almost on a cooperative basis (http://www.momtaznews.com/).

Reforming Macro Culture Policies (Eslah Siasathaye Kalan Farhangi) has been proposed and the directors of the Ministry of Culture and Islamic Guidance welcome the liberal approaches in the area of culture. This approach maintains that a sub-culture field should not be managed through a top-down style (http://icana.ir/Fa/News/233475). Having these policies enacted, the government sought to eliminate or ease the restrictions on previously unprinted publications and books in order to facilitate their publication. This was contested by hardliners and even the Supreme Leader of Iran Ayatollah Khamenei and expressed concern on cultural issues at a meeting with the Assembly of Experts in September 2015 (Retrieved from (https://en.trend.az/iran/2252927.html) on 16/8/2016). However, Rouhani remarked that it has been 35 years since the revolution in Iran, and yet there remain concerns about social and cultural issues. so if pressure was effective for resolving the problem, "we would not be concerned about the cultural issues today" (Retrieved from (https://en.trend.az/iran/2252927.html) on 2/9/2016)

At the same time, the use of social networks significantly gained momentum since the election of President Hassan Rouhani in 2013, and many of his advocators and supporters proceeded to gather force through the use of social networks. Frequent use of Twitter by Rouhani and informing the public of numerous issues were opposed by hardliners. Following the appointment of President Rouhani, some of his ministers also communicated directly with the people through the use of virtual spaces. For example, Javad Zarif, the Minister of Foreign Affairs, informed the public of the nuclear negotiations on a weekly or sometimes daily basis, and took their views into consideration. These actions would help to promote the use of virtual spaces. 
Even some clergymen such as Ayatollah Nouri Hamadani, accused Rouhani of showing tolerance toward insulting religious sanctities and for not being strict enough regarding religious principles. However, Rouhani's government has relaxed the curbs on media coverage of topics that were previously deemed sensitive. The wholesale blocking of social media websites including YouTube, Twitter, and Facebook, and surveillance of the activities of Iranians who manage to reach such platforms, remained in effect until 2015. However, the lifting of the ban on social media drew criticism from hardliners in the regime. Ayatollah Mahdavi Kani and Ayatollahs Jafar Sobhani and Nouri Hamadani And Ayatolah Ali Janati protested against the questioning of the provisions of the Qur'an in these magazines, and expressed dissatisfaction with the performance of these publications and called on the government to follow up the matter (Retrieved from (http://www.sarshar.org/archives/weblinks/post 1266.html) on 24/8/2016).

Ayatollah Makarem Shirazi also stated, "This is a very important matter and it's not something that the government itself decides on, and I have heard that in some matters the president himself decides alone and should not be this way" (Retrieved from (http://www.khabaronline.ir/detail/244706/politics/government) on 15/8/2016). The behavior of the $11^{\text {th }}$ Government's cultural officials and the impact of these remarks on the direction of cultural-artistic currents was raised by Ayatollah Mesbah Yazdi in mid-March 2014. During the presidential term of President Ahmadinejad ${ }^{18}$, the Supreme Leader stated that one of the ministers did not take any steps in line with Islamic guidelines and some of his actions were in fact, anti-Islamic. Unfortunately, the current government has also expressed views similar to those of the former government stating that "the government is in favor of freedom of expression with responsibility". It is clearly announced by this government that their task is to promote the arts and had nothing to do with religion. However, Khamenei said at the semiannual

\footnotetext{
${ }^{18}$ During the time of Mahmoud Ahmadinejad's administration (2005-213), legal experts and regular citizens were shocked and dismayed when they saw that the president could indeed exert great power. Although his critics in the Majlis tried to challenge him, he remained defiant. In fact, his exertion of power - with the support of the radical conservative establishment - was such that he was able to go beyond the legal limits of the presidency, overreaching his constitutional power without facing serious consequences for his actions and serving out two full terms, despite complaints (https://www.brookings.edu/blog/markaz/2013/10/02/what-rouhani-can-and-must-dofor-irans-women/).
} 
meeting of the Assembly of Experts ${ }^{19}$ that "cultural officials should pay attention to what they are doing because in cultural matters one cannot be reckless" (Retrieved from (http://www.khabaronline.ir/detail/337388/multimedia/1483) on 1/9/2016).

However, the position of the government and the President is to introduce the next idea. In a meeting with state officials and the Supreme Leader, Rouhani announced that there was a gap among the parties and even among the three constitutional powers of the state which would need to be repaired and modified. The government tried to adopt a new approach to achieve this desired and acceptable end. He added, "the government's approach in internal affairs includes good confidence, peaceful behavior, collaboration and exchange between different ideas in a civil society. Our approach in the cultural field is also paving the way for more open space for all the people of culture and art without crossing the margins of Islamic culture and moral judgments" (president.ir, News ID. No. 87762, Wednesday June 24, 2015).

Hardliners condemned the government and introduced it as the follower of Khatami's reformist government. However, the 11th Government's approach was decentralization and avoiding the government playing a patriarchal role in the cultural arena. This atmosphere has given an opportunity again for the women's movement to pursue their goals more freely.

\subsection{Women under the Rouhani Government}

The first success of the Rouhani administration was the reopening of the social and cultural space, including the republication of the women's magazine under the new title of Zanan Emroz $(\text { Women Today })^{20}$. The magazine was allowed to be published after seven years of censorship in June (2014) but unfortunately almost one year after republication, it was banned due to the promotion of 'white marriage' (Ezdevaje Sefid) de-facto partnership, living together as a couple with no formal legal registration) (Retrieved from (http://feedkhoon.rozblog.com/post/27076) on $3 / 9 / 2016)$.

\footnotetext{
${ }^{19}$ A powerful governing body consisting of 88 qualified jurists (elected by people for 8 years) tasked with supervising, dismissing and electing the Supreme Leader.

20 , But with the same personnel and Ms. Shahla Sherkat as the editor-in-chief.
} 
In this context, however, much criticism was given to the government by the reformists who tried to obtain permission to publish the magazine again. Although they know that the creation of barriers by opponents of Rouhani's government (especially the hardliners) has always led to problems in the executive branch, they believe that the overall performance of the government was positive (Alaeipour, 2014). Strengthening private institutions and associations has been another cultural achievement of the $11^{\text {th }}$ Government. Women's NGOs also resumed work following other associations. The Center for Women's Participation in the President's Office, renamed to The Center of Women and Families during the presidency of Ahmadinejad, was again returned to its previous structure because these changes were not as simple as just renaming the organization. Ahmadinejad's government decreased the budget for women's affairs and put its appropriations and allocations under the auspices of the Center. (Retrieved from (http://nahad.govir.ir/portal/home/?news/40436/40439/41383/) on 10/9/2016). The policies of this center were not always in the favor of women and would sometimes harm them.

The previous government (under the slogan of 'preserving the family') tried to take women back to their homes. Women were to be kept away from management and decision-making positions. A woman was defined only in terms of family, and special attention was paid to the role of being a mother. In the framework of the new policies, the use of any kind of birth control was prohibited, so that women would return to their home and play their procreational role to the full. But the policies of the Rouhani government were very different from the previous Ahmadinejad administration. In this regard, the Women and Family Affairs Deputy Office was completely transformed (Retrieved from (http://mehrkhane.com/fa/news/9352/) on 4/9/2016). The 11th Government started its work with the presence of three women in the Cabinet. Out of the whole cabinet, positions that were not entrusted to women previously (such as a spokesperson for the Ministry of Foreign Affairs, governor and mayor) were finally given to women politicians. Shahindokht Molaverdi, appointed as Vice President of Women's Affairs and Family, was one of the women's rights activist in Iran who published profusely on dealing with violence against women. She won the support of some of the country's most respected women's rights campaigners. One of her main differences with the previous managers was an emphasis on increasing women's economic participation. She signed many agreements with various 
ministries, so that more women could be employed, and commenced her international activities with a trip to New York to participate in the UN Fifty-Eighth Commission on the Status of Women (UNCSW). However, she came under huge pressure from hardliners, who threatened her with prosecution. Molaverdi's critics were mostly former officials in charge of women's affairs during the presidency of Mahmoud Ahmadinejad, and used conservative media outlets to criticize her before she attended the meeting. The critics warned that Molaverdi's "views on women and family are not compatible with the Islamic view" (Retrieved from (https://www.almonitor.com/pulse/originals/2015/03/iran-rouhani-female-adviser-molaverdi.html)

on 3/9/2016).

Planning for the improvement of the status of women and eliminating gender discrimination in universities and educational institutions have also been considered. Elham Aminzadeh, Vice President for Legal Affairs, published the Bill of Rights which has been among the most important measures implemented by of the 11th Government. Although it was welcomed by civil society, there has been wide criticism of it, including of the section on women's rights. After eight years marked with serious setbacks for women and a constant struggle to prove that they are capable enough to have a place in society, these changes were regarded as good enough. Once again, society saw an increased presence of women, and the condition of women in the country have improved tremendously. Female governors in different cities were in the news that filled the women's movement with joy. In some of these cities it was very strange to imagine a female governor. Sistan, Baluchestan and Golestan provinces are more traditional and, quite unexpectedly, have been witnessing the participation of women who have been welcomed in important managerial sectors (Retrieved from (http://www.bartarinha.ir/fa/news/100244/) on 8/9/2016).

A second chance for the formal presence of women in society created an opportunity for the women's movement to start their activity again. Their activity that has not been stopped by hardliners, but had become highly limited. One encouraging measure that attracted much criticism was the party held at Sa'dabad Palace in Tehran (2014) hosted by President Rouhani's wife. The party was held for the first time after 30 years on the occasion of the birthday of Hazrat 
Fatimah Zahra ${ }^{21}$ and the celebration of Women's Day (Retrieved from (http://forum.hammihan.com/thread120327.html) on 12/9/2016).

The guests were the wives of foreign ambassadors and Iranian women activists. The news of the guests being hosted by the first lady in such a ceremony was very pleasant for women because during the last thirty years, leading state officials' wives, particularly the President's spouse, have never done such activities. This action caused the Parliament to warn the President (Retrieved from (http://tmubasij.ir/?p=1614) on 22/9/2016) but it has left its traces in Iranian society demonstrating that there are changes occurring.

\subsection{Conclusion}

A comparison of these three eras reveal that how a power transition between reformists and Islamic extremists in Iran has been able to affect the socio-political environment in the society. Of special interest is how this has made the women's movement adapt itself to the new situation and act accordingly. The most significant measure that the reformist government takes is creating a criticizing environment that challenges the unquestionability of Islamic traditions and orders. With an open political atmosphere in Khatami's government, women can make some advances in entering social arena however insignificant they can be. Although Khatami's government faces harsh reactions from the extremists, the social taboos get criticized through media paving the way for reconsideration of issues yielding trivial changes though. For instance, hijab that has always been considered as the most decent and holy clothing for Iranian women gets challenged; Iranian women's movement puts forward the concept of the right to choose one's clothing as a basic right for humans. Therefore, the women's movement tries to fulfil its responsibility regarding the equality of rights via raising the awareness of different stratum of the society. However, women experience a lot of twists and turns as extremists gain the power again, and the socio-political atmosphere in Iran almost closes down again. Ahmadinejad's government tries to keep women away from the social arenas via passing strict laws to allegedly protecting the

\footnotetext{
${ }^{21}$ Fatimah is the daughter of prophet Muhammad. Fatimah is a vital character in the religion of Islam and is considered a role model for all Muslim women.
} 
institution of family. Iranian women's movement faces further restrictions. However, an overview of Rouhani's government leads to the conclusion that women have spared no effort in adopting various strategies to prevent stagnation so that the women's movement can prosper through a variety of channels. Whenever they perceived the social atmosphere as permissive, they have used it in the best possible way. When it has not been as permissive they have resorted to the most efficient replacement or alternative. The virtual space and the Internet has been one of the most remarkable achievements to utilize in the restrained circumstances of Iranian society. This has not been shown with sufficient force and clarity.

Taken together, the events that have occurred in the social arena, particularly the new opportunities provided to women, allow the conclusion that the Rouhani Government has not been, so far, the follower of previous governments, particularly the Ahmadinejad administration. Rouhani has limited room to maneuver. Powerful hardliners control key Iranian political structures, among them the Guardian Council, which has the final say on the interpretation of Islamic values and laws, and has the power of veto. A conservative majority in the parliament also prevents strong reforms from passing. The hardliners will continue to sabotage the reform, and intend to show that reforms by the government are against the religious values of Iran. The hardliners have formally and publicly announced that the feminist movement in the country has grown stronger over the last two years. However, the women's movement has continued its quest to obtain its objectives and create equal opportunities. Iranian women have learned how to challenge and have succeeded in removing some of the obstacles in their way. Debate over reform continues in Iran and the conservative elements within the state will try to use every opportunity for repression. However, the reform dialogue has tried to open a way into the different layers of society this time with a more moderate approach, away from stress and tension, towards taking advantage of these experiences given its previous unsuccessful experience to take a step towards domestic reforms. 


\section{Chapter Four: The State of Female Activities in Iran}

The focus of the previous chapter was on the status of Iranian women in the past and present, in particular during the presidency of the Rouhani Administration. This chapter examines the hypothesis of this research in order to confirm that Internet use has had a key role for the members of the women's movement to achieve its goals. This chapter will utilize Charles Tilly's theory (Tilly, 1984) on the social movements of women via the Internet and cyberspace, and will also examine the personal experiences of the Iranian women in this domain.

\subsection{Introduction}

As the history of social movements shows, people have tried to find a way to achieve the goals of their desirable movement by using suitable tools. Recent years and new experiences indicate that cyberspace has been able to play an instrumental role in this area. In the previous chapters, this thesis has shown that cyberspace has provided a new opportunity for everyone and more recently, Iranian women have decided to take advantage of these tools to achieve their goals. Although activity in cyberspace such as blogging, participation in social networks and other facilities that the Internet has made available to the users is a new phenomenon, it has had considerable effect on social and political relations in every society.

In fact, the use of cyberspace has been a response to increasing political and social restrictions. In this regard, according to studies conducted in the past as well as to the findings of this study, Iranian women have in many instances utilized the virtual space and the Internet. The members of the women's movement have found that the Internet has made it possible for them to make use of it without any time or place limits. After interviews with 50 women who actively use the Internet, it is possible to say that by using virtual spaces, women have effectively been able to communicate with others to raise awareness about the parts of their lives that others know little to nothing about. Using the opportunities provided by the Internet, women have attempted to create social mobility and have taken the required measures to change the traditional beliefs and ideas of Iranian society. Those who, by laws and customs, are prevented from being present in Iranian society and from showing themselves will be able to have a more effective presence in 
society, expressing their views and exchanging information upon using the Internet and taking part in this space.

Based on the theory of resource mobilization proposed by Charles Tilly (Tilly, 1984; McAdam et al. 2001), the role and effect of the virtual space on the mobilization model processes have been studied. This theory shows a successful interaction between cyberspace and the social movements of women. The online Internet model contributes to strengthening certain elements of Tilly's resources mobilization theory, particularly when the Internet shows sympathy and companionship to women's interests in the real world.

This chapter will be devoted to data analysis. It will present and examine the data collected in interviews and questionnaires completed by 50 activist women who use the Internet in Iran. It should be noted that, for security reasons, the names and identities of the participants are not disclosed in this thesis. Upon collection, this information has been made classified. The information provided by the research participants (the interview subjects) has been used to confirm the hypothesis of this thesis.

Firstly, this chapter will explain in detail Charles Tilly's theory (Tilly, 2004) that our research is based on and then will study the collected information from the viewpoint of this theory to prove that the considered hypothesis can be proven correct.

\subsection{Charles Tilly's Theory of Resources}

Charles Tilly may be best known for his theory of "Resource Mobilization" (Tilly, 1977, pp. 3-7). As mentioned in the introduction to his From Mobilization to Revolution, his work was intended to formulate a theory for explaining and describing "collective action" (Tilly, 1977, pp. 2-4). In his opinion, phenomena such as revolutions, riots, social movements, political intrigues and even coups are considered as various types of collective actions that occur to induce or precipitate changes in society. For this purpose, it is necessary to theorize about social actions to achieve the recognition of these phenomena. Tilly's systematic theory about collective action deals with the need to study social movements. Tilly also extensively reviews the classic and recent theories of his predecessors and provides a detailed critical analysis thereof. (Tilly, 2004, p. 104). 
Before addressing Tilly's main theory around collective action, it is necessary to explain his basic model for the analysis of political society. Tilly's basic model is called the "political model" and is static in nature. He also introduces the concept of the "mobilization model" which may explain collective action and changes in political society. Elements composing the political model include population, government, one or more contenders, a political society, and one or more coalitions. Political power contenders may be divided into two groups: members of the government, and government challengers. In fact, the core competitiveness and a source of dynamism in the political model are caused by competition between these contenders (members and challengers) in order to obtain a greater share of state power. From Tilly's point of view, government is an organization which makes use of basic and focused tools in order to control society. Relations and challenges between the government, members and challengers form political society. Sometimes coalitions are formed between the members and challengers whose purpose is collective synchronization with common goals (Tilly, 2004; Ayres, 2005).

\subsection{The Mobilization Model}

The dynamics of competition among the political contenders requires using a model for explaining the changes in political society, particularly explaining the collective action of each contender. Tilly uses the mobilization model to explain this collective action. This model is divided into two sections. The components of the first section include interests, organization, and mobilization, while the second section is made up of components including, 1) Repression and Facilitation; 2) Power; 3) Opportunity and Threat; and 4) Collective Action (Tilly, 1977, pp. 3-7).

\subsubsection{The First Section of the Mobilization Model}

This section may not explain revolutionary acts, but it shows the existing internal capacity to take proper action. Because, Understanding of activists is the very first step to define movement. 


\subsubsection{Interests}

The first element of the mobilization model is interests (Tilly, 1977). Interests are the common advantages and disadvantages arising from the different interactions between the considered population and other populations.

Analyzing the interests of women in becoming activists in society directed the research to the question of how to define such an interest. By the analysis of their actions, it is possible to discern a common interest among women. This means discovering the steps women take to become active and to handle their own personal needs themselves. In this regard, due to the limitations and difficulties they face, women living in Iranian society share common interests. The interests of the target group of this thesis include the ability to participate in the public realm and not to be confined to the private sphere, combatting social and legal discrimination against women, as well as the ability to hold public assemblies to promote collective interests.

In accordance with the above, Iranian women share common advantages and disadvantages. Among the common disadvantages are the problems associated with entering the social space which has always been an issue for this part of the society. While the women participating in this study are mostly well educated, the patriarchal system of Iranian society prevents them from participating in different social and political activities. A large percentage of the interviewees jointly agree in regards to this matter. About $87 \%$ assert that there have always been great obstacles in their way to enter the social and political arena, and this is well evident in their interviews. For example:

"Even though I was able to obtain my Master's degree in accounting, I was prevented from entering the labor market. In my dad's opinion, I should not waste my life. He had permitted me to continue my study in order to find a husband and marry. Now I have to think about housekeeping and satisfying the needs of my husband; the society does not need my abilities." $22^{22}$

\footnotetext{
22 Interview No 12, Group (Bbi).
} 
The bitter experience of this Iranian woman, outlined above, is an illustration of the point that after years of trying to define the true meaning of rights for women (except for their role as a mother and a wife), many Iranian women are dissatisfied with their restricted conditions. Many an Iranian woman spends her days worrying about questions regarding what needs to be done to keep the rest of the family happy and the family budget. It is important to note that an average Iranian woman has never been able to put herself first in any sort of matter. Due attention needs to be paid to the negativity of the above statement, since a woman who has never lived for herself will not be able to seek rights for herself. One interviewee stated:

"It was hard to convince my husband to allow me to go to the college. He agreed on the condition that it would not have an adverse effect on me doing the household chores. I had to have a little rest time, so that I could do everything as before, because he did not help me in any housework. When he arrived home, he expected me to be present, and I had to prepare the food and all entertainment for him as quickly as possible, and he didn't help me. Even when eating, he didn't move a plate, he only changed his seat from the sofa to the dining chair; and after eating, he came back to his seat on the sofa and watched TV. It seems that a servant should serve him all the time. All these things were tolerable, except that my next decision was followed by a strange occurrence. Upon receiving my Bachelor's degree, I decided to pursue my study to achieve a higher degree. I was enrolled in the relating exam. On the morning of the exam day, as I was looking for my exam card, I could not find it. I rummaged everywhere. I asked him to help me finding my card, but he calmly said that he knew nothing about it. There was no use. I enrolled for the next year, but the same thing happened again on the exam day. I could not believe that the card could have disappeared. I realized that he did not want me to obtain a higher degree, because he himself had obtained a Bachelor's degree, and he discarded my exam card to prevent me to pursue my study, and I had to give up."23

\footnotetext{
${ }^{23}$ Interview No 8, Group (Abii).
} 
These statements show the difficulties women face in a society where they are not considered as independent enough to pay their own tuition. A woman is not considered as an independent human being or even as a wife or a partner deserving of equal rights, but is perceived as a labourer. No one respects her interests and she is not defined through an independent social identity.

It is clear that patriarchy is deeply rooted in Iranian society and dealing with it is an exhausting task. Of course, some women consider confronting patriarchy as the first step towards reforming Iranian society and using it to create possibilities to move forward. However, some of them feel this issue is very deeply rooted in Iranian society and freedom is completely out of their reach.

"I was about 7 years old. My grandma recounted the story of her life and left me alone with a world of questions and ambiguities. I understood that she, as a woman, had suffered great pains, and how, as a woman, she had been deprived of her normal life in Iranian society. Since then, there has been a spark in my mind that I shall take my rights as a woman." 24

The standing and character of women in public opinion shows the importance and dignity of the women in a society. For example, the image of a woman that the culture presents represents the attitude of the people of that society. These images may be evaluated through the lens of traditions and customs, as well as the common values of the people. Public culture and beliefs of the Iranian people indicate that a woman is created only for homemaking; and showing bravery and courage by women in public culture is strange. Such a woman is called "weak", and if someone calls her "a brave woman", it is strange. It is clear that women living in this public belief system and culture may not find their real position and they are always considered as the second sex.

"I knew that if I lived with my family, I had to tolerate many restrictions. I was not allowed to go to a coffee shop with my girlfriends or spend some hours after school to talk with them, while my brother did not have these restrictions. When he wanted to get out of the house, he

\footnotetext{
${ }^{24}$ Interview No 21, Group (Baii).
} 
just had to inform the family, without explaining with whom or where he was going. So, I decided to marry. I thought that it was the only way to get out of my paternal home. If my husband leaves me free, I will live with him; otherwise, I will divorce him and never turn back to my dad's home. It seemed that it was the only solution." 25

Of course, these struggles have taken different forms and ways for different people.

"When I was a little girl, I used a bike. But as soon as I entered junior high school and was a little older, my family strongly opposed me biking. But I didn't heed these words. Every day when I came back home after cycling, I saw my dad frowning. He scolded me, but I didn't heed. I forced them to leave me free by hunger strike and locking myself in my room. When I decided to go to university, I chose a city far from our home. When the results were reported, my family began opposing me. Even my relatives were involved and forced my family to oppose me. But I stubbornly resisted and threatened to commit suicide. Finally, my dad agreed. However, he sometimes came to that city, and always controlled me from a distance." 26

Such restrictions were applied by the family and some other sections of the society to oppress women.

"Going to school was agonizing for me. The schoolmaster treated us like criminals. Our nails and hair were controlled every day. They came to our classrooms randomly and ordered us to put our hands on the desk, not to move, so that they could check our bags. I cannot say what happened when they found something other than our textbooks. This sometimes led to the expulsion of the students concerned and was put on their school records. This made students face many problems, problems with which they sometimes struggled for many years." 27

\footnotetext{
${ }^{25}$ Interview No 6, Group (Abii).

${ }^{26}$ Interview No 24, Group (Aai).

27 Interview No 13, Group (Bai).
} 
The interviewees imply that they have been facing these problems from primary school all the way to university. Although these issues may cause some women to avoid receiving an education due to the immense pressure they experience on a daily basis and being treated as if they had no human dignity; other women use these opportunities to rise above and better themselves in order to be able to make a change to these situations.

"The university's dormitory imposed restrictions and only women had to follow those certain rules. For example, we had to be present in the dormitory before 8 o'clock; otherwise, they called our family and there were problems. They inspected our personal bags in order not to have toiletries or certain books. The bigger problem was that the dormitory was located in a remote area, far from the university. If the buses arrived a little later, we arrived at the dormitory late. However, men were exempted from these restrictions. They arrived at the dormitory at any time they liked. Their friends were allowed to accompany them at the dormitory. One day, when I felt really tired and frustrated of those conditions, I decided to talk about it to the other girls. We gathered on campus to protest against those conditions. When the dean of the campus was informed, he didn't solve our problem but put me through more educational hardship at all stages of my education instead. I was not allowed to pursue my study at higher levels and I could not receive my diploma from the university." 28

As mentioned before, as well as facing issues and restrictions at home, women also have to face these obstacles at university as well. It is almost as if the society purposely does not want to see them succeed. Instead of focusing on what really matters, they get distracted easily since they have to deal with marginal issues like something as basic as living in a suitable place and not having to worry about having a social life in order to survive. However, the restrictions were not limited to the cases mentioned above. Legal restrictions are considered the most important obstacles standing in women's way since they are almost impossible to overcome, unless under conditions where these rules are adjusted or changed in some way.

\footnotetext{
${ }^{28}$ Interview No 22, Group (Bbii).
} 
"Even though I am a lawyer, I have not yet divorced my husband after six years. Since I got married at an early age, I didn't have an understanding of the limitations of marriage. But after much reading and performing activities in various fields over time I concluded that my husband was a great obstacle for my activities. Although he seemed to be a broad-minded man, he hated our [women's] gatherings and tried to prevent me from going to these gatherings. For him, our conversation topics were disturbing the order of life and mobilized us against the men. I endured this situation for a long time and did my work secretly. But every time he realized it, he started fights and arguments. Now it has been six years that I have decided that I want to divorce him, but unless he legally agrees, I cannot get a divorce. Custody of my son is the most important thing in my life by which he continually puts me under pressure." 29

It is clear that many of the obstacles women face are due to traditions getting in the way of any sort of adjudication. Iranian women have to prove themselves to be taken seriously and change the thoughts of society towards them. Traditionally, women are expected to run their families, and this duty puts them between the workplace and the family which eventually leads to emotional and psychological consequences. On the other hand, men consider the presence of women as a threat to their power and status.

"It is true that I didn't feel discrimination in my family, but when I got a career in the filmmaking field where a major part of it consisted of research, I faced many troubles. As I have worked in the field of women and children, I met many women who had grown up in families where they had faced discrimination against them for not being a man. While men are strong-willed creatures who are able to make decisions, women must be passive and dependent on them. This approach has inevitably created passive and weak-willed women who believe that they are the weaker sex. Perhaps many parents are not willing to raise their daughters this way, but I understood this approach was mostly developed unconsciously in these families, which later affected these girls when entering society and led to gender issues in our society. Inequality is highly obvious, both in the workplaces and in schools, which is very annoying and unbearable.

\footnotetext{
${ }^{29}$ Interview No 28, Group (Aaii).
} 
In general, I personally have not had any problems with my family. If they applied some restrictions on me, because I was a girl, they had justified reasons. They did not impose on me certain restrictions, because I was a girl, and I should be dependent on a man. They did not force me to be the weaker sex compared to men. One of the reasons for my success and my presence in Iranian society is my powerful mum, and the other very influential symbol is my aunt who was the first woman to graduate in industrial engineering in Iran. They are icons in my life, as my mum always insisted that we are human beings first and foremost, before being defined by our genders." 30

It should be noted that according to the census report of 1976 to 2011 (Zahedifar, 2012, pp. 473481), the number of higher education graduates during this 35-year period has increased by 16.6 times (11 times for men and 40 times for women). The proportion of women in the graduate population has also increased from $19.6 \%$ to $46.5 \%$ (about half of the graduates). In 2011 , the number of 20 to 34-year-old male graduates from higher education was around 1.58 million and the number of 20 to 34-year-old female graduates from higher education was 1.94 million (Statistical Center of Iran, 2011). Therefore, there is a population of educated young people entering the labor market and most of them are women. Statistics also show that the proportion of the educated employed women during $1976-2011$ has increased from $23.7 \%$ to $30.1 \%$. More importantly, the proportion of the higher educated women in employment increased from $22.8 \%$ to $30.9 \%$ during $1986-2006$, but decreased again to 30.1\% during 2006-2011 (Rezazadeh, 2011, p. 264).

Most educated women are employed in the public sector during 1976-2011, especially in the educational and health sectors. Government policies for the privatization and reduction of centralized control of the health and education sectors in society, as well as population decreases, have reduced job opportunities for women. An important factor is the increasing unemployment rate, where the unemployment rate for women is more than twice that of men). It seems that men's employment is prioritized over women's. One example is the centralized

\footnotetext{
${ }^{30}$ Interview No 14, Group (Bbi).
} 
government employment test held in June 2011 (Rezai-Rashti, 2015, pp. 479-481). 2284 out of 2800 employment places in 13 public organizations belonged to men while, 500 places in 16 public organizations belonged to women. Similar phenomena could be observed during past and recent years in the private sector where women have been severely underrepresented. Publicly available data show that government and private sector employers routinely prefer to hire men over women. According to the rules and culture of Iran, men are considered by default as the breadwinners of their families. Therefore, when boys are ready to enter the labor market, the legal, cultural, social and economic conditions in Iranian society are there to support them. Access to more economic resources, priority in employment, enjoying superiority in the labour market, freedoms and more social security are just examples of how men's dominant position in the economy has been facilitated. The opposite occurs for women in Iranian society and acts as an obstacle for them to gain employment.

Most unemployed women are those who have had no work experience and, therefore, due to their lack of work experience and not being socially accountable, they lose the opportunity of being employed. Restrictions on the diversity of the employment of women stems from cultural issues and is one of the most important obstacles in the way of employment growth. Saturation of the education and health sectors, growth statistics exaggerated by the government, and aggravated sexual views on employment such as women in Iran not being allowed to seek employment and work outside her home without first obtaining permission from her husband, are considered the main obstacles of the women's employment.

Such restrictions create a common sense of unity among the women. They feel that they are not able to confront these problems unless they unite and join forces. Consequently, they gain a good sense of satisfaction from holding meetings with other women.

"Every time I feel tired, I invite my friends to have a get-together. We speak of different things. Sometimes we confabulate. Sometimes we watch a movie together and use the topic of that movie for a friendly conversation. The common problems we face have brought us closer to 
one another and have strengthened our solidarity. I feel that I am ready for these women's gatherings, while I am not always ready for other gatherings." 31

In this study, all responses from the group who have been holding women's gatherings are positive and it is a fixed part of their social lives. According to data collected through these interviews, $100 \%$ of the women who participated in women's gatherings, consider participation as a fixed and necessary part of their active social engagement.

"I always take part in these gatherings. If I have not heard from my friends for a while, I will call and invite them. It does not matter what we serve each other. There is tea and water in all homes. Each friend brings what they have. There is no restriction for these gatherings. Sometimes, when we don't find a place for our gathering, we will go to a cozy and private coffee shop where no one can disturb our talks." 32

"I take part in the virtual space and the real world. I am a regular member of the women's associations. In my work area, I am also a regular member of the Association of Women Lawyers, and I am working for women. I work free of charge as their lawyer. We inform each other of these gatherings in the virtual space." 33

"I take part in a women's gathering once a month. All members of this group (except for me and one other) are housewives. We talk about daily issues and societal problems, including all things we are involved with in our daily lives. It is very interesting that people from all walks of life are present at these gatherings. Even uneducated people are present at these gatherings. However, interesting ideas are expressed from which I get many ideas. I enjoy these gatherings. I enter another world and hear about topics in a different way and understand problems differently." 34

\footnotetext{
31 Interview No 9, Group (Abi).

32 Interview No 30, Group (Bai).

33 Interview No 26, Group (Aai).

${ }^{34}$ Interview No 36, Group (Bbii).
} 
"We have gatherings held each time in a different city in Iran. They are usually held every two months. The purpose of these unofficial gatherings is to be aware of the situation of other activists and help each other in order to achieve our goals." 35

When the interview subjects are asked about the reasons of holding these gatherings, the first reply is that they need each other. More than $75 \%$ stated that they take part in these gatherings to be aware of each other, while $67 \%$ stated that they are interested in the topics and subjects discussed in these gatherings which affect their decision making for new activities. It is important to note that in recent years, and with the development of technology, these gatherings have not changed considerably. Only the manner of invitation has been changed. They are not forced to call each other, but they send messages in a group formed in virtual space to inform each other.

"We often arrange a meeting in a coffee shop to see each other and talk more closely. The atmosphere is completely feminine. We inform each other in the virtual space. Furthermore, I am a member of an NGO called Women Citizenship. I am a founder of this group, and have sent the related documents to the Ministry of the Interior for registration, but we have not received any response yet. This association was established after the arrival of the Rouhani Government. Only Iranian women over 18 years of age can become a member of this association. Of course, we accept any honorary men members, but the principal members are women. A great deal of my connections and communications are developed in this space which I'm fully satisfied with. Various tasks in the field of women are performed in this association. No matter what activity is performed, it is important that the activity is performed for the women. We created an Internet group whose members are women. Some rules have been codified for this group: firstly, no one has the right to share sex-related and anti-woman issues in this group; secondly, no one has the right to share porn films and topics. But we talk about these topics with each other and inform each other of our undertakings." 36

\footnotetext{
35 Interview No 41, Group (Baii).

36 interview No 46 Group, (Abii).
} 
The most important thing about the women's movement in Iran is that despite extensive planned organizational measures that are usually formed in women's gatherings, Tilly's mobilization theory does not exactly define the revolutionary organization. Women's gatherings may not be considered as an organization or group that leads the movement; however, undoubtedly, home network plays a revolutionary organizing role for the individuals involved with them instead of an organization. These networks have undertaken organization and facilitated the collection of the mobilizing resources. Women's gatherings constitute a unique network in Iran that is responsible for collecting women activists or the mobilization of resources. They bring together women without distinguishing between them for having different opinions and ideas, or even conflicting views. The other function of these gatherings is the collection and receiving of recent news and information through the interactions and relationships with other members. Mobilization actions and collective actions (such as organizing demonstrations, protests and campaigns) are considered as other functions of the gatherings.

In general, we can say that, apart from members having different opinion about how to overcome political and social obstacle placed in their way, all face limitations and problems which affect their situation and therefore provide them with common causes. Thus, they are considered to be a part of the same group.

\subsubsection{Organization}

The second element of this model is "organization". "Organization" is the common identity and unifying structure of individuals in a population. The more robust these elements are, the stronger the "organization" will be. To explain these two elements, Tilly refers to two components: "group relationships" and "network relationships" (Tilly, 2004). "Group relationships" are those relations identified by individuals with respect to their common features 
and features of other individuals. "Network relationships" include individuals communicating with each other directly or indirectly based on particular interpersonal relationships.

Answering the question "Is it possible to dichotomize these individuals as part of certain organizations?" is not simple. However, the first thing that connects them to each other is, certainly, their common gender. All women are placed in this framework due to their female gender. The results obtained from this research show that there is a common sense of identity shared among them. Of course, this common identity has been changed in different ways, and women's their external aspects such as personalities, appearance and their view toward life has been altered. Social identity is the common features and characteristics that a group has and is defined based on them. In other words, the social identity of a person refers to the features, characteristics and thoughts that the person has developed through the social commons, and membership in groups. Based on this definition, social identity may be considered as a type of self-analysis in relation to others. This process specifies who a person is 'psychologically' and 'socially', and what his/her is 'position' is. In other words, the identity process makes it possible for each female social activist to find a proper answer for the questions regarding who she is and what she is. Therefore, social identity is the identity that a person obtains in socialization processes and their communications with groups or social units in society. The most obvious ones are the social groups or areas that a person refers to as "we" and considers themselves belonging to in terms of commitment and affection. Mass communications strengthens this social identity. In this regard, questions about the amount and the type of interactions between the interviewees were asked. Understanding how these individuals take measures to discover their common features with the others is of high importance. In replying to these questions, about $89 \%$ of the women interviewed referred to their gender. It seems that the interviewees sought to emphasize that this feature makes a clear distinction between them and others.

Some of the answers are provided in this section to facilitate a better understanding of this distinction. 
"I've always been a critical woman. If there were limitations in my family, I've always criticized them. There is no difference between me and men. I bear no discrimination. I discussed with my teachers at school the rules and regulations specific for women and objected to these restrictions and limitations. I am a determined woman, so when I begin an activity, I do my best to perform it the best possible way. I am very sensitive about issues relating to women and get nervous quickly upon hearing any criticisms." 37

"As a female filmmaker, I've grown up in a family where, fortunately, all the girls have been able to achieve high positions in society. Thank God we had no restrictions; however, the personality of each individual is influenced by her relatives and also by Iranian society overall. My mum is an educated woman who entered society, before and after the Islamic Revolution of Iran. My dad has no problem with women playing an active role in society. They applied their approach to their daughters. We had no obstacles placed in our way to enter university. However, some parts of our personality are obviously affected by overall Iranian society." 38

"It is about 11 years that I have been working as a lawyer. Why I got into this profession comes from my childhood. Although I had grown up in a completely irreligious family and felt no gender discrimination, I was always concerned about spaces for women. Perhaps the reason was that we moved from our neighbourhood to a new one during my puberty and I had some restrictions in my new high school that I was unfamiliar with before. My understanding of my surroundings had been changed and I had mixed feelings. During that period I felt that I did not like to be a woman. I wore men's clothing and abandoned everything relating to women. I was under the impression that a woman is highly limited in society. But as soon as I realized that this was not the solution, I changed my way in confronting the matter. I felt that I had to learn the religious teachings by which Iranian society oppressed women. Despite the opposition of my parents, I went to the mosque and prayed. I tried to explore the religious rules. I tried to understand them. The more I read them, the more desperate I got. Then I entered university.

\footnotetext{
37 Interview No 4, Group (Bbi).

38 Interview No 32, Group (Bai).
} 
As I chose the field of Law, I became more familiar with the rules of Islamic Iran. I faced a bitter truth. I realized that those rules give no rights to women and that women are valued half as much as men." 39

One of the issues affecting Iranian women is a lack of self-esteem and self-confidence in social responsibilities outside of the home. In earlier times, from family to society, Iranian women were indoctrinated that they could not work outside their homes. A girl born in a home would grow up with the common belief that being a girl means avoiding many things. This eventually leads to lack of confidence. Self-confidence in women should be encouraged in the family, and then it should be extended as a common belief in the rest of society. However, it is not so in Iran.

It is to be noted that some of the obstacles in the way of Iranian women's social activities originated from natural functions specific to women including giving birth and breastfeeding; therefore, men are not able to perform these tasks, so women must do them and, as a consequence, are limited by them, often to the degree that they have neither opportunity nor time to do other things such as participating in social activities, and gathering knowledge and educating themselves. Of course, these tasks are similar among women all around the world. However, the patriarchal society of Iran highlights the roles for men and tries to promote their power. Iranian women, therefore become creatures who have no function other than reproduction. Aware that their main role is to give birth, they feel the need to take care of their children, but before experiencing motherhood, they should be able to find their own identity. When the children grow up and become independent, their mothers feel unsatisfied. Because, they essentially devote themselves to pregnancy, giving birth, breastfeeding, and the education of their children, and they have no time to pay attention to themselves. One day they find that their children have grown up, and they are old. Therefore, they realize that their children have grown up and these mothers are often left feeling purposeless. This feeling of dependency and need in women is caused by sexism that distances women from growth and change.

\footnotetext{
${ }^{39}$ Interview No 38, Group (Abii).
} 
In these relations, mothers cannot transfer independence, awareness and freedom to their children. Thus, it should be noted that the Iranian society is highly patriarchal where the influence of this patriarchy affects all members of this society. A patriarchal government is at the top of this pyramid that tries to preserve its patriarchal traditions and customs in accordance with its rules and regulations. Anyone who objects shall be marginalized. What should be considered is that in most societies, common values related to women have special sensitivity. Unfortunately, in most times, the common values are caused by improper and illogical limitations on women. For example, in some regions, the women who work outside their homes are accused of being irresponsible or un-Islamic.

Generally, gender is considered as a social system that determines the role of women and certain relations between women and men. Gender roles are not assigned according to biological differences, but it is defined based on the socio-political and economic considerations. These processes of social and cultural definition of gender leads to the distribution of unequal opportunities in job allocations, power structures and reward systems, and the unequal evaluation of positions and roles, which essentially legitimizes inequality. This legitimization leads men and women to unconsciously accept these positions and roles in their own classification system. Men control material resources and power, and use these as a means for the social definition of gender, ideological, and cultural adjustment of these unequal positions in order to apply their cultural power in planning relations and interpersonal relationships. The function of these social and cultural definitions of gender is that they will establish a fundamental relation on micro and macro levels that helps the reproduction of these unequal positions and roles. In terms of social status, women are not able to control these tools of power. As women's movement is considered as moving against the dominant societal and political trend, it can easily find itself in a dangerous position.

Many issues relating to women have social and cultural aspects. Problems are sometimes resolved in Iran, and some regulation have been enacted in this regard, but it is opposed to the customs of society and is practically ignored by it. However, people deal with these issues 
according to the culture of their society. Therefore, despite the ratification of some of these rules and regulations, women's issues will not be resolved. In this regard, some cultural work needs to be undertaken to make society aware of the issues and help change the attitudes of the people. In this regards, it is apparent from interviewees respondance that they have committed to take action towards cultural changes with patience:

"I am a patient woman and try to be resilient when faced with the difficulties of life. Although I faced with many difficulties in my life, I have always tried to revive myself." 40

"I am a woman sensitive to the society in which I am living, and I react to its problems. I have always tried to achieve my goals. If I don't succeed, I won't be disappointed, as I know I have done my best. The activism arena is a space that not all people can enter, as this arena is costly, difficult and time-consuming. However, I know that one of the features I identity with is activism." 41

"I know myself as a bold and strong woman. I can be stubborn, and under certain conditions I am a conservative woman. I cannot define myself in a certain type of way. I will decide how to behave depending on the circumstances. Filmmaking, particularly in the field of women and children, requires a patient, strong and stubborn person to succeed." 42

Based on Tilly's theory (Tilly, 2004), a group relationship can be identified between these women. It means that they have stated that they have common features. First, they explore themselves, and then take steps to understand their commonalities with other women. Furthermore, the study of women working in social arenas in Iran implies that they try to define their common identity in the form of their female gender. In fact, emphasizing their gender and giving priority to it, this identity is in the framework of their reactions against the patriarchal atmosphere ruling their social relations in the society of Iran. Defining a border between themselves and patriarchy,

\footnotetext{
40 Interview No 35, Group (Bai).

${ }^{41}$ Interview No 25, Group (Abi).

42 Interview No 7, Group (Baii).
} 
and highlighting this common factor means that Iranian women have tried to establish strong organizations to achieve their goals. Therefore, they take joint action to establish network relationships which are required for the formation of a group (Tilly, 2004).

In this regard, all women interviewed, including those who are in employment and those who are not, with higher or lower forms of education, of all ages, considered themselves as feminists. It is important to mention that, although Iranian society reacts very severely to their views and actions, they still carry on.

"Regardless of multiple, and sometimes contradictory, definitions of the word "Feminism", I am a feminist and always introduce myself as a feminist. It should be noted that there are opposition groups in Iran and all around the world. It is supposed that if a person is feminist, she is an 'anti-man' person and is seeking specific privileges. In this process, propaganda is highly effective, as it is difficult to agree to the equality of men and women. Giving privileges to women as an equal gender to men imposes pressure on society, and the patriarchal society in Iran prove that they don't want to agree to this. Therefore, there is a massive propaganda campaign against feminism, and the government misrepresents the demands of feminists to arouse animosity towards them to the extent that women refrain from joining the feminist cause. They have exploited religion to make an obstacle in the way of these demands. However, I am a feminist and support this process." 43

"I am a feminist and am not afraid to say so, as I believe that we must focus on being human, and then discuss the differences between the sexes." 44

"I am a feminist and am not afraid to say so, as I want equality, not the dominance of women over men. Although the view of society's view of this issue is negative, I insist to say that I am a feminist. In my opinion, many of the definitions of 'feminist' used in society are wrong, so the

\footnotetext{
${ }^{43}$ Interview No 17, Group (Bai).

${ }^{44}$ Interview No 44, Group (Bbi).
} 
reaction to it is a severe one. Many of those who want to suppress feminism rely on these wrong definitions, and offer wrong definitions to suppress it. There is little awareness of this term, so there are no positive reactions to it. What people know about feminism is the information offered by the government, but they themselves never sought to define it." 45

"I am proud to say that I am a feminist, and I insist on my position and defend it. Of course, in our society, when feminism is discussed, everyone objects to it, particularly the men in any profession. This is obvious from their behavior and conversation. For instance, once I asked a composer to compose music for my poetry about women, but when he realized that it was a feminist poem, he refused because he disagreed with feminism and felt strongly against it." 46

"I am a feminist and proud of it. I'm not involved in this subject that feminism has various subsets and I am forced to defend a specific definition. I keep away from any oriented definitions to prevent restrictions. I try not to limit myself by any name. My behavior may be a combination of different types of feminism such as radical feminism, liberal feminism and Islamic feminism." 47

"I am a feminist, however, I emphasize that I am a newcomer compared with many others, and I think that I have to get many experiences for years to introduce myself as a real supporter, and I should continue with conviction." 48

"In the modern world, even in democratic states, feminists and groups of women activists are hated. People assume that these groups oppress the men and have more demands than men. People try to reject them. Regardless of the definitions, this process is rooted in the fact that these individuals are seeking equality and the other people are their followers. Gender

\footnotetext{
45 interview No 37 Group (Abi).

46 Interview No 39, Group (Bbii).

47 Interview No 15, Group (Abi).

48 Interview No 21, Group (Bai).
} 
differences cannot deprive us of our human rights. I am a feminist and will do my best to achieve this equality." 49

These women highlight a process using feminist views that define a border between them and the others. However, they have failed to find a specific definition of the others who humiliate them and don't recognize their identity. In this case, they are confused and are not able to define their borders and distinguish between friends and foes.

"Even though some women show a strong reaction to the supporters of the feminist perspective, I am still a feminist. I must confess that one of my major problems is to persuade the women who have strong positions against this viewpoint. They say to each other in some of their meetings, 'Do not to talk with her because she is a feminist'. This position is highly agonizing, when a man is standing opposite you and he expects you to show a reaction to him. However, is difficult for women when other women stand against them." 50

One of the interviewees stresses that "one of my problems, is to face women who don't accept each other. As an example, when you talk to a woman and she finds out that you are a feminist, she behaves in a manner as to intimidate you and [to give the impression] that you are not someone important, nor does your activity distinguish you from other women. Of course, I have no claim in this regard, and I don't see any privileges as to the others, but those women try to show our personality and actions as not valued and suppressed. They don't want that other women make progress. They feel a sense of retardation. They don't know that they can thrive by supporting other women." 51

It is to be noted that there are several examples of women who have governmental jobs and are responsible for encouraging other women to enter social areas, but they object to the employment of women and think that women's employment is damaging. Consequently, they

\footnotetext{
49 Interview No 41, Group (Aai).

50 Interview No 31, Group (Abii).

51 Interview No 23, Group (Bai).
} 
exacerbate the problems for women in the social arena. In other words, it essentially stresses and advertises the sexual view of Iranian society. Some of them believe that the employment of women damages the social status and employment market of men who are seen by default as the breadwinners. They simply emphasize that there is no need for women to fight the hidden patriarchal culture in Iranian society, but it is better that they choose the simplest way to achieve their basic human rights. If this happens, the interests of Iranian men will not be affected, but also those interests will be met more than before; as domination provides men with more benefits they do not want to lose.

"As a woman, we have grown up in a patriarchal society that values woman in a way that she must be at home and accept all discriminations and should not object. But over time the situation has changed. Women are now working out of home alongside men, they have a new identity, but they are not properly trained and, therefore, we see that they don't interact well with their counterparts in the workplace. For example, when a man is talking about feminist ideas, you can persuade him better than a woman who disagrees with that idea." 52

Another interviewee gives an example of a personal experience to authenticate this point. "Once I visited a woman psychologist. She told me: 'You women are all the same (as if she had another gender). If someone is active in the field of women, psychologically there must be a problem that has led her to this position. If someone is active in the field of women or children, maybe it is because of her own family or society and/or some social or emotional trauma'. I agree that we are all affected, but the difference between us is that we've thought more than others, and we want to take measures to resolve the issues women have been facing. I think that I have not been personally affected. My interest in this field has led me into it. I feel that these women have not been trained properly, so they are not able to distinguish between friends and foes." 53

\footnotetext{
52 Interview No 26, Group (Aai).

53 Interview No 38, Group (Baii).
} 
One of the interviewees mentions an example:

"The law was changed in 2015: for the women and children who have committed crimes, a woman interrogator shall be employed. I was interviewed by Ghanoon newspaper. I stated that this was a good change, provided that these interrogators should be well trained, otherwise, the situation will be worse than before. A woman with no position now has a position, and she may not use it properly. She thinks that she is weaker than the men in the same position, so she can't use and control her power [properly]; instead she thinks that she can use her power on other women. Although, some of them have been able to find a better social position, they do not help other women in changing the patriarchal view of society and view other women in a degrading manner. ${ }^{\prime 54}$

These statements represented the women's new identity challenges in Iranian society. And since the Iranian society still has a closed space with Islamic traditions, achieving a new identity is often accompanied by a crisis. Iranian culture intensified by Islamic tradition does not permit women to have the idea of a freely created identity. As a consequence, Iranian women need to overcome external barriers to commit to the idea of redefining their identity and sometimes if they were not educated enough they might even stand in each other's way.

Although there are still barriers for women in finding a new identity and redefining previous values and norms, one of the factors putting these women together to find a stronger common identity is opposition to the external opposing element. When women come together, they feel that they have more to say to each other. The reason is not that they have common feelings and are of same gender, but they have a common foe (that is the patriarchal system) which restricts their freedom and imposes problems on them. The formation of women's organizations accelerates whenever new restrictions are placed on them. They start using their power and their relationships in order to find a solution for their problems. Combination of the group and network relationships leads to the formation of a group.

\footnotetext{
${ }^{54}$ Interview No 45, Group (Abi).
} 
In Tilly's opinion, when the individuals are able to distinguish themselves from the others, they will be able to form a specific organization whose members have several common features. (Tilly, 2004, p. 104)

In one of the questions asked in interviews with Iranian women, the response provided by about $96 \%$ of the interviewees is that one of the purposes of the patriarchal system is to separate women from each other to prevent their success and access to power. As stated by one of the interviewees: "this system wants to separate women, but women want their meetings. The only solution for changing the social system is collective work." 55

As mentioned before, diversity in women thoughts and actions should not be attacked. It is important that they are convergent and support each other. They cannot achieve this goal, unless by conversations, satisfaction and consensus.

For the establishment of a political active organization, members of the organization or some of them shall be informed of the interests of that organization and this awareness will develop a network. Commitment and awareness of the members to the collective interests is more, establishment of the organization will be more probable. Extent and quality of the organization will determine the mobilization power of that organization.

\subsubsection{Mobilization}

The third element in Tilly's model is mobilization which includes the controlled or accumulated resources of a claimant. It is a process by which a group of individuals are changed from passive to active participants in life. In fact, mobilization is a kind of attempt to obtain any type of resources that the group requires for advancing their collective action. Here, Tilly considers that the control and skill of using resources and assets of the group are more important than the amount of assets. He classifies mobilization into three types: defensive, offensive and preparatory. These three types have situational and cognitive differences. Defensive mobilization

\footnotetext{
55 Interview No 22, Group (Bbii).
} 
is when a threat from the non-members of a group induces the group to react to it. Offensive mobilization refers to the reaction of the group against the opportunity achieved by the group to the resource mobilization. Preparatory mobilization refers to the accumulation of the resources through prediction of the opportunities and threats in the future. (Tilly, 2003)

In this sense, Tilly's definition of the three different types of mobilization can be interpreted for the Iranian women's movement as follows:

1) Defensive mobilization

In defensive mobilization, an outside threat motivates the members of a group to gather their resources, causing them to maintain their benefits. One example of this mobilization is resistance towards laws. In this regard, many laws that are incompatible with the real benefits of the women will be resisted. The movement will become aware of the conflict presented by the new law towards women's rights, and then forces the legislators to adjust the new verdict. One example is the act debated in Parliament on the early retirement of women. This law was met with serious opposition and after two years it was still not legislated in 2017 , but it has been submitted to the Parliament for review.

2) Offensive mobilization

In offensive mobilization, the organization collects resources in response to opportunities to achieve new benefits. Holding elections in Iran is an example of this kind of mobilization, as women conclude that candidates wanting to be elected try to take advantage of the female side of the population during elections and their election slogan is chosen so that they would be able to achieve their goals. These women expect that their candidate would give in to their demands and obtain for them some advantages; otherwise, they will not support him in his later attempts at re-election.

3) Preparatory mobilization

In preparatory mobilization, the organization predicts future opportunities and threats. Subsequently, it collects and reserves its resources. To mobilize effectively in a society, various groups with different thoughts and goals unite to make positive changes. One example is the 'One Million-Signatures Campaign' that had a considerable effect on the society of Iran and it has 
become clear to men that women's problems in that society, and many men have understood that women can talk about their problems.

Women have more complex minds and are able to deal with problems since they have always been in positions of dealing with more difficult conditions in Iranian society. With this regard, the women's movement had included all three types of mobilization in different periods of time. Therefore, the use of cyberspace by women over the past decade may be considered a response to state oppression for defensive and preparatory mobilization. After the detention of women activists, websites and weblogs were developed to support them and create anti-government propaganda.

Moreover, based on data collected by this study, cyberspace is the current source base used by women activists. About $96 \%$ of educated women use it differently and $72 \%$ of housewives are online about 5 to 7 hours a day. Working women, whether working in public or private sectors, are all active in cyberspace. The only difference is that working women in the public sector (who form $19 \%$ of the subjects interviewed for this study), have no access to many sites and are forced to spend more time, energy and cost to use Internet. Employees of the private sector (who form $69 \%$ of the subjects), have more freedom and use these spaces more freely.

As the statistics show, women with a high school diploma form $17 \%$ of the interviewees, $58 \%$ of the women had Bachelor's degree, and $25 \%$ of them included women with higher degrees. Among these women, those having a high school diploma are active 4 hours a day, women having Bachelor's degrees spent 7.5 hours and women with Master's and higher degrees made use of the Internet for 4.5 hours a day.

One of the interviewee expresses her opinion in this respect thus:

"The Iranian women's movement has no official media. There is no media source to communicate with the women's society members. Internet has provided a platform for this movement. Members of the movement may express their thoughts, talk to other people, widen their circle 
of interactions, and reach those interested in this field but have no access to activists. Most of the activists in this field have been able to hold virtual classes for the awareness of women via the Internet. In my opinion, the Internet is a big change in many fields; particularly because it has had an important role in communication for the women's movement."

Another interviewee started using the Internet by creating an email account.

"Once or twice I've used email and I realized how much easier it is to communicate with others, and I could talk about the issues that were impossible to talk about on the phone. It was very attractive for me. I stayed awake all night, constantly searching, and was surprised by new information. It was a world where every moment I faced an information shock. I found topics that I had been searching for in the libraries over many years." 56

Another woman said: "My whole life is summarized on the Internet. The Internet has become my second world. It is my communication bridge with the world. I have a permanent relationship with the Internet. I am a member of various Internet groups active in the field of women, and I follow their news and share them with others. I write my comments and read the comments of other people, criticizing or approving them. I try to be involved more with gender topics. I mention my gender in any post I add." 57

In reacting to this new opportunity, women have mobilized their resources, i.e. the virtual space, for the fulfillment of their goals that they have already described as their fundamental rights.

"When Facebook started out, all bloggers and other activists started using it. It had a more interesting atmosphere. We found our friends there and knew where they were and what they were doing. We shared our subjects and inserted comments in our friends' subjects. I thought that I should be cautious. I preferred to be free. I didn't want to be imprisoned only for uploading a photo or a topic. Now, about a year later, I have not visited my Facebook page

\footnotetext{
${ }^{56}$ Interview No 46, Group (Bai).

${ }^{57}$ Interview No 23, Group (Aai).
} 
because of other virtual pages. Iran has blocked access to Facebook and we are forced to use a VPN ${ }^{58}$ to enter it, so we prefer to use other virtual spaces." 59

An interviewee confirmed these statements and stated that "Virtual pages, sites and blogs seem like a man with a limited shelf life. In the past few years Facebook was very interesting. It is less important now and people are not as active on it as there were in the past. The Internet opens a new space with a new name, suddenly all people become a member and uses the new application. Of course, it makes no difference for me where I am online. It is important for me that all people are interested in this new space and my activity favors the women's movement." 60

This statement like many others reveal that restricting access to such tool has become important to government crackdowns but surprisingly not, Iranian women activists still find ways to get around government restrictions by using tools that evaded Iran's censorship technology. Another frequently used example of how the Internet forms connections is stated below.

"I am very busy, so I can't read all the news, but I try to use the main news shared to be informed of all issues. For sharing the topics, I usually try to inform those people not involved in women's issues." 61

Women's activist praise the various possibilities of the Internet as a new space for social movement, however, asking interviewees whether they approve or disapprove with a certain characteristic of the Internet in Iranian society. One of the interviewees states that even though the Internet can be used by the government as a tool to suppress opponents but can be used at any opportunity given.

\footnotetext{
58. A tool that many Iranians use to get around an extensive government Internet filter. Because it lends them a temporary IP address and hides his/her true IP address from every website or email they connect with.

${ }^{59}$ Interview No 9, Group (Bbii).

60 Interview No 17, Group (Baii).

61 Interview No 1, Group (Abi).
} 
"We couldn't use Internet for our work. As the subject of our activity was the security of unaccompanied women and this demand was too much, our group was suppressed immediately, and our permit was cancelled. This community has been working without a permit ever since, so we are not able to use most of the resources and facilities, like the Internet. The women active in this field couldn't get together or we gathered in fear, so the topics discussed in our gathering could not properly be communicated, as there was no resource for communication. Therefore, a lot of people were not informed and our resources were limited. We are afraid that if we communicate the information via the Internet, the government will be informed of our activities. But the situation was different about the activities in the field of child labor. I created a weblog from the beginning of my involvement and communicated its activities and reports to others. We had no website to use, as the community was against its formation. This was because the community performed several activities in one space and they feared that if one of them faced a problem, the others faced the problem too. So, they tried to create personal weblogs. I created a weblog and communicated as well. I asked for help there but, unfortunately, I got into trouble and was imprisoned. After being released from prison, I was forced to leave Iran to continue my activities. When I felt that the situation had calmed down in the country, I returned to Iran and restarted my activities again. Now I am active in the field of women and child labor, and I try inform others about it." 62

The nature of interaction in cyberspace connects the political affiliations of the users and gives them hope by more radical actions against the frustrations caused by permanent repression by the government.

"I am constantly online throughout the day and read women's news in the different virtual spaces. I communicate with people and put comments for important news and try to start discussions which lead people to further information." 63

\footnotetext{
62 Interview No 35, Group (Baii).

63 Interview No 44, Group (Baii).
} 
It can be argued that the path that Iranian women activists have traveled through the online movement and blogging demonstrates how Internet restrictions are a means to create political opportunities and facilitate resource mobilization in Iran. Moreover, the successful interaction between cyberspace and social movements has arisen from a dynamic cooperation among the social and political groups in real world and virtual world. Virtual space, as a variable, affects social movements, facilitates their mobilization and provides a modern tool to challenge the challengers in order to organize opponents to the government and create collective action. With this interpretation, we can claim that those political groups with a stronger social position (if they can use the facilities of the cyberspace to create an opportunity for the movement) complete and facilitate the mobilization and organization. They can show the needs and demands of the real world in the virtual world and they will be able to develop their models for political and social life in Iranian society.

\subsubsection{The Second Section of the Mobilization Model}

Variables of the first chapter of the mobilization model may not explain the revolutionary action by themselves. This model only shows the existing intergroup capacity for taking measures and will not consider motivations or immediate opportunities for that action. Those motivations and opportunities will find their positions in the other half of the mobilization model and political society model. Therefore, concepts that have been studied in this thesis are the factors which cause the formation of a social action. The Second Section of Charles Tilly's Mobilization Theory is formed of components including (1) Collective Action (2) Power (3) Repression and Facilitation (4) Opportunity and Threat; that are included as the most important and out-group components (Tilly, 2004).

\subsubsection{Collective Action}

One of the most important tools for the announcement of the existence in political and social aspects is collective action. According to Tilly, the types of collective action are different 
according to the conditions of the period. In other words, in each period, there are various options that people may use to achieve their common goals. Tilly proposed two principles for the selection of the type of collective action: "What types of action are accessible and what is the use and application of those tools to which the groups must pay attention?" (Tilly, 1984, p. 153)

The collective action process, when starting too late, is a violent and complicated one with an uncertain outcome. The complication of this process is due to the fact that collective action is faced with different types of resistances from the government, since different demands are proposed, this accumulated energy is released in different ways that will be destructive. Therefore, the outcome will be uncertain. Collective action always begins with a problem, and this problem may include a wide range of issues such as injustice, marginalization by the government, and a lack of political freedom. There are also always leading groups in society that try to solve problems via different activities. This is called 'social movement repertoire' (Tilly, 2004 , p. 3), and it reminds the political elite that the result of such activity is being marginalized by the government, arrest and imprisonment. It may also lead to the closing of media outlets and creating a stifling repressive atmosphere in order to maintain regime survival and keep control of the society.

This trend will cause the continuation and intensification of the underlying problems. Under these conditions, some groups and political, intellectual and civil factions may turn to form a type of limited and sectional social movement, whose results are not achieved. This movement may divide the reformers in Iranian society and undermine the reforming project. On the other hand, actions taken by the reformers may lead to the formation of the social movement.

Upon comparison of these conditions with regard to Iran's domestic affairs and the situation of women, it can be concluded that Iranian women have turned to a type of social action in Iranian society through which they have tried to achieve their social movement goals. According to Tilly's theories (Tilly, 2004), the question arises: How have women taken the required measures for the formation of collective action? In response to this question, it should be referred to Tilly's point of origin and raise the question of what activities should be performed for achieving women's 
rights. That means what type of personal action is performed by each person that will lead to collective action.

The most important issue is why and how these persons turned to this movement. An overview of the interviews performed with the women shows that each person began performing activities as an individual. Overall, these women all stand side by side and rely on each other in order to take steps towards reaching certain objectives they have in mind.

Individual actions are determined according to a certain orientation as to a series of demands and goals. The activists consider certain definitions for their behavior and that definition will affect their behaviors. In explaining the subject statements, the women activists, first engage themselves with activities which have positive meaning and are suitable to reach the goal they pursue. These are activities for the improvement of women's situation. In this vein, any kind of involvement with women's affairs is considered positively and the woman shapes her personal traits accordingly. Taking the responsibility of a dormitory ${ }^{64}$ is one example where the main purpose is to pay special attention to girls in a context where they are under visible or invisible oppression, like in all other spaces which are managed by men. Therefore, she evaluates her presence in the dormitory positively. Although these decisions are mostly limited by intervention of the patriarchal cultural and social structures, individual actions will pave the way for prevailing on these structures, as the active and creative role of the activists may not be denied in adjustment of these structures.

Tilly considered activists' understanding of their work as a requirement of their action (Van Laer \& Van Aelst, 2010, p. 1149). The introduction of this action is clear since women feel differences since birth from men. However, their social activism starts once they enter the official sphere of society and begin to discover the predominant anti-women order of society.

Tilly stresses that activism in his opinion is not only a choice but insists that it shows a new identity for the presence of women. However, this will have consequences such as being accused by

\footnotetext{
${ }^{64}$ Interview No 22, Group (Bbii).
} 
family and others of being rebels and destroyers of the valuable traditions of the past. Without considering the predicted consequences, this behavior is inspired by the idea of the false antecedent conditions. In this sense, a person will devote themselves to the service of a goal. Women make decisions based on activism, will follow different social behaviors in response to social pressures and become activists in the social area. However, since there is opposition of the individual actions and social structures, women should be able to aggregate them and convert them to collective actions with common goals. In this regard, a basis will be defined.

A person's behavior in response to the pressures in society is not to leave the social arena, but initially it is to make an effort to remedy the situation. This effort will have consequences, and it will give the person countless problems. However, the goal is so great that such considerations will not prevent movement. There is a relation between powerlessness and social mobility, as well as between an organization and feeling powerless. When the membership of the organization grows, the feeling of powerlessness will decrease and those who are organized will feel less powerless than those who are not organized.

As mentioned earlier, collective action always begins with an issue or a problem that includes a wide range of issues such as inequality, marginalization by the government, lack of political freedoms and family issues that the interviewees face. Women feel that they should take action to overcome these problems, as insecurity or lack of action will not lead to positive results and no change will be made in their conditions. After raising an issue, the repertoire of the social movement will begin to move and they will strive to be active members of the society. In this regard, they will take action, along with other persons who have the same problem.

By reviewing these discussions, the conclusion can be reached that collective action among these women is accepted as necessary. They stand together in response to social pressures to achieve a common goal that meets the wishes and interests of individual members. The development of virtual activities and heavy use of the Internet provide an opportunity to the opponents of government policies that will inevitably result in the facilitation of the mobilization process. Of course, the response by the government to the mobilization process was suppression; however, though it does not solve the issues or make the problem go away, women have been encouraged to take as much advantage as they can from this space. 
Explaining this issue, it should be said that, in some cases, activity in this space is highly effective and provides the movement with many participants and fans. However, the movement cannot keep these participants in the long term, due to the suppression in the virtual space by the government. Although this suppression and punishment by the government have increased the expenses of the women activists, they have not forgotten the importance of applying virtual tools. Suppression has shown to be very ineffective with regards to this matter. Suppression has not only failed to stop female activists continuing their collective action, but also it has become a threatening factor that facilitates mobilization, as it encourages feelings of sympathy and closeness among this population.

\subsubsection{Power}

Power of the group for collective action depends on the resources mobilized by that group. Collective action is subject to:

1) mutual interests, i.e. advantages and disadvantages that may result from the interaction with other groups;

2) the intensity and power of its organization, i.e. common identity and unifying structure among the members of the group

3) the mobilization of resources, i.e. the resources owned by the group.

Talking about her activities from the beginning of to the present, one of the interviewee says:

"My main activities begun after I was admitted to university; however, I took part in some activities, such as the Islamic Association, during high school. I was admitted to study sociology at Shahid Beheshti University in 1987 and was immediately accepted as the head of the council of the dormitory. On the other hand, I became a member of the Islamic Council of the university and began to perform activities in the central council of the university. As I was interested in women's topics, I began to write for the Salam newspaper in 1991 and assumed responsibility for the Women's Tribune page where the articles embraced topics in the field of legal, political 
and social issues concerning women. Then I became the editor-in-chief of a publication called 'Printing and Publishing' (Chap va Enteshar), and then I was transferred to 'Hoda' at the Ministry of the Interior. I was interested in topics such as women studies, and social and cultural educational centers that performed activities in the field of empowering women and improving their conditions. At the same time, the debate was raised about NGOs and how our team could establish six educational workshops for Iranian women in all provinces. We had many accomplishments with the help of literature from the NGOs, mechanisms, and the efficiency of the facilitators. After several years working in the Office of Women's Affairs, I was transferred to the Office of Social Affairs, and there I individually pursued the topic of NGOs. An initial bylaw was written for the NGOs whereby the NGOs regulations were separated from any parties and groups. It was the first time that such a measure was taken in Iran and since there was no clear and accurate definition about what an NGO is, the relating activities were transferred from the Office of Political Affairs to the Office of Social Affairs. This center was responsible for the issuing of permits for the NGOs, writing the different bylaws for these organizations, and holding empowerment workshops. In those years, and with the intention of taking better measures for helping the women, a contract was concluded with United Nations Development Programme (UNDP) for which I was responsible, and I took the required measures for the empowerment of social organizations. I performed several activities, including holding about ninety workshops across the country that were conducted by NGOs for the empowerment of women. Several books on this topic were translated and provided to interested women. In the $8^{\text {th }}$ and $9^{\text {th }}$ Governments, I was transferred to the Department of Human Resources. At this center, I evaluated the whole ministry and offered solutions for better efficiency and performance. As a result, roles were described and capacities were specified resulting in the improvement of the methods employed within the Department. When the $10^{\text {th }}$ Government took office, I was the deputy for Ms. Molaverdi at the Office of Women's Affairs for about six months. It should be noted that since I was working at the Salam newspaper, I, along with some of the female journalists, established an informal group. In 1995, I became familiar with the idea of the NGOs at a meeting convened in Beijing and decided to create such a space. In 1997, when the situation was better in our society, we founded the 
Female Journalists Association of Iran that is still active today. We are still working there but effective measures must be put in place to control the situation.

In addition to my duties, I did other things as well, including rendering services as the Head of the Council of Women at the Office of the Secretary of State where many powerful women are working and pursuing the empowerment of women in relation to the parliament. Several workshops have been designed, and so far three of them have been conducted. There are three ongoing projects in this council: (1) Strengthening the Parliament's approach in relation to women's issues; (2) Establishing a project to increase the number of women in provincial, urban and rural council elections; (3) Plans to increase the number of female managers in the future government.

My other activities include Secretary of the Advisory Council of the Specialized Committees at the Office of Women's Affairs and as a representative of the Female Journalists Association of Iran in the political fields, and served on the Coordination and Policymaking Council."65

Although this woman mentions political activities in some government position, however, examples of female activists committed to the Iranian women's movement like her can rarely be found. Women mostly subordinate positions in Iranian politics which is not a hidden fact, as the political system combined with patriarchal culture encourages women to accept their subordinate position and not to challenge patriarchal structure. Despite the dominant view that attempt to marginalize women, active women constantly struggle to change the clichéd role for women and participate in socio-political activities whatever it is provided to change societies perceptions about women. In this regard, Tilly considered the activists' understanding of their role as an introduction to action (Tilly, 2004).

As is described by another interviewee:

"Starting with the voluntary and informal activities in the social fields relating to the women, I felt these restrictions more stringent than compared to what men had to deal with. Of course, this problem has remained within formal and family gatherings, but comes to the fore more whenever an individual woman decides to make an effort in order to change a situation. It is not as easily done for her since she has to deal with society, traditions, and even her own family

\footnotetext{
65 Interview No 18, Group (Baii).
} 
sometimes. Therefore, she concludes that her problems must be evaluated more accurately and aren't as easily resolved. The inequalities between women and men are clear and painful, but we should help each other to reduce these inequalities. Another annoying issue was that there was a serious conflict in law and custom for women's economic issues. For example, women receive their Mahrieh ${ }^{66}$ after their marriage, so they should make some investment after their marriage. However, we see that this doesn't happen, and women have no capital. If a woman demands her dowry, she will be in trouble in her personal life and will also be accused by her husband and his family of causing discord. Even her own family will tell her that she is not a good wife. This is not approved by the law and it will eventually result in making women economically deprived." 67

Women limited access to economic, political and cultural resources is an obstacle to the growth of capital and national productivity. Although, women can bring some changes in society but they are mostly in subordinate position and this condition cannot be changed until they reach the point of realizing they need to be united. Therefore, the analysis of above statement entails the relationship of individual to collective action. On the individual level one can easily imagine the formation of common grievances by everyday experience that lead to collective action from Tilly's point of view.

When women confront a problem, one person is not capable of changing the society's point of view, so collective action is predicted to occur. To challenge the subordination of women in society by the patriarchal order, the interviewee explain how she eventually got involved in activities and understood the importance of group activities:

"Upon admittance to university, I became familiar with women's activities. Since the One Million Signatures Campaign began, some of my friends had been active in that campaign, I was more familiar with these activities. I went to different places to collect signatures and did my best to achieve the goals of the movement. I was not afraid of going to jail. After that some

\footnotetext{
${ }^{66}$ Mahrieh is the sum paid or promised to be paid by the groom to the bride at the time of marriage, often not collected until the husband's divorce or death.

${ }^{67}$ Interview No 30, Group (Abi).
} 
of my friends and I formed a team and established an NGO, where I have been working since its foundation. Our site named Feminist informs the people. Of course, we have another site named Stop Violence that is active in the field of violence against female activists. It makes an optional change towards forming new groups for pursuing an offensive movement to achieve new rights and benefits." 68

Therefore, for women group based emotions resulting from perceived injustice are thought to motivate collective action in an attempt to rectify the state of unfair deprivation. The extent to which women respond to this deprivation involves several different factors and varies from extremely high to extremely low across different conditions.

"A personal experience of my childhood caused me to go into such topics. When I was a child, my older brother was a political prisoner; he was a pro-Marxist and performed activities with Marxist groups. He was arrested and imprisoned after the Islamic Revolution of Iran. For many years, he was transferred from one prison to another, and those specific conditions were my concern. When I grew up, I became a social activist and social issues were my concern. I began my activity in the fields of the security of unaccompanied women and working children. I saw a woman who was working at an NGO and running an association. I was 18 years old, very inexperienced, and highly sensitive in dealing with these issues. As I didn't have enough information, I dealt with them emotionally. I did whatever was possible and felt that these poor women should be supported. It was very important as to who they received help from, as they might have no proper motivation or might be doing it for the wrong reasons, which could eventually harm the organization. During the first six months, I helped with the least facilities and received no support or contribution. Thus, I harmed myself more, materially and spiritually. We prepared several forms and asked the right people to approach our center, so that we could help them for gaining experience. It was very difficult at first, because many women didn't trust us and wouldn't approach us; therefore, we tried to solve this problem by negotiation. A few women approached us and their friend accompanied them on their next

\footnotetext{
68 Interview No 47, Group (Baii).
} 
visit. Our contributions gradually took on more of an organized form. We trained them at our center and help them, but our certificates were not valid, so we tried to receive a permit and convinced the Ministry of Public Education to accept the certificates issued by our center. We approached the governmental schools and took the required measures for those people to receive a valid diploma which they can use for employment." 69

The vested interest of an activist to participate in a team effort is a motivation for him/her, while the lack of this vested interest becomes a barrier. An almost obvious interest for active women that applies to most interviewees is their willingness, readiness and in most cases eagerness to become involved in group activities:

"The members of this group were mostly university students who tried to help, but our activity was more widespread. We all get started reading the Convention on Human Rights, bent on finding the origin of the problems and understanding why the United Nations does not prevent governments from neglecting human rights. On the other hand, the problem was that our data were not accurate, because some countries didn't provide true data. This was in order not to be blamed at the global level in terms of the protection of human rights. This problem has put Iran's government under pressure by international public opinion. On the other hand, the United Nations has no proper tool for pursuing these issues in different communities and the situation has exacerbated." 70

Explaining her personal experience, another interviewee shows that she shares a common belief with the other participants in this collective action. In this regard, the struggle of being women in Iranian society is more understandable for other Iranian women, therefore, she can establish a closer relationship with her peers.

\footnotetext{
${ }^{69}$ Interview No 9, Group (Aaii).

${ }^{70}$ Interview No 36, Group (Bbii).
} 
"I grew up in a traditional family who strictly follows traditional culture and is highly sensitive to the role of women. I have always been curious and active-minded. This question always came back to me: Why am I so different from my male peers? They have more freedom than me. There were no sensitivities and restrictions for them. But I had to bear these issues. Another bad incident was that I was raped by one of my male peers when I was nine years old. It was very bad and after many years, I still think about it and I'm always upset. Later, I tried to be a top student so I could be accepted into Law (which is a difficult field of study) to solve this problem for myself and women like me. Some of the women who are my relatives were involved in divorce. They had many problems and there was no one to help them. I desired to receive my diploma earlier to help them solve their problems. During my education at the university, I had girl roommates who were abused and maltreated by a male-dominated culture. As I was such a caring person and couldn't be indifferent to those problems, I was involved with them as much as possible and tried to be empathetic and sympathetic. I told them they didn't need to be under the control of men, should satisfy their own needs and to not be indifferent to themselves and their emotions. I was highly active during my education at the university and was a member of the Guild Council, the Academic Association and the Islamic Association, and all my activities were focused on the adjudication of the girl students. I have always reacted badly to men who wanted to impose his will on me, even if that person was my father. If he raised his voice, I raised my voice ten times higher and didn't allow him to bully me. If I see a man annoying a woman in the street, I won't be silent; I'll interfere and blame him. I act like that at my workplace, too. I help the women who are alone and oppressed. I guide them legally. Although the Iranian laws don't favor women, I try to use all my knowledge and ability to find the best solution. I prefer to accept the cases involved in social affairs. For example, I accepted to act as for a thirty-year-old physician who was raped, because I sympathized with her. Most of my cases are family-based and l've tried to spend all my time and energy in solving my clients' problems." 71

\footnotetext{
${ }^{71}$ Interview No 19, Group (Bai).
} 
Undoubtedly, women came together to pursue a common goal. It is obvious from the words of the interviewees how these common goals have been formed. Sometimes women are not able to remember the starting point, so they will figure the cause of the issue without considering the starting point. More details are given in another interviewee's statement:

"I've read and heard that many women states that they have been tightly controlled as girls in their childhood and it caused them to think about women's issues. But the more I think, I can't draw a conclusion about where it began [for me]. We felt the restrictions in society and in our families, but I really don't know if that is where it began. When I started working, I was not active in the field of women, it began from the issue of political prisoners. Discussions about political prisoners and supporting them was a very important issue for me and I was seriously active in the field of human rights. In this regard, I got to know met female activists. Topics related to women were interesting to me and I was motivated to know more about them. When we read and hear more, we know that we have experienced these issues and problems, and it causes you to be more involved in these issues. One person alone is not able to deal with the restrictions, issues and problems." 72

Although she has not been able to remember the starting point of being women activist but she knows how to play the strong women role in Iranian society. As Tilly clarified 'a group of people, voluntarily and with determination, take the required actions for the implementation of a common plan by investment in a certain social identity, a unifying belief, a common plan, and a collective action' (Tilly, 2004). Therefore, she is determined to take action and be a part of a group that would create a collective action. Because of same struggles, another interviewee points out her experience of working as a group:

"In our family, as my mum was a social activist, she gathered a group of women to meet every month. At first, these gatherings were only friendly meetings, but gradually they formed as a group to try to take positive measures. They sometimes decided to help poor people and collect

\footnotetext{
72 Interview No 28, Group (Aai).
} 
contributions. I hold gatherings with my friends. We gather and watch documentaries on women and children and discuss current issues."73

In addition to this basic personal experience, the next statement revolves around interview's personal decision to seek certain forms of engagement when the opportunity arises:

"I have been serving as a lawyer for ten years. The main area of my activity is women and I am always the lawyer for women's cases. I've got to this point due to my experience in my adolescence. I grew up in a traditional and religious family, so I became aware of differences as a girl. I had a cousin of the same age and I was always astonished to see the differences between him and myself. The veiling imposed by my family was very annoying. I also had to perform religious rituals. Therefore, I began reading books banned by my family and these new radical thoughts opened a new world to me. I could understand to be different and bear the difficulties of being different. When I was 18 years old, Iranian society was better due to the presidency of Mr. Khatami and I was able to get involved in the work of different groups. Meeting people like myself and our similar problems brought us closer together."74

She clearly states that having a problem and a disability to deal with made her a social activist. Another interesting point is that about $96 \%$ of the female subjects have declared that they have been inspired by a popular slogan that encouraged them to gather and act in the virtual media. One example is the following quote from an epic poem "Join us dear, join us dear, don't stay alone, as this joint pain can never be treated individually". So, any field research about a given social movement shall take into account its members' conception of their movement and what they consider to be their main problems. Thus, the most reasonable way to engage in social activity is to pay attention to the activists. They are certainly reasonable, able to choose, define a strategy and a discourse, mobilize the resources and take advantages of their political opportunities. Activists interact, communicate and influence each other. They negotiate and

\footnotetext{
73 Interview No 34, Group (Bbii).

${ }^{74}$ Interview No 5, Group (Bai).
} 
make their decisions which creates a public, organized and sustainable activity by which they also demand certain services from the authorities who have been chosen by them. Tilly calls this the 'campaign' (Tilly, 2004, pp. 4-10). Using political acts, including forming an organization or a union, holding public meetings, marching, striking, collecting signatures, public speeches, and the distribution of promotional leaflets are what Tilly calls 'the action reserve' of the movement (Tilly, 2004, pp. 2-4). They perform activities and show their commitments to their movement and demands publicly.

\subsubsection{Repression and Facilitation}

Repression is any act of a group that increases the costs of the collective act. Repression from Tilly's point of view is the government's strategies to raise the costs of collective action. (Tilly, 2006, Chapter 4). On the one hand, repressive strategies by ruling government such as banning demonstration, censoring information, surveillance and arresting dissidents might increase the cost of contention. On the other hand, however, acts that decrease the cost of the collective act of a group is a form of facilitation (Tilly, 1978, P. 100). In fact, despite the recent years of the Iranian government's repressive efforts toward women activists, providing no facilitation for

them, the Iranian women's movement continued to pursue their socio-political activities merely demanding a quick transition to the more open platform. In fact, the development of virtual activities and the increasing use of the Internet have provided an opportunity for the opponents of government policies to facilitate the mobilization process. It is also considered a threat for their challengers, as it may lead to a concentration on cyberspace censorship and the repression of cyberspace activists in the real world. A majority of the interviewed women have realised the power of the Internet to organize, mobilize and express dissent. They considered the Internet to be a facility to challenge patriarchy and work towards a more just and equal society. However, to facilitate collective action in terms of the interviewees point of view cyberspace should be used with caution to prevent repression by the government: 
"The Internet has become an extension of our offline lives. As we challenge gender inequalities in all aspects of society, we must recognise that the government view it as an invading force that threatens the Islamic state's strict social, religious, and political values, therefore the control over the means of publication and consumption of content online is growing rapidly." 75

In terms of the government's intention to restrict access from websites and massive censorship another interviewee gives an example:

"After the Internet played an important role in the opposition movement that followed the disputed presidential election of June 12, 2009, the Iranian government rewarded an active campaign against Internet freedom, using extensive and sophisticated methods of control that went well beyond simple content filtering." 76

The interviewee simply pointed out the new strategy that the government has adopted to repress the contention. In this case the type of repression employed by government officials included online organising efforts by extending regime propaganda into the digital sphere. Both hacking and production of pro-regime online content are the efforts that the Iranian government believed to be a method to repress and exert their power. Therefore, this space has been under threat for women activist who face backlash in the form of repression by the government:

"One of the methods of suppressing the opposing voices is to reveal their undesirable faces on the Internet. That is, whenever they felt that our activities on the Internet caused the formation and attraction of the audience, the government tries to create an image of these women being against Islam in order for them not to be accepted by the majority of society."77

From the interviewee's point of view the Internet is a critical space for women's rights activism, a struggle that is sharpening a conflict with the government but Women have long realized the

\footnotetext{
75 Interview No 28, Group (Aai).

76 Interview No 16, Group (Bbi).

77 Interview No 7, Group (Baii).
} 
importance of freedom of expression and access to information in voicing opposition to patriarchal systems and challenging the status quo. As an extension of offline life, the Internet can be a transformative public and political space where women can criticize patriarchal order and express their identities, feelings and thoughts in a rather safe space.

Therefore, despite these limitations, the Internet remains the only means available for Iranian citizens and dissenters to obtain news and organize themselves:

"I've found my way after involving myself in different activities for pursuing gender equality and I'm not afraid of prison and investigation. But those women who cooperated with us are no longer amongst us. They have been made to disappear by the Government. For example, after the $\mathbf{2 0 0 9}$ presidential elections, many of the activists were arrested, including me. Many different activities were performed in cyberspace at that time. Our situation was reported to others, and the freedom for political prisoners was demanded many times. But when I was released from prison, no one knew me when I walked down the street. If you search on the Internet about human rights, my photo is the first one that you may see. But the Iranians quickly forgot us. Many rallies were held for my release at that time, but they no longer exist these days." 78

According to the interviewee, for women activist, the Internet has become a critical space to access relevant information, provide support and mobilize women. The repression strategy such as arresting dissidents, torture and corrupt trials, that women activists are subject to, not only has failed to cause fear and hesitance amongst women activists, it has further enhanced the importance of this sphere for them. In this regards another interviewee talks about her bad experiences during her imprisonment:

"When I was imprisoned, I was transferred to a room for interrogation every day. The interrogator asked me different questions. But one of the main questions was to tell them about my friends or to snitch on them, but I resisted. One day when I was tired of resistance,

\footnotetext{
78 Interview No 19, Group (Bbi).
} 
they tried to threaten me. The interrogator told me to write down my friends names. I answered him that I wouldn't snitch. He told me, 'if you continue resistance, I'll rape your younger sister who is only sixteen years old; then you'll beg me not to do it and write your friends' names'. I told him 'you are wrong, there will be a punishment for everything. We must pay the price of being women in the Iranian society, and I was punished, and now that I am imprisoned, my sister will be punished; but she'll understand that she must struggle and resist throughout her life, but not with you, but with the traditions and history that created such a patriarchal society'." 79

This pattern of compelling others to also push for change, coupled with the willingness to take personal responsibility teaches an important lesson. This is that the repression of the collective action employed to change the Iranian society does not prevent these women from continuing their activities; in fact, they become more motivated to continue and to not be afraid of repressive actions. Here, too, her participation to engage in new forms of activism:

"When the government fears our activities on the Internet, it is clear that this space has had positive effects such as awareness and revealing actual news, so the path is right and will help us to achieve our goals." 80

These elaborations underline the crucial importance of pursuing the Iranian women's movement goals through being active on the Internet.

\subsubsection{Opportunity and Threat}

Controlling websites, weblogs and social networks are the tools that show how the protest movement uses the Internet. In fact, the Internet is a tool providing a widespread and decentralized access for organizing the movement. Cyberspace is able to transfer the messages

\footnotetext{
79 Interview No 32, Group (Baii).

${ }^{80}$ Interview No 17, Group (Bai).
} 
of the organisation to the outside world and meanwhile communicate with its members. The open information sharing system in the developed field of the Internet has provided this opportunity for the movement's activists to be active in a space with a decentralized structure, where there is less pressure than in the real world. The other benefit is that people living in other countries will be informed of the activists' activities. Also, their intellectual contributions may impose pressure on the government and force them to retreat from their positions. Cyberspace is similar to a tool which aids in the organisation of movements and focuses the attention of their supporters on one specific subject, which could lead to changes in the real world.

With this regard, several questions were raised in the interviews to elicit the opinions of the Iranian female activists regarding whether cyberspace is an opportunity (or a threat) relating to the activities of the Iranian women's movement. Several short and long answers were given to these questions, and part of them is provided in a classified table as described in the next chapter.

The other part of the answers included the opinions of interviewees to this question: Was the Internet successful as a tool to render services to the women's movement? The answers were very clear. $83 \%$ of the women interviewed agreed with the effectiveness of this tool and considered it as an opportunity for achieving the movement's goals. One of the interviewee elaborated on this:

"In my opinion, cyberspace has been effective in the field of homemakers and the general female population. For example, I see that I share a topic in the field of the women and two of the women who know these spaces and have no information about them will repost them and inform other people. I think that it is very good and a communication bridge has been formed. I am not saying that the Internet has had an inhibiting role, the virtual sphere has been able to have a $50 \%$ effect, whether in terms of informing or other facilities provided to the movement. When we are really involved in a problem, for example when we become a member of an organization and talk to many people ask them questions or answer their questions, it is highly different from the news that is read on the virtual space. I don't say that it has an inhibiting 
role, because if there is not such a resource, we will obtain no information. Currently, Facebook and Twitter or other similar websites are informing us, but they don't have the same effectiveness. People read the news and ignore them, and they are not motivated to take action in the real space. In previous years, when the weblogs were of high importance, they were more effective and directed the people towards activism." 81

The prime reason for her engagement is that she believes currently this space is the only information reference that is accessible and more highlighted. The most important benefit of the Internet is to inform people about the women's movement and the groups who have met each other through it. Communication had been formed and the group continued with performing the same activity; however, the result obtained was not the one the activists had been hoping for.

"In my opinion, the Internet, like other tools, has specific advantages and disadvantages; the greatest advantage being it's effectiveness. For example, the campaign on changing the masculine face of the parliament ${ }^{82}$ was developed through the Internet. We were a 10-person team who were informing the people. Since we couldn't inform other people via telephone, we tried to gather the unknown people and then we formed an Internet group. The number of followers doubled in a short time. The site of this campaign was developed and the process of informing the people was started. After that, Internet activists began their activity and even the international space was affected. However, the cyberspace had disadvantages as well. Many people have failed in practice, but they show themselves very well in the virtual environment, while they have poor knowledge and insufficient information. For example, the topic of the reduction of working hours for women was not important for people and many didn't want to be involved. But the virtual space turned their minds on. Regarding the abovementioned campaign, I talked to the deputy of a department of the government who was a successful and active woman. I asked her why she was not running as a candidate for parliamentary representation, and I assured her that our campaign would support her. She

\footnotetext{
81 Interview No 44, Group (Bbii).

82 Read more at (http://www.feministschool.com/english/spip.php?article538)
} 
replied: 'I can't. If my husband finds out, I'll be beaten and he'll make my life bitter'. I was very surprised to see how such a successful woman is weak in her home.

Even though I was away from my family, I communicated with them on the Internet. I wanted them to know that I was an activist in the field of women and I provided them with new information. It is interesting for me to see the extent of the effect of cyberspace on people. The virtual space and the amount of involvement of the people with it causes inactivity and a lack of mobility required in the real space. This is general, and is not specific for women or men. For example, while there is a law for wearing the hijab, and it is not observed by a vast population of women, and they'll convince themselves that it is sufficient if only part of the body is covered. These people have obtained their information and this information has impact on them, so that Iranian society has been forced to give in to them. Activism, therefore, does not depend on [physical] presence and mobility. It should be noted that inactivity and lack of social activism are the undeniable characteristics of the virtual space.

It has occurred in many cases, and I think that rather than the virtual space being more harmful for women, it has been effective in helping them and played a useful role. Homemaker women have good access to information, and I see that it has occurred in a large part of our community. Even the elders use this space and are affected by it. In my opinion, this space has helped women come out of their minds and play a pivotal social role. Women who are merely housewife's have been a player in the virtual space and can be useful. Of course, the Internet is a tool that may be used in any form, and despite the fact that it can be useful and effective, it may also cause further problems. Its main disadvantage is that it is an information resource and if you enter it with no purpose, it is not useful, and is also harmful. In my opinion, the much of Iranian society has yet to uncover the many advantages of the Internet and the proper use of the Internet and this causes more harm than good. I think that it is highly important to provide intellectual and cultural development [opportunities] in using the Internet. We communicate with each other through the routine use of the virtual space, because it is not possible to plan a gathering at short notice. Fortunately, we may protect our communications 
and continue our activities through the Internet. Different concerns will induce people to search for information; as an example, a person who is concerned with women's issues will search for information and news about this field. They share women's issues with each other and search the weblogs and websites relating to women. However, I prefer to be a social activist rather than an Internet activist. Although the Internet space has its own effects, considering my profession as a journalist, I'm forced to use the Internet. Of course, I never encourage people to take part in street protests as, considering the security situation in Iranian society, participation in these protests will impose costs on the people involved and they may be imprisoned; therefore, I only inform them. I actually do what is required but I never suggest to other people to do so. I argue why I participate, but I never insist them to do the same. Some people may not know the consequences or they may not intend to be involved in this issue; therefore, I never suggest it to them. I only inform them." 83

The interviewee here emphasises that although she is an activist and participates both online and offline, she does not encourage other to do the same due to the costs associated in Iran's society. She merely insists other stay informed and at least have an online presence. However, the virtual space has caused isolation and anonymity in the society and created weak relations networks that are meaningless interactions. The Internet has played a positive role in the women's movement, as it has speeded the process of informing people. Of course, the virtual space makes people good at "liking" and makes them believe that this all that is needed to create an activist. For example, the post-election fallouts in 2009 have demonstrated this issue. Many people stayed in their homes and chanted and thought that they had performed their duty to society. Also, in the One Million Signature Campaign, the virtual space was not as active as it currently is now. People gathered, talked and showed their true faces. No one could enter the space knowing nothing about it. Therefore, people who shared these concerns gathered and took advantage of one another's knowledge. Some people on the virtual space have no knowledge about these issues, or they have obtained wrong information, and may be overwhelmed. The manner of using the Internet in Iran is not right. Iran's society must learn how to correctly use this new tool. Unlike

\footnotetext{
${ }^{83}$ Interview No 39, Group (Abii).
} 
what most of Iranians predominantly believe, Google is not the only search engine and source of information on the Internet, believing so Iranians may obtain incomplete information and a false sense of confidence with that. Although the Internet is widely used in Iran, due to the way it is used, the opportunity for change and influence it has for the Iranian women's movement has not been effectively utilised. Here the Iranian women's movement must be cautious that this ungrasped opportunity does not turn into a threat for the movement.

\subsection{Conclusion}

The findings outlined in this chapter indicate that the cyberspace has been instrumental in increasing self-esteem and the sense of independence of Iranian women. Without worrying about the patriarchal attitude of Iranian society, they talk about their social problems and life much more easily than in the past. It has also been shown that the Internet has changed the traditional beliefs and thoughts of Iranian women. This transformation may undoubtedly be an effective factor in the revision of the traditional ideas about women's problems, which may result in a transformation in the existing social structures. Today, women have left their traditional roles in Iranian society and want more of an effective presence in society. The Internet has helped them discuss their demands and make their presence stronger with the support of others. On the other hand, cyberspace has provided the opportunity for engagement and discussion for Iranian women. As for those who need to express their feelings and ideas (due to experiencing social pressures and difficulties), the virtual space gives them the possibility of uncensored presence and expression and the ability to find solutions for their problems through discussion with others.

Cyberspace as the fastest and cheapest means of information exchange has a great potential for helping women to become members of the information society. News spread quickly, and unity and integrity are easily achieved. Thus, social movements to change the conditions and situations of women are organized with better integration. The social isolation of women (which has always been a goal for the Iranian patriarchal society) gets weaker every day, and women are driven from isolation to work. As a result, their social base is somewhat strengthened. Therefore, the 
social movement of Iranian women has achieved great things via the Internet, and their achievements cannot be denied.

By reviewing the views of fifty Iranian women activists, concentrating on their activities on the Internet, and analyzing the impact of these activities on the components of the resource mobilization process, this chapter has identified various examples illustrating the beneficial changes for women in the Iranian patriarchal society and real space. In fact, the empirical study of these cases was undertaken with the intention to explore and analyze the capacities and limitations made by cyberspace in the process of formation and mobilization of social movements. Accordingly, we conclude that cyberspace now offers some great possibilities that affect the promotion of social movements and completion of the mobilization process. Firstly, it provides the opportunity for the leaders of movements to be heard by the population in a few seconds. Secondly, it provides the opportunity for organizers to coordinate and plan activities undertaken by its different sections at different geographical points, even at great distances, virtually. Thirdly, it provides opportunity for members of the population to express and share their beliefs, ideas and experiences in the form of speech, photo, or video. Finally, cyberspace is able to provide the ground where mutual relations between organizers and the population at large are created, so that everybody could put their words together. Thus, it provides a unique opportunity to the social movement for the promotion of its organization and communication. It also provides a new form of engagement amongst the different levels of the movement.

As a result, the empirical study of Iranian women's use of cyberspace indicates, as some analysts say, that although the Internet and cyberspace do not completely provide freedom speech they are an effective tool towards obtaining it. As some claim, the limited number of Internet users in relation to the total population in the social movements does not imply that the importance of cyberspace for the social movements is negligible. Cyberspace, as a means of mobilisation and organisation of resources, is important when it is provided to the organisers of a movement. It plays the role of a communication interface between leaders and the active sections of the population. Apart from organized movements, significant numbers of ordinary Iranian women 
have access to the Internet. Housewives generally use the Internet more than working women. From this viewpoint, cyberspace cannot to be the only valuable variable for the process of communicating resources to mobilise and cannot solely provide the solution and method for attaining the goals of the social movement. Social challengers have access to this new facility, and it provides them with the opportunity to accelerate the process of mobilisation and collective action.

\section{Chapter 5: Discussion}

\subsection{Introduction}

Based on the study of the attitudes of fifty Iranian women activists presented in Chapter 4, this chapter provides a summary of the findings. These include the role of women activists in addressing women's concerns in Iran and how they evaluate the status of Iranian women, as well as the effective factors in forming their present positions and activists' strategies in changing the status of Iranian women. In fact, answering these questions helps obtain a perspective on the efforts of Iranian women activists, and also paves the way for achieving their goals as the answers shed light on the reasons behind the successes and failures of the Iranian women's movement. It appears that the Iranian women's movement is not a mass movement. Most of the activists of this movement belong to the country's elite, and include women serving at universities, working as authors and senior civil servants. However, they strive to change the situation for all Iranian women and to remove discrimination from their personal and social lives. They challenge the vision of this Islamic state and its legal manifestations that fail to promote legal change and any gender justice for women. Therefore, although only a small minority of women in Iranian society

is represented in the movement, they use every opportunity to change the status of Iranian women as a whole. It has emerged from the research that the Internet is an important tool in the social movement of women who use it as a means to interact with one another and to access and diffuse vital information. 


\subsection{Findings}

As outlined in the Introduction above, Iranian women activists have been working towards achieving their goals for many years and, as previously mentioned, while they have changed the form and type of their efforts against the country's social frameworks, they have not given up on the movement. At a time where the capabilities of cyberspace are apparent to everyone, with the use of the Internet they can determine the most effective approach according to the tools available. Cyberspace has been effective in achieving the purposes of the movement and expanding it further.

The purpose of this study is to research Iranian women activists, a select group of collegeeducated, middle and upper class, mostly married and employed Muslim women. Research in this direction was conducted with the help of the interview method and of the simple random sampling method. Out of a large number of Iranian women active in the field of women's issues, 50 women were selected and interviewed face to face in different Iranian cities: Tehran, Mashhad, Isfahan, Shiraz, Rasht, Arak, Ardebil, Ghazvin, Kish, Tabriz, and Zanjan. The related findings are described hereunder.

Table 1: Educational level of the interviewees

\begin{tabular}{|l|c|c|}
\hline $\begin{array}{l}\text { Highest Educational } \\
\text { Qualification }\end{array}$ & Frequency & Percentage \\
\hline Diploma & 4 & $8 \%$ \\
\hline Graduate certificate & 2 & $4 \%$ \\
\hline Bachelor's degree & 18 & $36 \%$ \\
\hline Master's degree & 16 & $32 \%$ \\
\hline PhD & 10 & $20 \%$ \\
\hline Total & 50 & $100 \%$ \\
\hline
\end{tabular}

Table 1 shows the interviewees' level of education. As indicated above, most of the activists interviewed for this research have higher education. $88 \%$ of them have Bachelor's or higher degrees, while only a small percentage (12\%) have lower-level degrees. 
Table 2: Findings related to the opinion of the interviewees about women's status in Iran

\begin{tabular}{|l|c|c|}
\hline $\begin{array}{l}\text { Assessment of the status of Iranian women } \\
\text { based on the interviewees' perspective }\end{array}$ & Frequency & Percentage \\
\hline Inequality & 17 & $34 \%$ \\
\hline Difference & 10 & $20 \%$ \\
\hline Oppression & 23 & $46 \%$ \\
\hline Total & 50 & $100 \%$ \\
\hline
\end{tabular}

According to the interviewees, the status of women in Iranian society can be described in three ways: in terms of difference, inequality and oppression. $34 \%$ of the interviewees evaluated the position of women in Iran as unequal to that of men. From their perspective, the inequality between men and women has an enormous effect on the kinds of lives Iranian women lead or experience. In contrast, a higher percentage of the interviewees (46\%) emphasized that inequality alone cannot reflect the status of women in Iran as they have been effectively oppressed in comparison to men. They see this oppression of Iranian women manifested in political, social and economic terms. This is due to the inequitable exercise of authority in Iran's patriarchal society, and is especially evident in laws preventing women from being free or equal to men. The findings show that a lower percentage of the interviewees (20\%) saw the status of women in Iranian society as merely different from men's and accepted this as normal. They think that, since men and women are inherently different, their way of life and their capabilities and limitations are also diverse. In their view, the gender differences, and hence certain characteristics that are apparent and different between men and women, justify the existing unequal treatment of men and women in society. However, the majority of the interviewees (80\%) believed that the oppression and inequality of women in Iranian society is in fact unjust, and that in this society women are deprived of their human rights in comparison to men. They emphasized that, Iranian women have been continuously experiencing systematic disadvantages, structural inequalities and institutionalized injustice in their male-dominated society for decades.

Table 3: Relationship between education and the opinions of interviewees

\section{Education}




\begin{tabular}{|l|c|c|c|}
\hline $\begin{array}{l}\text { Assessment of the } \\
\text { status of women }\end{array}$ & Lower than Bachelor & Bachelor & Higher than Bachelor \\
\hline Inequality & $30.8 \%$ & $39.7 \%$ & $30.0 \%$ \\
\hline Difference & $46.1 \%$ & $14.3 \%$ & $3.3 \%$ \\
\hline Oppression & $23.1 \%$ & $46.0 \%$ & $66.7 \%$ \\
\hline Total & $100 \%$ & $100 \%$ & $100 \%$ \\
\hline
\end{tabular}

This study shows that there is a significant connection between the educational level of the interviewees and their opinion of the status of women in Iranian society. Indeed, as the educational level increases to Bachelor's and higher degrees, more women believe that there is an unjust inequality and oppression of women in Iranian society and women usually suffer oppression disproportionately compared to men. Therefore, although they have studied in an Islamic country and are familiar with Islamic law, they believe that Islamic laws in Iran are not properly implemented. From their point of view, a true Islamic society does not discriminate against part of its members on the basis of gender and is not oppressive towards women. Conversely, as the educational level decreases, more women (46.1\%) view the existing differential treatment as being just. The reasons behind this is probably that the expectations of women and their rights and treatment in society is greater when they are more educated.

Table 4: Reasons proposed to explain women's status in Iranian society

\begin{tabular}{|l|c|c|}
\hline Reasons & Frequency & Percentage \\
\hline Gender inequality in Law & 32 & $64 \%$ \\
\hline Physiological factors & 12 & $24 \%$ \\
\hline $\begin{array}{l}\text { Society's negative attitudes } \\
\text { toward women }\end{array}$ & 6 & $12 \%$ \\
\hline Total & 50 & $100 \%$ \\
\hline
\end{tabular}

A high percentage (64\%) of the interviewees believe that the existence of gender inequality in the law is the most significant reason behind the unequal status of women in Iranian society. Accordingly, the hypothesis that the Iranian women's movement considers gender inequality in the law as its most important issue is proven as they claim that Islamic laws in Iranian society 
unduly favour Muslim men. Therefore, it can be reasonably argued that the main goal of the women's movement is to achieve equal rights for men and women.

Nearly a quarter of the interviewees (24\%) believe that women's status in society is due to the differences between the physiology of men and women and to the fact that men and women are created differently and, therefore, should be treated differently.

A further $12 \%$ of the interviewees say that Iranian society's negative attitude towards women is a notable reason behind their inequality and oppression in that society. This negative attitude is evident both in the personal aspects of women's lives in Iran and in their treatment in the wider society.

Based on the above findings, currently the primary focus of the Iranian women's movement is to address the patriarchal framework of the Iranian legal system. Although other factors contribute to women's status in society, such as physiological factors and society's negative attitudes towards women, the activists believe that the first step is to evoke a change within Iran's patriarchal laws.

Table 5: Relationship between education and the reasons proposed to explain women's status in Iranian society

\begin{tabular}{|l|c|c|c|}
\hline \multirow{2}{*}{ Reasons } & \multicolumn{3}{|c|}{ Education } \\
\cline { 2 - 4 } & $\begin{array}{c}\text { Lower than } \\
\text { Bachelor's degree }\end{array}$ & Bachelor's degree & $\begin{array}{c}\text { Higher than } \\
\text { Bachelor's degree }\end{array}$ \\
\hline Gender inequality in law & $46.1 \%$ & $79.3 \%$ & $78.7 \%$ \\
\hline Physiological factors & $38.4 \%$ & $12.7 \%$ & $18.1 \%$ \\
\hline $\begin{array}{l}\text { Society's negative } \\
\text { attitudes toward women }\end{array}$ & $15.5 \%$ & $8 \%$ & $3.2 \%$ \\
\hline Total & $100 \%$ & $100 \%$ & $100 \%$ \\
\hline
\end{tabular}

The findings show that there is a slight correlation between education and the evaluation of women's issues from the perspective of the interviewees. The different levels of education of the interviewees can explain different opinions of gender inequality in the law as with an increase in education more and more women believe this to be an issue in society. Of the interviewees with an educational level lower than a bachelor degree, $46.1 \%$ believe gender inequality to be a 
significant issue, $38.4 \%$ consider physiological factors to be important and $15.5 \%$ view their society's negative attitudes towards women influencing the status of women in society. Of the interviewees that have obtained a Bachelor's degree, a large percentage (79.3\%) believe gender inequality in the law to be prevalent in society, with $12.7 \%$ concerned with physiological factors, and $8 \%$ viewing society's negative attitudes to be issues that keep women in Iran in the position that they are in. Lastly, the interviewees with the highest level of education, like the other levels, prioritise gender inequality with $78.7 \%$ viewing it as the most significant issue. $18.1 \%$ are concerned with physiological factors, and 3.2\% believing society's negative attitudes towards women to be most prevalent issue. Overall, according to the findings, it is evident that, judging by the opinions of the interviewees, women believe that the main reason for their treatment and status in society is the lack of gender-neutral laws in Iran.

Table 6: The impact of economic, legal, physiological and cultural factors on the situation of women from the interviewees' perspective

\begin{tabular}{|l|c|c|c|c|c|c|}
\hline \multirow{2}{*}{ Factor } & \multicolumn{5}{|c|}{ Efficiency } \\
\cline { 2 - 7 } & Very Low & Low & Average & High & Very High & Total \\
\hline $\begin{array}{l}\text { Economic } \\
\text { factors }\end{array}$ & $14.7 \%$ & $31.2 \%$ & $28.4 \%$ & $13.8 \%$ & $11.9 \%$ & $100 \%$ \\
\hline Law & $1.8 \%$ & $6.4 \%$ & $9.2 \%$ & $22 \%$ & $60.6 \%$ & $100 \%$ \\
\hline $\begin{array}{l}\text { Physiological } \\
\text { factors }\end{array}$ & $52.2 \%$ & $20.2 \%$ & $19.3 \%$ & $5.5 \%$ & $2.8 \%$ & $100 \%$ \\
\hline $\begin{array}{l}\text { Cultural } \\
\text { factors }\end{array}$ & $0 \%$ & $0 \%$ & $5.5 \%$ & $29.4 \%$ & $65.1 \%$ & $100 \%$ \\
\hline
\end{tabular}

From the perspective of the interviewees, the factors that played the most significant role in the status of women in Iranian society are the economic, legal, physiological and cultural factors. According to the data shown in Table 6, $82.6 \%$ of the interviewees evaluated laws and regulations as playing a highly influential role in the current situation and status of the women. Such findings demonstrate the interviewees' belief that the inequality of their legal rights vis-à-vis men should be prioritised, and achieving equal rights may be considered the main objective of the women's movement. $45.9 \%$ of the interviewees found the effect of the role of the economic factors on the 
current situation of women low to very low, while $25.7 \%$ believe that this factor plays a highly effective role in the current status of women. So, more than half of the activists do not believe that the current situation of women is the result of economic factors.

However, the percentage of those interviewees who have evaluated the role of cultural factors (such as religious beliefs, customs, values, acceptable gender roles and occupations, etc.) on the current situation of women being high and very high is significant (94.5\%). Considering this together with the percentage of interviewees to perceive the role of the physiological factors in the status of women to be high or very high ( $8.3 \%$ of the interviewees), it can be concluded that the women subjects have evaluated the role of cultural factors as much more influential than the factors related to physiological differences. It is to be noted that no one rated the role of cultural factors as low or very low in the current status of women, and most interviewees emphasized this as a highly influential factor.

Overall, the interviewees believe that law and culture in Iran have a significant impact on the situation for women and that these must be addressed by the Iranian women's movement.

Table 7: Findings related to the evaluation of the relationship between the Iranian women's movement and feminism from the interviewees' perspective

\begin{tabular}{|l|c|c|}
\hline The movement ... & Frequency & Percentage \\
\hline is associated with feminism & 30 & $60 \%$ \\
\hline is a branch of feminism & 3 & $6 \%$ \\
\hline $\begin{array}{l}\text { is not associated with } \\
\text { feminism }\end{array}$ & 12 & $24 \%$ \\
\hline does not exist & 5 & $10 \%$ \\
\hline Total & 50 & $100 \%$ \\
\hline
\end{tabular}

Interviewees responded differently to the question of what the connection is between the Iranian women's movement and the feminist movement. Is the Iranian women's movement related to feminist movements? Is the Iranian women's movement a branch of feminism? Is there no connection between the two? Or, from the interviewees' point of view, does the women's movement even exist in Iran? 
According to the findings presented in Table 7, 24\% of the interviewees have evaluated the movement of the Iranian women as a movement belonging to the Iranian women but believe it to be entirely disassociated from feminism. These women claim that, although it is a movement that is structurally unstable and in a constant state of flux, it is also unique and does not belong to any feminist movement rooted in other places. Despite their critical views of misguided and repressive Islamic policies in Iran, the interviewees are willing to cooperate with the Islamic framework of Iran, hoping to achieve a gradual shift in its position on women.

The majority (60\%) of the interviewees believe that the Iranian women's movement is closely associated with the feminist movement and that this connection has evolved during the era of cyberspace which enables quick communication of information and ideas. They strongly believe that Iran should be gradually reintegrated into the International community. From their point of view, as the space for communication expands, sharing experiences and having strong ties are eye openers and create favourable conditions for establishing links with the global women's movement. Considering this together with the $6 \%$ of interviewees who perceive the Iranian women's movement is a branch of feminism, it can be understood that they mostly accept the linking between the Iranian women's movement and feminism. Notably, $10 \%$ of the interviewees have denied the existence of the Iranian women's movement and deemed that such a movement requires the active presence of women in a public sphere. They argue that through decentralized, informal and semiformal activities there cannot be a women's movement. Despite an emphasis on the importance of feminist ideologies, the interviewees distinguish the Iranian women's movement from the feminist movement and deny any connection between the two.

Overall, the interviewees, from those who believe the women's movement to be a unique movement within the Islamic society to those demanding changes from an International framework and even those who deny the existence of an Iranian women's movement altogether, know that there is a significant amount of aversion and discrimination to the feminist movement and feminism in Iran. In order to avoid further disapproval of, and creating obstacles for their movement, despite their true beliefs, some activists deny any link to, or relationship with feminism, $24 \%$, to be precise. 
Table 8: Comparative assessment of men and women from the interviewees' perspective

\begin{tabular}{|c|c|c|c|c|c|c|c|}
\hline & & $\begin{array}{l}\text { Strongly } \\
\text { Agree }\end{array}$ & Agree & No Opinion & Disagree & $\begin{array}{l}\text { Strongly } \\
\text { Disagree }\end{array}$ & Total \\
\hline 1 & $\begin{array}{l}\text { Men and women are } \\
\text { the same }\end{array}$ & $13.8 \%$ & $16.5 \%$ & $6.4 \%$ & $44 \%$ & $19.3 \%$ & $100 \%$ \\
\hline 2 & $\begin{array}{l}\text { Men and women are } \\
\text { different and have no } \\
\text { similarities }\end{array}$ & $3.7 \%$ & $8.3 \%$ & $14.7 \%$ & $20.2 \%$ & $53.1 \%$ & $100 \%$ \\
\hline 3 & $\begin{array}{l}\text { Men and women are } \\
\text { similar in some } \\
\text { aspects and different } \\
\text { in other aspects }\end{array}$ & $63.3 \%$ & $11 \%$ & $0 \%$ & $16.4 \%$ & $9.3 \%$ & $100 \%$ \\
\hline 4 & $\begin{array}{l}\text { Men are more mature } \\
\text { than women, so they } \\
\text { are superior to } \\
\text { women }\end{array}$ & $0 \%$ & $0 \%$ & $6.4 \%$ & $7.3 \%$ & $86.3 \%$ & $100 \%$ \\
\hline 5 & $\begin{array}{l}\text { Considering some } \\
\text { characteristics of } \\
\text { women, women are } \\
\text { superior to men }\end{array}$ & $1 \%$ & $4.6 \%$ & $7.3 \%$ & $64.2 \%$ & $22.9 \%$ & $100 \%$ \\
\hline 6 & $\begin{array}{l}\text { The concept of men's } \\
\text { superiority over } \\
\text { women or vice versa } \\
\text { is not valid; they } \\
\text { complement each } \\
\text { other }\end{array}$ & $86.2 \%$ & $7.9 \%$ & $0 \%$ & $5.9 \%$ & $0 \%$ & $100 \%$ \\
\hline
\end{tabular}

Another question asked during the interviews was whether the interviewees believe there to be any similarities or differences between men and women and whether they think men have superiority over women or vice versa. This question was asked to identify their assessment of the qualities of men and women from their perspective.

Table 8 shows that $63.3 \%$ (1) of the interviewees disagree or strongly disagree with the idea that there is no difference between men and women, and $30.3 \%$ (1) of them agree or strongly agree 
with it. Indeed, $73.3 \%$ (2) of the interviewees disagree with the idea that men and women are different, while $12 \%$ (2) of them agree. Furthermore, $74.3 \%$ (3) of the interviewees agree with the idea that men and women are different in some aspects and similar in some other aspects, while $25.7 \%$ (3) disagree.

The final analysis of the findings shows that most of the interviewees with different approaches disagree with the idea of similarity and difference between men and women and, with a realistic approach, noting a difference between men and women in some aspects, while accepting their similarities in other aspects.

In relation to the natural superiority of either of the two sexes, $93.6 \%$ (4) of the interviewees disagreed with the superiority of men over women. Also, $87.1 \%$ (5) of the interviewees denied the intrinsic superiority of women over the men, with only $5.6 \%$ (5) of the interviewees believing in the intrinsic superiority of women over men. Finally, the response rate to the question of denial of superiority of either sex over the other was considered as the index of evaluation of the realistic approach to the relation of the two sexes. From these findings and the consensus of a denial of a superior gender it can be gathered that the interviewees adopt an impartial rather than an extremist approach.

In this regard, $94.1 \%$ (6) of the interviewees agreed that men and women complement one another and disagreed with the superiority of either one over the other; only $5.9 \%(6)$ of the interviewees disagreed with this statement.

Most of the interviewees (74.3\%) (3) agreed with the existence of similarities and differences between men and women and, by acknowledging that men and women complement each other, they adopted the impartial approach. To sum up, from the interviewees perspective, the Iranian women's movement does not have an extreme view on differentiation between the two genders. Since it promotes impartiality and equality, it could even attract men to stand with women to change the patriarchal attitudes and practices of Iranian society. 
Table 9: Findings related to the relationship between the Internet and Iranian women's movement from the interviewees' perspective

\begin{tabular}{|c|c|c|c|c|c|c|c|c|c|c|c|c|c|}
\hline & \multirow{2}{*}{$\begin{array}{l}\text { Statement } \\
\text { Number \& percentage: }\end{array}$} & \multicolumn{2}{|c|}{$\begin{array}{l}\text { Strongly } \\
\text { Agree }\end{array}$} & \multicolumn{2}{|c|}{ Agree } & \multicolumn{2}{|c|}{$\begin{array}{c}\text { No } \\
\text { Opinion }\end{array}$} & \multicolumn{2}{|c|}{ Disagree } & \multicolumn{2}{|c|}{$\begin{array}{l}\text { Strongly } \\
\text { Disagree }\end{array}$} & \multicolumn{2}{|c|}{ Total } \\
\hline & & No. & $\%$ & No. & $\%$ & No. & $\%$ & No. & $\%$ & No. & $\%$ & No. & $\%$ \\
\hline 1 & $\begin{array}{l}\text { The Internet is a positive tool } \\
\text { to participate in women's } \\
\text { movement in Iran }\end{array}$ & 28 & $56 \%$ & 17 & $34 \%$ & 2 & $4 \%$ & 3 & $6 \%$ & 0 & $0 \%$ & 50 & $100 \%$ \\
\hline 2 & $\begin{array}{l}\text { The Internet is an } \\
\text { indispensable part of } \\
\text { women's movement in Iran }\end{array}$ & 33 & $66 \%$ & 14 & $28 \%$ & 2 & $4 \%$ & 1 & $2 \%$ & 0 & $0 \%$ & 50 & $100 \%$ \\
\hline 3 & $\begin{array}{l}\text { Use the Internet as a } \\
\text { communication tool for } \\
\text { spreading news }\end{array}$ & 19 & $38 \%$ & 18 & $36 \%$ & 0 & $0 \%$ & 11 & $22 \%$ & 2 & $4 \%$ & 50 & $100 \%$ \\
\hline 4 & $\begin{array}{l}\text { The Internet enables women } \\
\text { to find their voices }\end{array}$ & 41 & $82 \%$ & 6 & $12 \%$ & 0 & $0 \%$ & 2 & $4 \%$ & 1 & $2 \%$ & 50 & $100 \%$ \\
\hline 5 & $\begin{array}{l}\text { The Internet provides the } \\
\text { opportunity to connect with } \\
\text { international women's } \\
\text { movements and coalitions }\end{array}$ & 23 & $46 \%$ & 13 & $26 \%$ & 9 & $18 \%$ & 3 & $6 \%$ & 2 & $4 \%$ & 50 & $100 \%$ \\
\hline 6 & $\begin{array}{l}\text { Internet provides the } \\
\text { opportunity to raise } \\
\text { awareness about the plight } \\
\text { of Iranian women } \\
\text { internationally }\end{array}$ & 9 & $18 \%$ & 19 & $38 \%$ & 1 & $2 \%$ & 16 & $32 \%$ & 5 & $10 \%$ & 50 & $100 \%$ \\
\hline 7 & $\begin{array}{l}\text { Discrimination against } \\
\text { women has been reduced } \\
\text { through the growth of the } \\
\text { Internet }\end{array}$ & 11 & $22 \%$ & 8 & $16 \%$ & 0 & $0 \%$ & 20 & $40 \%$ & 11 & $22 \%$ & 50 & $100 \%$ \\
\hline 8 & $\begin{array}{l}\text { Some changes to the laws } \\
\text { related to women will be } \\
\text { considered as a consequence } \\
\text { of women's activities on the } \\
\text { Internet }\end{array}$ & 18 & $36 \%$ & 13 & $26 \%$ & 3 & $6 \%$ & 10 & $20 \%$ & 6 & $12 \%$ & 50 & $100 \%$ \\
\hline 9 & $\begin{array}{l}\text { Use of the Internet as a } \\
\text { communications tool to } \\
\text { reach larger audiences }\end{array}$ & 36 & $72 \%$ & 7 & $14 \%$ & 0 & $0 \%$ & 3 & $6 \%$ & 4 & $8 \%$ & 50 & $100 \%$ \\
\hline
\end{tabular}




\begin{tabular}{|c|c|c|c|c|c|c|c|c|c|c|c|c|c|}
\hline 10 & $\begin{array}{l}\text { Internet as a tool for resisting } \\
\text { state control and battling } \\
\text { with opposing points of view }\end{array}$ & 20 & $40 \%$ & 16 & $32 \%$ & 5 & $10 \%$ & 5 & $10 \%$ & 4 & $8 \%$ & 50 & $100 \%$ \\
\hline 11 & $\begin{array}{l}\text { Virtual demonstrations can } \\
\text { satisfy the protester's desire } \\
\text { for the emotional rush and } \\
\text { thrill of real, physical action }\end{array}$ & 7 & $14 \%$ & 13 & $26 \%$ & 3 & $6 \%$ & 6 & $12 \%$ & 21 & $42 \%$ & 50 & $100 \%$ \\
\hline
\end{tabular}

The set of statements presented to the interviewees to gather information and to help gain a more comprehensive understanding of women activists relationship with the Internet are described hereunder.

1. The Internet has provided women with a platform to participate in women's movement in Iran.

2. The Internet has become an indispensable part of women's movement in Iran.

3. The Iranian women's movement is able to use the Internet as a communications tool for spreading news.

4. The Internet enables women to find their voices.

5. The Internet has given the Iranian women's movement the opportunity to connect with international women's movements and coalitions.

6. The Internet has given the Iranian women's movement the opportunity to raise awareness about the plight of Iranian women internationally.

7. The existing discrimination against women in Iranian political culture and the the patriarchal discourse derived from Iranian political culture have been affected by women's activities on the Internet.

8. Some changes that have occurred to the laws concerning women in the last decade, and the improvement in women's status in Iranian society will be considered as a consequence of the efficacy of women's activities on the Internet.

9. The Iranian women's movement can use the Internet as a communications tool to reach a larger audiences.

10. The Internet can be considered as a tool for resisting state control and battling with opposing points of view. 
11. Virtual demonstrations can satisfy the protester's desire for the emotional rush and thrill of real, physical action.

The findings show that a majority of the interviewed women activists (90\%) stated that the Internet has provided them with a platform to participate in women's movement in Iran. they consider cyberspace as a positive tool, and it has never been a barrier for them in continuing and succeeding in their activities. 94\% (2) of the interviewees have specified that they could not imagine the current state of the Iranian women's movement existing without cyberspace as an integral and operating component. 74\% (3) of the women interviewed use the Internet as a tool for spreading news. Most interviewees, $94 \%$ (4), have been able to find a new identity and voice by using the Internet to make their opinions public, and only $6 \%$ (4) disagreed with this function of cyberspace. $72 \%$ (5) acknowledged that cyberspace provided the opportunity for the movement to communicate with other activists in other countries; only $10 \%$ (5) believe that they can communicate with other activists in other countries without using the Internet. 56\% (6) agree or strongly agree that the Internet has provided a new opportunity to raise people's awareness of the Iranian women's movement internationally, while $42 \%$ (6) of the activists disagree with this and believe that the movement has a good domestic and international presence without the use of the Internet.

It is to be noted that despite an increased use of cyberspace, the interviewees do not believe that this space can prevent discrimination against women or have a significant role in decreasing it, for more than half of them (62\%) (7) disagree with the statement that cyberspace has been helpful in removing discrimination against women. Others (38\%) (7) have accepted that cyberspace is a tool that helps women, but they believe that they should not rely solely on the Internet. $32 \%(8)$ of the interviewees disagree with the impact of cyberspace on changing laws which discriminate against women, however, most (62\%) (8) agree with the impact of cyberspace activities on reducing discrimination against women.

Also, $72 \%(10)$ of the interviewees use the Internet to object to the government's discriminatory policies against women. These women believe that cyberspace has provided an effective platform for doing so. $86 \%$ (9) of the interviewees use this tool to attract more advocacy but $14 \%$ (9) believe that this tool is unable to undertake real and influential activities, despite it attracting 
more audiences. Therefore, the impact of these activists may be seen as minimal, as a person is not a 'real' activist by merely studying women's issues in cyberspace. More than half of the interviewees (54\%) (11) believe that cyberspace and the activities performed in this space will not achieve the real goals of the movement, and that physical activities carried out in the real world are still more effective. On the other hand, $40 \%$ (11) of the interviewees believe that the Internet has met the demands of the movement's activists, and gave those who had no chance to take part in the direct activities of the movement the opportunity to be involved and have a voice without taking the risk of actual activism.

Table 10: Findings related to the solution of women's problems in Iran from the interviewees' perspective

\begin{tabular}{|l|c|c|}
\hline Solution & Frequency & Percentage \\
\hline $\begin{array}{l}\text { Changing the attitude of society } \\
\text { towards women }\end{array}$ & 22 & $44 \%$ \\
\hline $\begin{array}{l}\text { Ensuring the economic } \\
\text { independence of women }\end{array}$ & 20 & $4 \%$ \\
\hline $\begin{array}{l}\text { Improvement of laws and } \\
\text { regulations }\end{array}$ & 6 & $40 \%$ \\
\hline Promoting women's awareness & 50 & $12 \%$ \\
\hline Total & & $100 \%$ \\
\hline
\end{tabular}

The interviewees were asked which of four solutions provided would, in their opinion, best address women's issues in Iran. The solutions included changing the attitude of society towards women, ensuring the economic independence of women, improving laws and regulations, and promoting women's awareness in Iran. The findings shown in this table can be taken as implicitly referring to the goals of the Iranian women's movement. Most interviewees (44\%) consider changing the attitude of society towards women as the main solution to women's problems. This is due to their belief that women's problems in Iran arise largely from the negative attitude in this patriarchal society towards women. $40 \%$ of the interviewees consider improving laws and regulations as the solution which makes improving laws and regulations the second most highly favoured solution. Only $12 \%$ of the interviewees believed in promoting women's awareness to be the most effective route to solving women's problems in Iran. Notably, a mere $4 \%$ of 
interviewees believed that ensuring the economic independence of women to be the most effective solution.

In interpreting these results, it seems to be true that the interviewees rate the solutions according to what they believe to be the major obstacle for the improvement of women's status in Iran. From the interviewees' perspective, it can be concluded that the main priorities of the Iranian women's movement are to change attitudes in society towards women and bring about a change in laws and regulations in Iran whilst focusing less on promoting women's awareness and ensuring their economic independence.

\subsection{Conclusion}

It can be deduced from the findings presented in this section of the research that an important characteristic of the Iranian women's movement is its realism in accepting the differences between men and women in some aspects, on one hand, and emphasizing the similarity and the existence of common characteristics between them, on the other hand. Indeed, they emphasise that a person's humanity and their human rights are characteristics that must be free from gender discrimination. Therefore, women activists are asking for equality on the grounds of similarity, while not denying the differences existing between men and women. Laws and regulations promote the inequality of men and women, cultural attitudes consider women weaker than, and inferior to men, and societal constraints on women based on their 'inequality' are the most important issues tackled by the Iranian women's movement. Therefore, achieving equal rights for men and women, and gaining respect for the human dignity of women are among the most important goals of the Iranian women's movement. In this regard, the activists have tried to achieve greater influence and presence in their society by using the Internet while pursuing their activities in other forms as well. The main purpose of using cyberspace as a new platform is to open new channels of communication and help to create a new identity free from the traditional attitudes towards women in Iranian society. Data obtained from interviewing women activists indicate that cyberspace is an effective tool and it has an important role in constructing an independent identity for Iranian women. Furthermore, cyberspace provides 
opportunities for the activists to invent and employ different methods in achieving the goals of their movement.

\section{Chapter Six: Conclusion}

Among contemporary Iranian women there is a growing social movement. This may be called a movement because the common elements that exist in the definitions of new social movements apply to the Iranian women's movement. This movement in Iran has been defined by the challenges women face in removing legal and social inequalities and barriers in various fields between men and women. However, the social movement of Iranian women has been optimistic about the emancipatory potential of the Internet for women since it allows a higher chance for women to apply changes in their lifestyles in Iranian society. By increasing awareness and creating a communicative open space without any limitations in time and space, the Internet has provided an opportunity for Iranian women to share the events of their lives and their personal stories. This has reduced their social isolation and facilitated interaction between women with different ideas. Therefore, much effort has been made in this study to fully examine the real impact of the virtual space on the Iranian women's movement and, as far as possible, its consequences for the actual achievement of its goals.

In Chapter 2, this thesis examined the existing academic literature on the changes made by cyberspace and on the position of the Internet and its relations with social movements. Works proposing a positive evaluation of the role of cyberspace concluded that cyberspace has a high potential in this sphere as different groups may express their opinions and build bridges between personal and social affairs. As a result, these activities are considered suitable for social movements. Those with a skeptical view of the role of cyberspace believe, however, that cyberspace has a low impact on social movements and is relatively easily controlled by governments through censorship and by closing the virtual websites, which is an important 
weakness of this tool. There are, however, strong arguments, backed by Tilly's theory, for the utilization of this tool to contribute to the progress of social movements, acknowledging that social movements occur in different forms and ways.

In Tilly's 'mobilization model', there are elements that are affected by external factors, and activists may use these opportunities in their work. Cyberspace is considered as a suitable opportunity for activists. The Internet, as a phenomenon, has penetrated social relations and creates opportunities and limitations for social movements. Cyberspace is important when it is available to movement organizers, and also because it plays an essential role in the communication between activists and other members of society. Therefore, ignoring this phenomenon renders a study of social movements incomplete. Currently, social movements are inseparable from the lives of people who are significantly affected by the Internet. However, one should definitely consider the features of Iranian society, and the role of Internet and its position in making changes therein. Therefore, chapter three reviewed the overall political and social environment governing Iranian society over the last ten years; especially, one of the most important events that changed the social and political space in Iran many years after the Islamic Revolution.

Mahmoud Ahmadinejad's eight-year presidential term (2005-2013) became a significant period in the history of Iran. The Iranian women's movement (which had reached its peak of activity during Mohammad Khatami's presidential term from 1997 to 2005) encountered a huge obstacle with the Ahmadinejad administration that ignored the results of many years of effort and resistance. The Ahmadinejad administration intended to stop this movement by isolating women in their homes and by creating conditions in which they would spend more time with their children. The renaming of 'women's' organizations to 'women and family' organizations was not just a subtle name change but, in fact, structurally changed the organizations to bring them in line with recovering the traditional roles and concepts of women in Iranian society. These roles envisaged women as slaves in the home with no right to engage in activities in civil society and endeavored to keep them far away from politics and decision making. Their main purpose was to stop the women's movement, or to divert it so that it would lose its unity and power. Limiting education of women at tertiary levels and changing laws and regulations in order to weaken 
women with respect to their family relations, were all efforts to stop the logical progression of women in Iran during these eight years. Fortunately, the Iranian women's movement found its way regardless. They knew that despair could not help improve the situation, and they could only continue their work by making changes in politics.

Cyberspace has had its benefits, and due to its capabilities it is considered as a tool suitable for meeting the needs of the Iranian women's movement. Accordingly, the movement has tried to take advantage of a more open space as a substitute for the stifling space of Iranian society. Activities have been significantly changed and the Internet has become a space for creating virtual campaigns for reaching the goals of the women's movement. One example was the One Million Signatures campaign for removing legal discriminations against women. This example demonstrated the impact of the virtual space on a social movement. Several campaigns have conducted held in the virtual space, and women have been engaged in different activities in this space, so that the movement of Iranian women may continue its activity.

Cyberspace enabled women to communicate with each other easier and reach out to each other through sharing their thoughts and ideas with other people faster than before. Even though these women may not necessarily share the same ideas and thoughts regarding with how the movement should proceed; they also have no conflict with each other about using cyberspace. Thus, after the end of the post-reform period, at the beginning of the presidential period of Hassan Rouhani (2013 - the time of writing), the civil societal space of Iranian society has improved. Activities performed on cyberspace have had a perceivable impact on Iranian society. This research was designed using Tilly's theoretical framework. The data collected which were analyzed with reference to this framework. By studying different cases, this study has tried to understand and substantiate the capacities afforded, and limitations imposed by cyberspace on the process of the formation and mobilization of the social movement of women. The analysis of the data collected for this study shows that cyberspace has provided superb facilities that are effective in the advancement and development of the social movement, as well as the completion of the mobilization process. Clearly, this has helped the movement's organizers and activists to make information available to the population within a few seconds. Cyberspace has provided a new form of presence and interaction for women. The virtual space has offered a new 
venue of participation and interaction for women. This has been a new kind of experience with all its feminine similarities and concerns in the real world. It has brought autonomy, as well as being able to freely express themselves. Therefore, the definition of feminine identity is shaped via the interactions which influence feminine identity in tangible and concrete conditions. Thus, a new generation of women can be witnessed in Iranian society who join group activities through their adoption of an active role within the movement.

In Tilly's theory, the most fundamental needs of social movements include active forces who are engaged in activities. The Internet meets these needs. The Internet provides the possibility to organizers to coordinate and plan actions amongst different sections as well as at great geographical distances, including outside the geographical boundaries of a country, via the Internet. Contrary to the views on the impact of the virtual space on social movements to the effect that the Internet carries people away from the present and facilitates passivity, this study of the Iranian women's movement shows that being active in the virtual space can complement and reinforce mutual interaction in the real world. In fact, cyberspace has been able to represent an effective substitute for the old forms of activism, and plays a significant role as a variable in mobilization and collective action. It has provided a possibility for the women's movement to eliminate despair and disappointment through this new form of interaction. The Iranian women's movement shows that, despite governmental repressions, the Internet has provided relatively new resources for women, resulting in their new ability to accelerate mobilization and collective action.

However, suppression in the process of mobilization is more effective and less costly than suppression in the process of action. Although the Iranian government blocked the mobilization of women through legal means, they were not fully aware of the potential of the Internet as a tool of mobilization and organization against the government. When the government confronted it, and adopted certain strategies to suppress and control it, it was not able to do so completely as the Internet provided the movement with different avenues to circumvent control. As soon as a website or weblog was blocked, new avenues were provided to the members of the movement to restart their activity. Supporters of the women's movement outside Iran made new Internet routes to prevent the stopping of resistance activities. On the other hand, global assemblies were 
informed of the suppressive measures of the Iranian government, so that more pressure was imposed on Iran's government and as a result, suppressions were minimized. Therefore, through turning the social sphere into a political one and providing uncensored news, the Internet has become a platform for negotiations, lobbying and fighting which will all be used to bring about social changes via social coalitions.

Subsequently, the use of the Internet by female activists for the development and advancement of women's rights is divided into two periods: the first is the period during which the activities of Iranian female activists had discovered and were more present on the new space in order to acquire a better understanding of this space and its efficiency. They created a network inside and outside Iran through Internet sites which enabled them to discuss women issues and draw attention to the plight of Iranian women in the context of global communication. The second period, however, started with activists understanding the potential held by this space to change political stances and public freedoms, hence using the Internet to its maximum capability. They have discovered that the women's movement should use the Internet as one of its many tools for the development and the advocacy of women's rights. Through this they have converted their potential abilities to actual capabilities. Considering the change in political space, the Iranian women's movement should take better initiatives in the real world as well as the virtual space. Contrary to all objective changes made for women, the rules governing their lives are based on their weakness and, in this regard, they suffer from discrimination. It is on this ground that the identity and organizational contexts which are thought to change these unfair relationships are formed. Therefore, in the promotion of women's rights in Iranian society, a majority of the forces of the women's movement have been concentrated in non-governmental organizations (NGOs) for about one decade. This means that most of these NGOs have had offices and projects, as well as financial and human resources. This period may be called the organizational-based activity of the women's movement in terms of team structure. After some years, however, the activities of the women's movement were limited by the changing political and social atmosphere of Iranian society. Therefore, the Iranian women's movement considers the development of technology and cyberspace as a means for achieving women's rights. Fighting via cyberspace was an initiative that was started in 2005, through the women's movement. The women's movement has been 
developed by holding different campaigns for removing laws and regulations based on inequality, developing websites, women's weblogs for information and interaction, and finally by developing objection pages for opposing certain laws, regulations and customs.

Social networks as a tool for the women's movement have maintained their influence despite censorship by government agencies. It has been nearly over a decade since the movement of Iranian women has tried to notify, inform, and claim women's rights by using this new tool. It has successfully done this by holding campaigns of opposition, establishing educational sites related to women, providing information, creating new campaigns on Facebook, and holding individual weblogs by women's rights activists. The result of most of these activities in the virtual space has been tangibly and adequately evident in the social arena in Iran. To give an instance, the women's movement acted to address the underrepresentation of women in the parliament by launching the 'Campaign to Change the Male Face of Parliament'. The campaign aimed to support candidates who favor gender equality while drawing public attention and disapproval to those whose records or statements showed opposition. Although, the Campaign did not reach its goal of achieving 50 seats for women in the 2016-2020 Parliament, it was successful in providing the largest female representation in the history of Iran's parliament. This is just one example out of many to illustrate the fact that the Iranian women's movement are well familiar with the new trend of the net and can familiarise themselves with ways to use technology to attain their objectives.

Publicizing the women's issues is one of the most important tools for the women's movement, and diversity of discussions may attract more followers. Therefore, many followers may be attracted to websites associated with women's issues. Considering the expanse of Iranian society and its diverse cultures, each website may help attract new followers with different interests. Consequently, such websites help publicize women's issues. They may also connect people who are outside the movement to those inside the Iranian women's movement, and even help attract new activists to the movement. Women's websites may help form a communication network amongst different teams. It means that each site is a representative of some parts of the active forces in the women's movement; therefore, it may be the source for the development of a communication network with other women's teams. 
When a team of women are active in the field of the news media and the press, making communication with them will be easier and performing joint work with other teams will be possible. Notification of the activities and viewpoints in the movement will also occur. These websites have great impact on their members, and since each of them recruits new writers or encourages already active writers to write more. Website authors provide their viewpoints to be criticized and analyzed by their peers and audience, by writing about their concerns on the weblogs. These actions help them to promote their ideas, since their ideas will be improved and modified through online interaction and they can learn more. Women's movements had always occurred in a closed space before, and making communication with the people at large easier is one of the benefits that social networks provide for the women's movement.

Before the advent of Internet, most people thought that discussions initiated by the women's movement were specific to certain people. Activists were not able to show their abilities to different parts of Iranian society. However, websites and Internet media created by women has revealed women's needs and demands to the people and the government, effectively taking the women's movement out of a closed space. Making communication with people is the key to the success of each social movement, and this can be achieved through the Internet. People may be informed of the women's movement through media and social networks. For example, most of the volunteers across the country adopted the movement's demands through campaigns and signing petitions, following the goals of the women's movement. Subsequently, due to the lack of a dynamic civil society and definitive political parties in Iran, the Internet has been especially useful in social movement activities including its use by women's movements. Notification networks are able to spread their information within a short time frame at the lowest cost, and they are not forced to answer to people. Even though severe rules are imposed on Internet activities by the government, Internet publishing problems cannot be compared to those faced by most of the print media, particularly the high cost of circulation of materials printed on paper. Thus, the Iranian women's movement can make some of its demands public via the Internet. Of course, people can access a great deal of diverse information online.

it should be stated that another application of the Internet is to remove limitations placed on women in society where talking about women's issues is not easily possible. The Internet has 
made a space where there is no filter or censorship applied to the thoughts of women. Women's websites have succeeded to create a collective identity in the Iranian women's movement. Of course, there are other factors effective in molding the identity to the women's movement, among them the very feminine weblogs owned by young Iranian girls who write about their needs and problems. Even though these young women work with no specific planning, their 'group' has been highly successful. Social networks have succeeded in attracting men's attention to women's issues and their activities in recent years. This has also led to a number of men also joining the movement. As a result of the success of their new strategy, the Iranian women's movement have even been able to receive support from Iranian men in their plight.

It should be considered that one weakness of cyberspace is that it is not able to provide peace of mind to activists of the women's movement. This means they are not confident that virtual activities are sufficient for achieving the goals of the movement. Spreading the news and making communication with more people is very good when they can be motivated and engaged in real activities in this way. Engaging in virtual activities alone, however, is not enough to make positive and sustainable changes, and can only be effective if followed up with corresponding activities in the real world. It is done by running information campaigns and mobilizing forces that can then actively participate in different arenas, for example by actually voting for someone for whom publicity has been shown on the Internet.

However, activities of the movement of Iranian women in different periods show that this civil societal movement under differing conditions has changed its methods and strategies. It has developed as a new organization in accordance with its existing needs and limitations. Since the government has not allowed meetings to be held, activists have decided to use the virtual space to prevent cutting off communication with the movement. The Iranian women's movement have come to the realization that the Internet and the activities of individuals on cyberspace play an important role in the promotion and strengthening of the status of the social movement, although it is not able to resist the threats posed by the governing authority. Therefore, instead of only celebrating the effectiveness of the Internet, they should be prepared for circumstances under which government access to the Internet and ability to repress may lead to the interruption of their activities. 
Based on the data, the conclusions drawn, and the connections made, it can be said that four major result from this research are obtained:

Firstly, a strong case in favor of the Internet has been built, as it has given social movements new and improved opportunities to engage in their movement particularly women's movement in Iran. At the same time, avoided a naive Internet-optimism, by pointing out several limitations. These restrictions make clear that even a wide digital action repertoire will not, and probably never will, be able to replace traditional forms of activism and face-to-face communication. Hence, it can be accepted to some extent that the Internet is capable of distracting women from actual activism in the society, as it is viewed that online interactions are inferior to and less effective than, face-to-face interactions. However, the study of Iranian women's movement shows that communication in the virtual space can complement and enhance the interaction face-to-face in real space.

Secondly, Internet activity is merely innovative in social movements, and although it has not been able to effectively replace the older forms of challenge and struggle with the government in the real world, it has played a significant role as a major contributor to the mobilization and collective action process.

Thirdly, despite the risk of imprisonment, women activists have persisted in fighting back by using alternate forms of communication including the Internet, a forum that provides self-expression with anonymity. Cyberspace became a liberating territory that provided women activists with a new form of self-empowerment and independence, that led many to discover and adopt feminist ideals. Therefore, the Internet represents a new glimpse of hope for women activists.

Finally, the study was conducted as an interview with a small number of active women in the Iranian women's movement. Indeed, their views on the impact of virtual space on this movement cannot be a general reflection of the Iranian women's movement, as they are a small minority of educated and often middle class women and this does not represent the views of the movement as a whole. Therefore, while some ground work has been done, more research is necessary to gain better insight into this matter. 
Of course, a characteristic of good research is to open the door for future research, with that said, there are still many areas within this subject that needs to be explored. To begin with, who leads the Iranian women's movement? While one feminist group believes genuine Islam can be emancipating for women, the other considers secularism as the first step out of male domination. Urban and rural women are also divided. Middle and upper-middle class women seek occupational and educational rights, while for poorer women, health issues and welfare are women's primary needs. Who defines when, where and which of these differences are rendered important in particular circumstances, and which are not. Who decide the priorities, goals and strategies?

Another area that requires more research is touched on briefly in this thesis and related to the quality of progress in gender equity in Iranian society through Internet. Can Internet assist Iranian women's movement in solving problem of no having the elements of a real organisation with structured leadership and to assist in the decision-making process for the Iranian women's movement?

This question will lead to future investigation and open a new area of research on the role of Internet in promoting awareness and activities of Iranian women's movement. 


\section{Bibliography}

\section{Books \& Journals}

Abdo, G. (2010). Dealing with Iran: Time for middle way between confrontation and conciliation. The Century Foundation. Retrieved 26 August 2009, from

Abbas, J. (2002). Internet Use in Iran: Access, Social, and Educational Issues. Educational Technology Research And Development, (1), 80.

Abbasgholizadeh, M. (2014). To Do Something We Are Unable to Do in Iran: Cyberspace, the Public Sphere, and the Iranian Women's movement. signs 39(4), 831-840.

Abbott, J., (2012). Democracy@Internet.org Revisited: analysing the socio-political impact of the Internet and new social media in East Asia, Third World Quarterly, 33(2), 333-357.

Afary, J. (1989). On the Origins of Feminism in Early 20th-Century Iran. Journal of Women's History, 1(2), 65-87.

Afary, J. (1996). The Iranian Constitutional Revolution, 1906-1911: grassroots, democracy, social democracy and the origins of feminism. New York: Colombia University Press.

Ahmadi Khorasani, N. (2010). Iranian Women's One Million Signatures Campaign for Equality: The Inside Story, Publisher Women's Learning Partnership for Rights Development and Peace.

Ahmadi Khorasani, N. (2012). The spring of Iranian women's movement. A story of smiles and tears. Tehran: Moalef Publications.

Ahmed, L. (1992). Women and Gender in Islam: Historical Roots of a Modern Debate. New Haven: Yale University Press.

Akhavan Kazemi, B. (2009). Ellale nakaramadi ahzabe siasi dar Iran (The Inefficiencies of the Political Parties In Iran). Tehran: Markaze asnade enghelabe eslami.

Alfoneh, A. (2013). Iran unveiled: how the revolutionary guards is turning theocracy into military dictatorship / Ali Alfoneh. Washington, D.C. : AEI Press.

Alavi, N. (2006).We are Iran. London: Portobello. 
Amitai Etzioni, a., \& Oren Etzioni, a. (1997). Editorial: Communities: Virtual vs. Real. Science, (5324), 295.

Amir-Ebrahimi, M. (2008). Blogging from Qom: Behind walls and veils. Comparative Studies of South Asia, Africa and the Middle East, 28(2), 235-249.

Amir-Ebrahimi M. (2008). Transgression in narration: The lives of Iranian women in cyberspace. Journal of Middle East Women's Studies, 4(3), 89-118.

Ansari, A. (2012).The role of social media in Iran's Green Movement (2009- 2012). Global Media Journal, 6(2), 1-6.

Arjomend, S. (2002). The reform movement and the debate on modernity and tradition in contemporary Iran. International journal of Middle East studies, 34, 719-731.

Asemi, A. (2006). Information technology and national development in Iran', presented at the International Conference on Hybrid Information Technology, Computers and Society, 558-565, Retrieved 15 October 2009, from:http://ieeexplore.iee.org/stamp/stamp.jsp?tp=\&arnumber=4021147\&isnumber=402104 7 ?tag=1\&tag=1

Attia, A. M., Aziz, N., Friedman, B., \& Elhusseiny, M. F. (n.d). Commentary: The impact of social networking tools on political change in Egypt's "Revolution 2.0". Electronic Commerce Research And Applications, 10(4), 369-374.

Atkinson, R. D., \& Information Technology and Innovation, F. (2010). Who's Who in Internet Politics: A Taxonomy of Information Technology Policy.

Barlow, R. (2012). Women's human rights and the Muslim question: Iran's one million signatures campaign. Melbourne: Melbourne University Press.

Barlow, R. (2008). Shirin Ebadi and the Question of Women's Rights in the Islamic Republic of Iran: Reform or Reconstruction? In B. MacQueen, K. Baxter and R. Barlow (eds.), Islam and the question of reform: Critical voices from Muslim communities. Carlton, Australia: Melbourne University Press.

Barlow, R. (2012). Women's human rights and the muslim question: Iran's one million signaturees campaign. Australia: Melbourne University Press.

Basmenji, K. (2005). Tehran Blues: how Iranian youth rebelled against Iran's founding fathers. London: SAQI.

Bennett, W. (2003). Communicating Global Activism. Information, Communication \& Society, 6(2), 143168.

Berkeley B. (2006), Bloggers vs. Mullahs: How the Internet roils Iran. World Policy Journal, 2(31), Spring, 71-79.

Bimber, B. A., Flanagin, A. J., \& Stohl, C. (2012). Collective action in organizations: interaction and engagement in an era of technological change. Cambridge [UK] ; New York : Cambridge University Press, 2012. 
Bimber, B. (2001). Information and American democracy: Technology in the evolution of political power. Cambridge, UK: Cambridge University Press.

Bimber, B., Flanagin, A. J. \& Stohl, C., (2012). Reconceptualizing Collective Action in the Contemporary Media Environment. Communication Theory, 15(4), 365-388.

Bimber, B. (1998). The Internet and political transformation: populism, community, and accelerated pluralism. Polity, (1), 133.

Biran, S. (2002). Nashriyate vijeh zanan: Seyre tarikhiye nashriyat zanan dar Iran moaser. (Historical biography of women's publications in contemporary Iran.) Tehran: Roshangaran va Motaleate Zanan Publications.

Books LLC, (2010). Iranian People by Political Orientation: Iranian Anti-Communists, Iranian Monarchists, Iranian Reformists, Iranian Religious-Nationalists. Books LLC.

Boyd, D. (2008). Can social network sites enable political action?. International Journal Of Media \& Cultural Politics, 4(2), 241-244.

Brownlee, J. (2015). The Arab Spring: Pathway of repression and reform. Oxford, UK: Oxford University Press.

Brunsting, S. \& Postmes, T. (2002). Social movement participation in the digital age: Predicting offline and online collective action. Small Group Research, 33(5), October, 525-554.

Bqe, M. (2015). Family law in Iran:women's right activism and shari'a. London \& New York: I.B.TAURIS.

Camron Michael, A. (2002). The making of the modern Iranian woman: gender, state policy, and popular culture, 1865-1946. Gainesville, FL: University Press of Florida.

Carafano, J.J. (2009). All a Twitter: How Social Networking Shaped Iran's Election Protests,Center for Foreign Policy Studies at the Heritage Foundation, Backgrounder \#2300, retrieved from: http://www.heritage.org/research/reports/2009/07/all-a-twitter-howsocial-networking-shapedirans-election-protests

Carolyn, M. Y. (2011). Recent events in Egypt and the Middle East: Background, direct observations and a positive analysis. Organizational Dynamics, 40, 222-234.

Castells, M. (2012). Networks of Outrage and Hope. Social Movements in the Internet Age. Cambridge: Polity Press.

Chadwick, A. (2006). Internet politics: states, citizens, and new communication technologies. New York : Oxford University Press.

Coleman, S., \& Shane, P. M. (2012). Connecting democracy : online consultation and the flow of political communication. Cambridge, Mass. : MIT Press.

Dabashi, H. (2010). Iran, the green movement and the USA: The fox and the paradox. New York, NY: Zed Books. 
Deibert, R. J., \& Rohozinski, R. (2010). Risking Security: Policies and Paradoxes of Cyberspace Security. International Political Sociology, (1). 15.

Diamond, L., (2010). Liberation Technology. Journal of Democracy. 21(3), 68-83.

Downing, J. (2001). Radical media: rebellious communication and social movements. Thousand Oaks, Calif. : Sage Publications.

Duranti, A. (2013). The Green Screen: Neda and the Lost Voices. International Journal of Communication, 7, 1344-1370.

Earl, J. \& Kimport, K. (2011). Digitally Enabled Social Change: Activism in the Internet Age. Cambridge: MIT Press.

Enayat M. (2010). Iran: one year after elections; Importance of Internet and small media. Human Rights, House Network, Retrieved 25 October 2013, http://humanrightshouse.org/Articles/14441.html

Entessar, N. (2012). The Iranian Revolution. New York: Oxford University Press.

Etling, B., Kelly, J., Faris, R., \& Palfrey, J. (2009). Mapping the Arabic blogosphere: politics, culture, and dissent. [Cambridge (USA)]: Berkman Center for Internet \& Society at Harvard University.

Etzioni, A., \& Etzioni, O. (1999). Face-to-Face and Computer-Mediated Communities, A Comparative Analysis. Information Society, 15(4), 241-248.

Farshadmehr, F. (2003). Negahi be hozore modiriyati zanan dar Iran va Jahan. (A look into the presence of women in management in Iran and around the globe.) Reyhan faslnameh, 7 (Summer).

Fathi, N. (2012). Dispatches From an Unfinished Uprising: The Role of Technology in the 2009 Iranian Green Movement. Joan Shorenstein Center on the Press, Politics and Public Policy. Discussion Paper Series \#D-75. Retrieved 24 January 2013 fromhttp://shorensteincenter.org/wpcontent/uploads/2012/08/d74_fathi.pdf.

Feezell, J.T, Conroy, M. \& Guerrero, M. (2009). Facebook is... fostering political engagement: A study of online social networking groups and offline participation. UC Santa Barbara, August, Retrieved from http://irevolution.files.wordpress.com/2009/09/apsa-feezell- 2009.pdf

Fuchs, C. (2008). Internet and society. Social theory in the information age. New York: Routledge.

Fuchs, C. (2012). Behind the news: Social Media, riots and revolutions. Sweden: Uppsala University, Capital \& Class. Reprint and Permission: Sage pub.

Fuchs, C. (2012). Some Reflections on Manuel Castells' Book Networks of Outrage and Hope. Social Movements in the Internet Age, triple c, 10(2), 775-797.

Garrett, R. K. (2006). Protest in an information society: A review of literature on social movements and new ICTs. Information, Communication and Society, 9(2), 202-224.

Gedmin, J. (2010). Democracy isn't just a tweet away, USA Today, (22 April).

Gerbaudo, P. (2012). Tweets and the streets. Social Media and Contemporary Activism. London: Pluto Press. 
Ghanbari Baghestan, A. \& Abu Hassan, M. (2010). Iran's Media Landscape: Law, policy and media freedom, Human Communication. A Publication of the Pacific and Asian Communication Association, 12(3), 239-254.

Ghasemi, F. (2016). The Islamic Republic of Iran: From Bazargan to Rouhani (Persian Edition), H\&S Media.

Ghavam, A. A. (2005). Chaleshhaye tosei siasi. Third edition. Tehran: Ghomes Publicatios.

Gheytanchi, E. \& Rahimi B. (2009). The politics of Facebook in Iran, Recently unblocked, Facebook provides a space for political discourse in Iran. Open Democracy, Retrieved 2 March 2014, from http://www.opendemocracy.net/article/email/the-politics-of-facebook-in-iran

Ghorashi, H., \& Boersma, K. (2009). The 'Iranian Diaspora' and the New Media: From Political Action to Humanitarian Help. Development \& Change, 40(4), 667-691.

Ghorbani, N. (1999). Tahazob va tosei: barresi mavane tahazob dar iran, ketabe dovom. Tehran: Markaze Nashre Beynolmelali.

Gills, B. K., \& Gray, K. (2013). People power in an era of global crisis: rebellion, resistance and liberation. London; New York, New York: Routledge.

Gladwell, M. \& Shirky, C. (2011). From Innovation to Revolution: Do Social Media Make Protests Possible? Foreign Affairs. Retrieved 18 April 2013 from http://www.foreignaffairs.com/print/67189.

Gladwell, M. (2010). "Small change: why the revolution will not be tweeted". The New Yorker. Retrieved 18 October 2013 from https://web.stanford.edu/class/comm1a/readings/gladwell-smallchange.pdf

Golkar, S. (2011). Liberation or suppression technologies? The Internet, the green movement and the regime in Iran. International journal of emerging technologies and society, 9(1), 50-70.

Grami, A. (2013). Islamic feminism: a new feminist movement or a strategy by women for acquiring rights? Contemporary Arab Affairs, 6(i),102-113.

Grossman, L. K. (1995). The Electronic Republic: Reshaping Democracy in America. New York: Viking.

Habibi, N. (2014). The Economic Legacy of Mahmoud Ahmadinejad, Crown Center for Middle East Studies: Brandeis University.

Haghighat, S., Hadi. M.\& Mansouri, Sh. (2010). International Journal of Emerging Technologies and Society; Hawthorn, 8(1), 24-41.

Hajarian, S. (2000). Ahzab va zarorate vojode anha dar ravande enghelab. (Parties and their Necessity in the Process of Revolution) Mosharekat, 23th of March 2000.

Hajarian, S. (2001). Daramadi bar reform va enghelab. (Income in reform and revolution). Economic and Political Journal, 1\& 2 (6), 9-13. 
Hajarian, S. (2001). Estrateji haye siasi dar Iran emroz: goftego ba Saeed Hajarian (Political strategic policy in today's Iran: Interview with Saeed Hajarian). Aftab Journal, 12 (2), 12-15.

Hajarian, S. (2008). Enghelabe eslami Iran:akharin enghelabe kelasik ya avalin enghelabe narm. (Islamic revolution of Iran: The last classical revolution or the first soft revolution). Aeen, 19 \& 20 (December), 10-13.

Hajarian, S. (1999). Tavane Eslahat (Charged for Reform). Tehran: Majmoe maghalat, sokhanraniha va mosahebeha.

Harcourt, W. (2011). Using the master's tools: women's movements and social media. Media Development, 58(1), 19-22.

Hashemi, N., \& Postel, D. (2017). Sectarianization: mapping the new politics of the Middle East. Review Of Faith \& International Affairs, 15(iii), 1-13.

Hendelman-Baavur, L. (2007). Promises and perils of weblogistan: online personal journals and the Islamic Republic of Iran. MERIA: The Middle East Review Of International Affairs, 11(ii), 77-93.

Hilbert, M. (2011). Digital gender divide or technologically empowered women in developing countries? A typical case of lies, damned lies, and statistics. Women's Studies International Forum, 34, 479489.

Hoodfar, H. (1999). The Women's movement in Iran: Women at the Crossroad of Secularization and Islamization. WIN News, (4).

Hoodfar, H. \& Sadeghi, F. (2009). Against All Odds: The Women's movement in the Islamic Republic of Iran. Development, 52(2), 215-223.

Howard, P. (2010). The Digital Origins of Dictatorship and Democracy: Information Technology and Political Islam. Oxford: Oxford University Press.

Internet World Stats 2010, Usage and Population Statistics, Retrieved 12 March 2014: from http://www.Internetworldstats.com/middle.htm\#ir

Interview with Zibakalam, S. (1999). Estebdad mane tarikhi hezb dar iran, Hezb va tosei siasi, ketab aval (party historical despotism in Iran: Party and Political Development).

Jahanshahrad, H. (2012). A Genuine Civil Society and Its Implications for the Iranian Women's movement. Women's History Review, 21(2), 233-252.

Jalayipur, H. R. (2013). Jameshenasi iran: jame kaj modern. (Iran's sociology: tilt community.) Tehran: Elm Publications.

Jalayipur, H. R. (2002). Jameshenasy jonbesh haye ejtemayi ba takid bar jonbeshe eslahi dovome khordad. (Sociology of social movements with emphasis on correctional movement on the 2 nd of Khordad.) Tehran: Tarheno Publication.

Joseph, S. (2012). Social media, political change, and human rights. Boston College International and Comparative Law Review, 35(1), 145-188. 
Karagiannopoulos, V. (2012). The role of the Internet in political struggles: some conclusions from Iran and Egypt. New Political Science, 34(2), 151-171.

Kadivar, M. A. (2014). Alliances and Perception Profiles in the Iranian Reform Movement, 1997 to 2005. American Sociological Review, 78(6), 1064-1086.

Kamran, "IRIB.ir, Islamic Republic of Iran Broadcasting official website is hacked." CNN iReport,20 June 2009, Retrieved on 24 June 2013 from http://ireport.cnn.com/docs/DOC-277431)

Kamrava. M. (2001). The Civil Society Discourse in Iran. British Journal of Middle Eastern Studies 28:2, pages 165-185.

Keddie, N. R. (2006). Modern Iran: Roots and Results of Revolution. New Haven: Yale University Press.

Kelly, J. \& Etling, B. (2008). Mapping Iran's Online Public: Politics and Culture in the Persian Blogosphere. Cambridge, MA: Harvard Law School.

Khatami, M. (2000). Women and youth. Tehran: Gameno Publications.

Kouhi Esfehani, M. (2014). Iranian Women: One Step Forward, Two Steps Back Ortadoğu Etütleri, 5(2), 31-53.

Kress, G. R. (2003). Literacy in the new media age. [electronic resource]. London : Routledge, 2003.

Krueger, B. S. (2006). A comparison of conventional and Internet political mobilisation. American Politics Research, 34(6), November, 759-776.

Kurzman, C. (2012). The Arab Spring: Ideals of the Iranian Green Movement, Methods of the Iranian Revolution. International Journal of Middle East Studies, 44, 162-165.

Lee, L. F \& Chan, J. M. (2012). Activating support for social movements, the effects of the Internet on public opinion toward social movements in Hong Kong. Taiwan Journal of Democracy, 8(1), 145167.

Lerner, M. (2010). Connecting the actual with the virtual: The Internet and social movement theory in the Muslim world - the cases of Iran and Egypt. Journal of Muslim Affairs, 30(4), 555-574.

Livingstone, S. (2004). Media literacy and the challenge of new information and communication technologies. Communication Review, 7(1), 3-14.

Mahbaz, E. (2005). Zanane Irani cheraghi dar dast cheraghi dar rah. (Iranian women, with a light in hand, light in way.) Iran: Baran Publications.

Mahdi, A. (2004). The Iranian Women's movement: A Century Long Struggle. The Muslim World, 94, 427-448.

Marks, J. (2013). From Twitter Revolution to Twitter Diplomacy in Iran. NextGov.com.

Media and Public Sphere in Iran. (2009). Asian Journal of Social Science, 37(2), 256-273.

Mirhoseini, Z. (1999). Bazbiniye tajrobe ettehade meli zanan. (The National Union of Iranian Women Revisited). City: Noqteh Publications. 
Mirebrahimi, R. (2009). Zir - e Hasht. (Under Eight.) Pacoima, CA: Ketab Corp.

Moallem, M. (2005). Between Warrior Brother and Veiled Sister: Islamic Fundamentalism and the Politics of Patriarchy in Iran. Berkeley: University of California Press.

Moazami, S. H. (2011). Khoshonate Khanevadegi: gozareshe vaziate ejtemaee Iran. (Family violence: report on the social status of Iran.) Tehran: Moaseseh Rahman.

Moinifar, H. (2013). Participation of Women in Iran's Polity. GEMC Journal, No.4, 24-35.

Morozov, E. (2010). The Net Delusion: The Dark Side of Internet Freedom. New York, NY: Public Affairs.

Mortensen, M. (2011). When citizen photojournalism sets the news agenda: Neda Agha Soltan as a Web 2.0 icon of post-election unrest in Iran. Global Media \& Communication, 7(1), 4-16.

Mottahedeh, N. (2010). Green Is the New Green: Social Media and the Post-Election Crisis in Iran, 2009. Special Section: The World in Crisis, New Politics, 65-68.

Negroponte, N. (1995). Being Digital. New York: Vintage.

Nouraie-Simone, F. (2014). Wings of freedom: Iranian women, identity, and cyberspace. In , On shifting ground: Muslim women in the global era. Ed. Fereshteh Nouraie-Simone. New York: Feminist Press at the City University of New York.

Osanloo, A. (2009). The Politics of Women's Rights in Iran. Princeton, N. J.: Princeton University Press.

Pavlik, J.V. (1994) 'Citizen Access, Involvement, and Freedom of Expression in an Electronic Environment', in F. Williams and J.V. Pavlik (eds) The People's Right to Know: Media, Democracy, and the Information Highway. Hillsdale, NJ: Erlbaum

Payrow Shabani, O. (2013). The Green's Non-Violent Ethos: The Roots of Non-Violence in the Iranian Democratic Movement. Constellations, 20(2), 347-360.

Putnam, R. D. (2000). Bowling Alone. New York: Touchstone.

Rabasco, M. J. (2002). Civil society in Iran, in Mazarr, M. J. (ed.), Information technology and world politics. London: Palgrave Macmillan.

Rahaghi, J., (2012). New Tools, Old Goals: Comparing the Role of Technology in the 1979 Iranian Revolution and the 2009 Green Movement. Journal of Information Policy. 2, 151-182.

Rahimi, B. (2003). Cyberdissent: The Internet in Revolutionary Iran. Middle East Review of International Affairs, 7(3), (September), 101-15.

Rahimi, B. (2011). The agonistic social media: Cyberspace in the formation of dissent and consolidation of state power in postelection Iran. The communication review, 14:158-178.

Rahimi, B. \& Gheytanchi, E. (2008). Iran's Reformists and Activists: Internet Exploiters Middle East Policy. Middle East Policy Council, 15(1), 46-59.

Rajabzadeh, A. (2002). Moghayeseye faaliate farhangi zanan va mardan dar iran. (Comparison of cultural activities of women and men in Iran.) Nameye Pajohesh, 7 (3, Fall), 37-53. 
Rezai-Rashti, G. M. (2015). The politics of gender segregation and women's access to higher education in the Islamic Republic of Iran: the interplay of repression and resistance. Gender and Education, 27 (5), 469-486.

Report of development of women conditions. (2005), (1), Tehran: Sureh Mehr Publications.

Report of execution of Article 158 of the 3rd Five-Year Plan. (2005). Tehran: Ruzeno Publications.

Rhodes, F. (2007). Iran and the Rise of Its Neoconservatives: The Politics of Tehran's Silent

Revolution. The Middle East, (383). 65.

Rivetti, P. \& Cavatorta, F. (2013). 'The Importance of being Civil Society': Student Politics and the Reformist Movement in Khatami's Iran. Middle Eastern Studies, 49(4), 645-660.

Sadeghi, F. (2010). Bypassing Islamism and Feminism: Women's Resistance and Rebellion in Postrevolutionary Iran. Féminismes islamiques, 128, 209-228.

Sadeghi, F. (2004). Jonbeshe zanan va democracy. (Women's movement and Democracy.) Nameh Journal, 42, 46-51.

Sahliyeh, E. (2010). The presidential election in Iran, June 2009. Notes on Recent Elections. Electoral Studies, 29 ,171-195.

Sameh, C. (2010). Discourses of Equality, Rights and Islam in the One Million Signatures Campaign in Iran. International Feminist Journal of Politics, 12(3-4), 444-463.

Sanasarian, E. (1982). The Women's Rights Movement in Iran: mutiny, appeasement, and repression from 1900 to Khomeini. New York: Praeger.

Sanasariyan, E. (2004). (N. A. Khorasani, tr.) Jonbeshe hoghoghe zanan dar Iran. (Women's rights in Iran) Tehran: Akhtaran Publications.

Sax, L. J (2012). Empowering Women in Higher Education and Student Affairs: Theory, Research, Narratives and Practice from Feminist Perspectives In P. A. Pasque, S. Errington Nicholson,. Sterling, VA: Stylus Publishing.

Schuster, J. (2013). Invisible feminists? Social media and young women's political participation. Political Science, 65(1), 8-24.

Semati, M. (2008). Media, culture and society in Iran: living with globalization and the Islamic state. London; New York: Routledge, 2008.

Shekarloo, M. (2005). Iranian women take on the constitution. Women living under Muslim Laws, 21 July 2005. http://www.wluml.org/node/2370

Shirazi, F. (2011). Information and communication technology and women empowerment in Iran, Telematics and Informatics, volume 29, Issue 1, February 2012, Pages 45-55.

Shirazi, F. (2012). Free and Open Source Software versus Internet content filtering and censorship: A case study. The Journal of Systems and Software, 85, 920-931. 
Shirky, C. (2008). Here comes everybody: the power of organizing without organizations. New York: Penguin Press, 2008.

Shirky, C. (2011). The Political Power of Social Media. Foreign Affairs, 90 (1), 28-41.

Shojayi, Z. (2004). Hasht sal kar baraye zanan: goftego ba Zahra shojayi (Eight years work for women: interview with Zahra Shojayi.) Women's Journal, 14 (121), May.

Siddiqi, A. (2006). Khatami and the Search for Reform in Iran. Stanford Journal of International Relations (SJIR), Retrieved 2 October 2013 from https://web.stanford.edu/group/sjir/6.1.04_siddiqi.html

Soguel, D. (2010). Iran: Women Online Brave Heavy Web Surveillance. Retrieved 17 September 2013 from: <http://www.wluml.org/node/6171>.

Sreberny, A. \& Khiabany, G. (2010). Blogistan: The Internet and politics in Iran. New York \& London: Publisher.

Tilly, C. (1978). From Mobilization to Revolution. Reading: Addison-Wesley.

Tilly, C. (1998). Where Do Rights Come From? In T. Skocpol (ed.), Democracy, Revolution, and History. Ithaca, NY: Cornell University Press.

Tilly, C (2000). Processes and Mechanisms of Democratization. Sociological Theory 18: 1-16.

Tilly, C. (2003). The Politics of Collective Violence. Cambridge: Cambridge University Press.

Tilly, C. (2004) Social Movements, 1768-2004, Paradigm Publishers, Boulder, CO.

Tilly, C. (2004) 'Trust and rule', Theory and Society, vol. 33, no. 1, pp. 1-30.

Tilly, C. (2004). Contention and Democracy in Europe, 1650-2000. Cambridge: Cambridge University Press.

Tabriznia, K. (1992). Ellale napaydari ahzabesiasi dar Iran. (English Translation here.) Tehran: Markaze nashre beynolmelal.

Tahmasebi-Birgani, V. (2010). Green Women of Iran: The Role of the Women's movement During and After Iran's Presidential Election of 2009. Constellations, 17(1), 78-86.

Tajzadeh, S. M. (1992). Yaddasht, tahazob va tosei siasi, ketabeaval, Mabani nazari va amozeha. (Note, Political engagement and Development, first Book, Theoretcal Framework and Teaching) Tehran: Hamshahri.

Tamadonfar, M. (2015). Islamic law and governance in contemporary Iran: Transcending Islam for social, economic, and political order, London: Lexington books.

Terman, R. \& Fijabi, M. (2010). Stoning is Not Our Culture: A Comparative Analysis of Human Rights and Religious Discourses in Iran and Nigeria, Report, The Global Campaign to Stop Killing and Stoning Women and Women Living under Muslim Laws. Retrieved on 4 February 2013 from http://www. violenceisnotourculture. org/sites/default/files/Terman_Fijabi. Pdf

The State Statistics Calendar (2001), (1997-2001), e volumes, Iran Statistics Center. 
The State Cultural Report (2001). Tehran: Ministry of Culture and Islamic Guidance.

Tohidi, N. (2006). Iran's Women's Rights Movement and the One Million Signatures Campaign. November. Archived at http://www.we-change.org/spip. php?article208

Tohidi, N. (2010). Women's rights in the Middle East and North Africa: Iran. New York, NY: Freedom House. http://www.freedomhouse.org/sites/default/files/inline images/iran.pdf

Tohidi, N. (2016). Women's Rights and Feminist Movement in Iran. Sur: International Journal On Human Rights, 13(24), 75-89.

Tolbert, C.J. \& McNeal, R.S. (2003). Unraveling the effects of the Internet on political participation? Political Research Quarterly, 56(2), 175-185.

Torres Soriano, M. R. (2013). Internet as a Driver of Political Change:Cyber-Pessimists And CyberOptimists. Revista del Instituto Español de Estudios Estratégicos, Núm 1, 332-352.

Turkle, S. (1995). Life on the Screen: Identity in the Age of the Internet. New York: Simon and Schuster.

Vogt, C., \& Chen, P. Feminisms and the Internet. Peace Review, 13(3), 371-374.

Warnaar, M. (2013). Iranian Foreign Policy during Ahmadinejad: Ideology and Actions. Basingstoke, UK: Palgrave MacMillan.

Weber, L. M., Loumakis, A. \& Bergman, J. (2003). Who participates and why? An analysis of citizens on the Internet and the mass public. Social Science Computer Review, 21(1), 26-42.

Wells, M. (1999). Thermidor in the Islamic republic of Iran: the rise of Muhammad Khatami, British Journal of Middle Eastern Studies, 26(1), 27-39.

William A. Gamson, a., \& Gadi Wolfsfeld, a. (1993). Movements and Media as Interacting Systems. The Annals of The American Academy of Political and Social Science, 114.

Wolfsfeld, G., Segev, E., \& Sheafer, T. (2013). Social Media and the Arab Spring: Politics Comes First. The International Journal of Press/Politics, 18(2), 115-137.

Xenos, M., \& Moy, P. (2007). Direct and Differential Effects of the Internet on Political and Civic Engagement. Journal of Communication, 57(4), 704-718.

Yaghmaian, B. (2002). Social change in Iran: An eyewitness account of dissent, defiance, and new movement for rights. New York: SUNY Press.

\section{Websites}

http://www.theguardian.com/world/sakineh-mohammadi-ashtiani

http://www.amnesty.org.au/news/comments/29297/

http://topics.nytimes.com/top/reference/timestopics/people/a/sakineh mohammadi ashtiani/index.ht $\underline{\mathrm{ml}}$

http://www.abc.net.au/news/2014-02-04/facebook-turns-10-the-social-network-in-numbers/5237128 
http://zananemrooz.com/

http://iranprimer.usip.org/resource/womens-movement

https://www.al-islam.org/excerpts-from-the-holy-quran-an-eternal-guidance-to-mankind/hereafterday-judgement-paradise-hell

http://www.Internetworldstats.com/me/ir.htm

http://fararu.com/fa/news/22739/

http://www.khabaronline.ir/detail/367456/Politics/parties

http://www.yjc.ir/fa/news/4371853/

http://sur.conectas.org/en/womens-rights-feminist-movements-iran/

https://en.qantara.de/content/interview-with-iranian-womens-rights-activist-mahboubeh-

abbasgholizadeh-no-woman-can-be

www.tebyan.net/newindex.aspx?pid=12469

http://theiranproject.com/blog/2013/12/15/all-irans-women-mayors/

http://www.refworld.org/pdfid/4157d0904.pdf

http://mohammad-khatami.persianblog.ir/post/40/

http://hamshahrionline.ir/details/169329

http://www.bashgah.net/fa/content/show/13345

http://www.bashgah.net/fa/content/show/13345

http://www.unic-ir.org/hr/convenantion-women.htm

http://zananmag.org/spip.php?article120

http://www.mei.edu/content/new-challenges-iranian-women

http://khabaronline.ir/detail/314415/society/family

http://mardomsalari.com/template1/News.aspx?NID=181725

http://www.al-monitor.com/pulse/originals/2015/05/iran-womens-magazine-zanan-emrooz-

suspended.html

http://www.parsine.com/fa/news/193093

http://www.vajehyab.com/dehkhoda

https://www.oxforddictionaries.com/

https://www.huffingtonpost.com.au/

$\underline{\text { http://rc.majlis.ir/fa }}$

http://we-change.org/site/english/

https://www.theguardian.com/world/sakineh-mohammadi-ashtiani 
https://www.amnesty.org/en/documents/MDE13/001/2012/en/

http://www.sistani.org/

https://makarem.ir/

$\underline{\text { https://safi.ir }}$

http://en.farsnews.com/newstext.aspx?nn=13931007001137

https://www.reuters.com/article/us-iran-west-vigilance/irans-khamenei-calls-for-vigilance-against-

wests-soft-war-state-tv-idUSKCNOYH1OP

https://Persianfemale.com

https://IranDokht.com

http://www.alef.ir/vdca.enek49nma5k14.html

http://www.bbc.co.uk/persian/science/story/2006/10/061020

http://ham-mihan.org/Released/86-03-17/348.htm

http://www.ilna.ir/83495/50-

http://khordadnews.ir/print.php?id+24414

www.dadiran.ir/portals/0/khanevade.doc

http://www.hawzah.net/fa/Magazine/View/6432/6448/73720/

http://biographyha.com/8002/biography-marzieh-vahid-dastjerdi-photos.html

https://www.khabaronline.ir/detail/387638/society/family

https://www.khabaronline.ir/detail/387638/society/family

www.bbc.co.uk/persian/iran/2014/11/141130-nm-research-women-violence

http://www.ilna.ir/165/279015

http://www.bbc.com/persian/iran/2010/06/100612 elec anniv ngos.shtml

http://asre-nou.net/php/view-print-version.php?objnr+5881

https://en.trend.az/iran/2252927.html

https://en.trend.az/iran/2252927.html

http://www.sarshar.org/archives/weblinks/post 1266.html)

http://www.khabaronline.ir/detail/244706/politics/government)

http://www.khabaronline.ir/detail/337388/multimedia/1483

http://www.momtaznews.com/

http://icana.ir/Fa/News/233475

https://www.brookings.edu/blog/markaz/2013/10/02/what-rouhani-can-and-must-do-for-iranswomen/ 
http://feedkhoon.rozblog.com/post/2707

http://nahad.govir.ir/portal/home/?news/40436/40439/41383/

http://mehrkhane.com/fa/news/9352/

https://www.al-monitor.com/pulse/originals/2015/03/iran-rouhani-female-adviser-molaverdi.html

http://www.bartarinha.ir/fa/news/100244/

http://forum.hammihan.com/thread120327.html

http://tmubasij.ir/?p=1614 


\section{University Library}

\section{- M I N E R VA A gateway to Melbourne's research publications}

Minerva Access is the Institutional Repository of The University of Melbourne

Author/s:

Karimi, Sedigheh

Title:

The virtual sphere and the women's movement in post-reform Iran

Date:

2018

Persistent Link:

http://hdl.handle.net/11343/213542

Terms and Conditions:

Terms and Conditions: Copyright in works deposited in Minerva Access is retained by the copyright owner. The work may not be altered without permission from the copyright owner. Readers may only download, print and save electronic copies of whole works for their own personal non-commercial use. Any use that exceeds these limits requires permission from the copyright owner. Attribution is essential when quoting or paraphrasing from these works. 